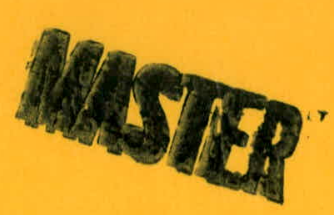

\title{
BEHAVE-2: \\ OXIDE FUEL PERFORMANCE CODE IN TWO SPATIAL DIMENSIONS AND TIME
}

S. OLDBERG, JR.

U.S. ATOMIC ENERGY COMMISSION

CONTRACT AT(O4-3)-189 PROJECT AGREEMENT 10 


\section{DISCLAIMER}

This report was prepared as an account of work sponsored by an agency of the United States Government. Neither the United States Government nor any agency Thereof, nor any of their employees, makes any warranty, express or implied, or assumes any legal liability or responsibility for the accuracy, completeness, or usefulness of any information, apparatus, product, or process disclosed, or represents that its use would not infringe privately owned rights. Reference herein to any specific commercial product, process, or service by trade name, trademark, manufacturer, or otherwise does not necessarily constitute or imply its endorsement, recommendation, or favoring by the United States Government or any agency thereof. The views and opinions of authors expressed herein do not necessarily state or reflect those of the United States Government or any agency thereof. 


\section{DISCLAIMER}

Portions of this document may be illegible in electronic image products. Images are produced from the best available original document. 
GEAP- 13788

AEC Research and

Development Report

February 1972

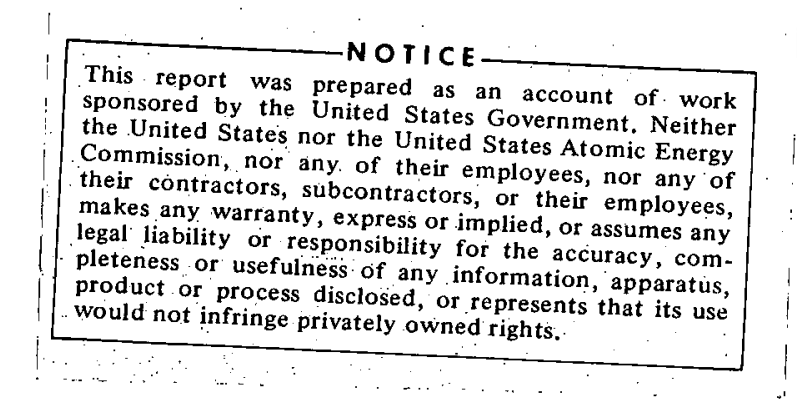

\section{BEHAVE-2: OXIDE FUEL PERFORMANCE CODE} IN TWO SPATIAL DIMENSIONS AND TIME

S. Oldberg, Jr.
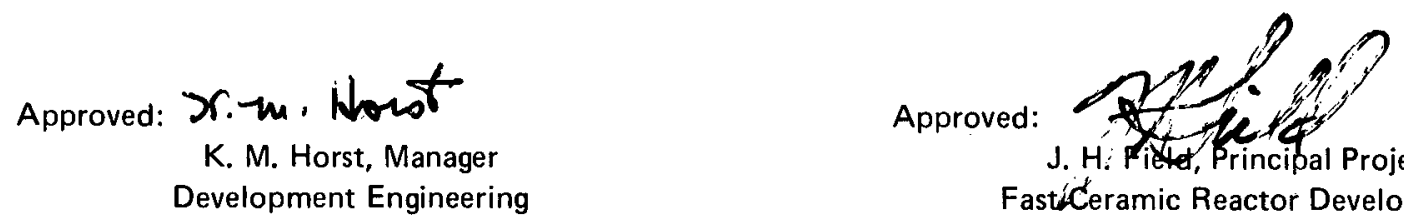

J. H. Piet, Principal Project Engineer

FastiCeramic Reactor Development Program

Prepared for the

United States Atomic Energy Commission

Under Contract No. AT(04-3)-189

Project Agreement No. 10

BREEDER REACTOR DEPARTMENT — GENERAL ELECTRIC COMPANY

SUNNYVALE, CALIFORNIA 94086 


\section{NOTICE}

This report was prepared as an account of work sponsored by the United States Government. Neither the United States nor the United States Atomic Energy Commission, nor any of their employees, nor any of their contractors, subcontractors, or their employees, makes any warranty, express or implied, or assumes any legal liability or responsibility for the accuracy, completeness or usefulness of any information, apparatus, product or process disclosed, or represents that its use would not infringe privately owned rights. 


\section{TABLE OF CONTENTS}

ABSTRACT

1. INTRODUCTION

2. DESCRIPTION OF MODEL . . . . . . . . . . . . . . . . . . . . . . . . . . . . . . . . . . 2-1

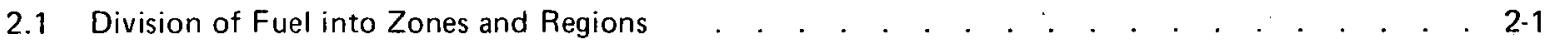

2.2 Assumption of Fuel-Cladding Gap Closure c . . . . . . . . . . . . . . . . . . . . . . . . . . 2-1

2.3 Mechanics of the Cladding and Structural Fuel Zones . . . . . . . . . . . . . . . . . . . . . . . . 2-4

2.4 Fuel Movement within the Inviscid Fuel Zone . . . . . . . . . . . . . . . . . . . . . . . . . 2-16

2.5 Redefinition of the Nodal Grid . . . . . . . . . . . . . . . . . . . . . . . . 2-18

2.6 Calculation of the Temperature Distribution . . . . . . . . . . . . . . . . . . . . . . . . . . . 2-20

2.7 Discussion of Model Mechanics _. . . . . . . . . . . . . . . . . . . . . . . . . . . . . . $2-20$

2.8 Flow Diagram . . . . . . . . . . . . . . . . . . . . . . . . . . . . . . 24

3. MATERIAL PROPERTIES . . . . . . . . . . . . . . . . . . . . . . . . . . . . . . . . . . .

3.1 Primary Properties . . . . . . . . . . . . . . . . . . . . . . . . . . . . 3-1

3.2 Secondary Properties . . . . . . . . . . . . . . . . . . . . . . . . . . . . . . . . . . . .

4. RESULTS OF A SAMPLE PROBLEM . . . . . . . . . . . . . . . . . . . . . . . . . . . . . . . . . . . 4-1

5. USER'S INFORMATION . . . . . . . . . . . . . . . . . . . . . . . . . . . . . . . . . . . . 5-1

5.1 Input Deck Format . . . . . . . . . . . . . . . . . . . . . . . . . . . . . . . . . . . . . . .

5.2 User Supplied Subroutines . . . . . . . . . . . . . . . . . . . . . . . . . . . 5-8

5.3 Run Deck Format . . . . . . . . . . . . . . . . . . . . . . . . . . . 510

5.4 Running A Problem . . . . . . . . . . . . . . . . . . . . . . . . . . . . . . . 5-11

5.5 Output . . . . . . . . . . . . . . . . . . . . . . . . . . . . . . . . . . 5-11

5.6 Running Costs and Memory Requirements . . . . . . . . . . . . . . . . . . . . . . . . . . . . 516

ACKNOWLEDGMENTS . . . . . . . . . . . . . . . . . . . . . . . . . . . . . . R-1

REFERENCES . . . . . . . . . . . . . . . . . . . . . . . . . . . . . . . . . . R-1

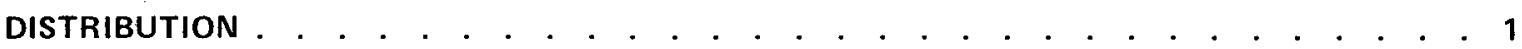




\section{LIST OF ILLUSTRATIONS}

Figure

Division of Fuel into Structural and Inviscid Zones; Subdivision of Inviscid Fuel into Nontransport and Transport Regions Assumed Fuel Configuration at Zero Power, Start of Life . . . . . . . . . . . . . . . . . . . 2-3 Fuel-Cladding Gap Formation During Shutdown . . . . . . . . . . . . . . . . . . . 25 Idealization of Cladding and Structural Fuel Zones . . . . . . . . . . . . . . . . . . . 2-6 Formulation of Force-Displacement-Rate Relations for Fuel or Cladding Ring . . . . . . . . . . 2.7 Assembly of Individual Ring Elements and Shear Elements into Overall Fuel Pin Structure . . . . 2-14 Idealization of Inviscid Fuel Zone . . . . . . . . . . . . . . . . . . . . . . . 2-17 Redefinition of Inter-Ring Boundaries in Fuel . . . . . . . . . . . . . . . . . . . . . 2-19 Length Through Which $\mathrm{UO}_{2}$ Will Flow in an Axial Direction Under a 400 psi Pressure Difference, Assuming a Uniform Volumetric Dilatation Rate of the Fuel as Shown . . . . . . . . 221 Flow Diagram of BEHAVE-2 Control Program and Major Subroutines . . . . . . . . . . . 225 Subroutine REGRID and Associated Subroutine . . . . . . . . . . . . . . . . . . . . . . 226 Subroutine FISIK and Associated Subroutines . . . . . . . . . . . . . . . . . . . . . . . . . . 2-27 Subroutine PROMAT and Associated Subroutines . . . . . . . . . . . . . . . . . . 228 Subroutine SS2 and Associated Subroutines . . . . . . . . . . . . . . . . . . . . . . . . . . . . 229 Subroutine DPLACE and Associated Subroutine . . . . . . . . . . . . . . . . . . . . $\quad$ 2-30 Stress-Plastic Strain Rate-Fluence Relation for Stainless Steel Employed in BEHAVE-2 . . . . . . . 3-5 Stress-Plastic Strain Rate-Temperature Relation for Unirradiated Type-316 Stainless Steel . . . 3-6 Inter-Regional Boundary Temperatures Employed in BEHAVE-2, versus Length of Timestep . . . 3-11 Permanent Cladding Diameter Increase Due to Plastic

Strain versus Linear Power During Crack Closure . . . . . . . . . . . . . . . . . . 3-16

Schematic Illustration of the Cyclical CUR Effect . . . . . . . . . . . . . . . . . . . . . . . . . . . . 3-17

Power, Strain, and Hoop Stress Histories at the Peak Flux Position

from a Simulation of Fuel Pin F2H . . . . . . . . . . . . . . . . . . . . . . . . . . . . . . 4-2

Cladding Hoop Stress at Inner and Outer Cladding Rings

and Power Plotted versus Timestep Number . . . . . . . . . . . . . . . . . . . . . . . . . . . . 4-3

Length Increases of the Fuel and Cladding Relative to the Unirradiated,

Room Temperature Lengths and Power Plotted versus Time . . . . . . . . . . . . . . 44

Radii of Microstructural Features and Power Plotted versus Timestep Number . . . . . . . . . . . 4-5

Predicted Strain Distributions at the End-of-Life Room Temperature Condition . . . . . . . . . 4-7

Predicted Void Fraction Distribution After Final Shutdown . . . . . . . . . . . . . . . . . 4-8

Prediction of Noble Gas Concentration versus Radius . . . . . . . . . . . . . . . . . . . . . . . 4-9

Format of Non-Time Varying Information Supplied in Order Shown at Beginning of Data Deck . . . 5-2

Format of Time Varying Information Supplied in Order Shown, One Set for Each Timestep . . . . . 5-3

Automatic Time Grid Generation to Hold Maximum Power Change

Less Than Input Maximum Power Change . . . . . . . . . . . . . . . . . . . . . . . . . . . $\quad .54$

Definition of the Input Quantity "Axial Expansion Length" in the Unirradiated Fuel Pin at $20^{\circ} \mathrm{C}$. , 5-5

Definition of the Input Array "Radial Fuel Dish Volume Distribution" . . . . . . . . . . . 5-7

Format of Non-Time Varying Information Printed Out at the Start of Each Problem . . . . . . 5-13

Format of Time-Varying Information Printed Out on File Code 03 . . . . . . . . . . . . . . $5-14$

Format of Time-Varying Information Printed Out on File Code 02 . . . . . . . . . . . . . . . . . . 5-17 


\section{ABSTRACT}

1. Designation of Program - BEHAVE-2.

2. Computer for which the program is designed and others upon which it is operable - GE-635.

3. Nature of physical problem solved - BEHAVE-2 calculates the position in space of cladding, fuel, and voidage in an operating oxide fuel pin with unfailed cladding. Axial symmetry is assumed throughout the program. Also calculated are stress, strain, displacement, and temperature fields. Influential processes simulated include cracking of fuel, dilatation of fuel and cladding due to irradiation effects and thermal expansion, fuel densification by both stress- and diffusion-controlled processes, axial slippage or locking at the fuel-cladding interface and axial flow of fuel.

4. Method of solution - The finite element method is used in the cladding and outer fuel zones. Displacement compatibility is maintained axially as well as radially between adjacent elements. Circular cylindrical ring elements with three degrees of freedom are used in the fuel and cladding. No relative shear deformation is permitted between ring elements, but a special shear element at the fuel-cladding interface permits relative slippage or produces friction-induced fuel pellet locking. An interior inviscid fuel zone interacts with the outer, structural fuel zone as a constant pressure boundary condition. Within the inviscid zone, axial transfer of fuel by a flow process occurs under certain conditions. Swelling of fuel and cladding and fission gas release are represented by empirically derived models.

5. Restrictions to complexity of the problem - The program is dimensioned for a maximum grid structure as defined below:
a. Cladding divided radially into 10 rings.
b. Outer (structural) fuel zone divided radially into 10 rings.
c. Middle (nontransport) fuel region divided radially into 10 rings.
d. Inner (transport) fuel region divided radially into 10. rings.
e. Fuel and cladding divided axially into 5 sections.

6. Typical running time - A problem employing the maximum grid structure in the fuel, 2 rings in the cladding, and 37 timesteps has required approximately thirteen minutes of GE-635 processor time.

7. Unusual features of the program:

a. Axially interactive effects are calculated.

b. Cracks are represented as a continuum, producing zero stress normal to the crack plane. Cracking occurs under any positive stress normal to two possible directions of cracking $[(r, \theta)$ and $(r, z)$ planes].

c. Rapid closure of the fuel-cladding gap is assumed, permitted by immediate cracking of the fuel at the first application of power.

d. Fuel is divided into two phenomenological zones, the inner zone being made up of two regions. Boundaries between the zones and regions are defined by time-temperature relations and move in space as a function of time. Crack closure is assumed in the inner zone.

e. The nodal grid is redefined in the radial direction every timestep by averaging conditions from the old grid. A fine grid is imposed in regions of rapidly changing properties.

8. Related and Auxiliary Program - none.

9. Status - Production.

10. References - This report.

11. Machine Requirements $-41 K$ of fast memory.

12. Programming Languages Used - FORTRAN-IV.

13. Operating System or Monitor Under Which Program is Executed - GECOS III, SAL-3.

14. Other Programming or Operating Information or Restrictions - None.

15. Material Available - Source tape, test run deck, this report. 


\section{INTRODUCTION}

The past several years have seen the development of a number of computer programs intended to predict the performance characteristics of circular cylindrical oxide fuel elements. Starting with CYGRO- $I^{1}$ and continuing through further refinements of CYGRO ${ }^{2,3}$ as well as OLYMPUS, ${ }^{4}$ LIFE, $^{5}$ and FMODEL, ${ }^{6}$ thre primary emphasis of these codes has been the prediction of plastic and total strain within the cladding because of the importance of these quantities with regard to cladding failure probability and core thermal-hydraulics. Ancillary results include predictions of fuel and cladding temperature distributions, fuel microstructural features, and fission gas release.

The marked variations in the methods of approach exhibited by these codes reflect two factors: first, an improved understanding of fuel behavior which has come from analyses of recent data from irradiated fuel and materials properties tests; second, a sometimes considerable divergency of opinion regarding the dominant mechanisms shown by the data and the most effective method of modeling these mechanisms.

A view of fuel element behavior and the concomitant possibilities for idealization has evolved over several years devoted to data correlations and preliminary analytical work. That view consists of the following elements: ${ }^{7-9}$

1. Axial Fuel Movement

Several categories of axial fuel transport, including sliding between the fuel and cladding, flow of fuel in the hot "plastic core" region, and fuel vapor diffusion are important in defining the location of the fuel within the cladding. These phenomena can affect the local fuel smeared density by several percent, an amount sufficient to mean the difference between substantial fuel-cladding interaction and none at all in some cases. Axial fuel flow can be of importance in defining the shape of the plastic strain versus length curve for an irradiated fuel pin; it tends to produce a strain concentration toward the peak power location in the pin.

2. Power Increase Strains

A substantial fraction of experimentally observed plastic cladding strain appears to be associated with power change effects.

\section{Fuel Cracking}

Operating fuel cannot withstand tensile stresses on the order of $10^{6} \mathrm{lb} / \mathrm{in}^{2}{ }^{2}$ which would have to be endured for the fuel pellet to remain intact under the thermal strain field induced by large radial temperature differences; it therefore cracks into a moderate number of pie-shaped pieces. The mechanics of fuel-cladding interaction are profoundly affected by the presence of cracks. A model not allowing cracking will issue predictions differing qualitatively as well as quantitatively from those of a model allowing cracking.

\section{Radial Property Variations}

A radial temperature difference across the fuel of as much as $2000^{\circ} \mathrm{C}$ causes a gradient in creep strength approaching 10 decades across the fuel. Stresses can drop from high values to virtually zero within the space of a few thousandths of an inch. The steep gradient in properties is in marked contrast to most classical stress analyses in which property values are nearly constant. The radically different situation calls for a modified approach. For instance, in the numerical solution of a problem, a large number of radial nodes is needed in the narrow zone of rapidly changing stress; a fewer number is needed both inward from that region, where the stress is negligible, and outward where the stress is constant.

\section{Fission Product Effects}

The mechanisms of fission product swelling and fission gas release have not yet been defined in a generally accepted manner. In view of the large number of proposed models for these phenomena, each yielding different predictions, it is prudent to adopt, where possible, a model independent empirical approach.

The BEHAVE- 2 code is the embodiment of this view of fuel behavior and modeling. 


\section{DESCRIPTION OF MODEL}

\subsection{DIVISION OF FUEL INTO ZONES AND REGIONS}

In the BEHAVE-2 code, the fuel is divided into two phenomenological zunes (Figure 2-1). Within the outermost or structural fuel zone, the viscosity of the fuel is within a few decades in magnitude of the viscosity of the cladding. Cracks are simulated in planes normal to the pin axis $[(r, \theta)$ planes] or along radially oriented $(r, z)$ planes. The fuel is assumed to have negligible tensile strength, and it cracks under tensile stresses applied in the directions normal to the two crar.king planes,"

Inward of the structural fuel zone, the fuel viscosity is low relative to the cladding viscosity at high linear powers and correspondingly high fuel temperatures; this produces a zone, termed the inviscid zone, which is assumed to be at constant hydrostatic pressure. The high temperatures within the inviscid zone promote crack closure by diffusional or plastic flow processes and the assumption is made that no cracks exist. ${ }^{* *}$

The inviscid zone is further subdivided into two regions. The outermost, the nontransport region, retains its porosity unless it is eliminated by a mechanical hot pressing process induced by elimination of the central void as a sink for further fuel expansion. In the transport region, on the other hand, porosity is assumed to be eliminated by diffusion-controlled processes except for a residual porosity of $1 \%$.

The temperature which delineates the boundary between the structural and inviscid zones is termed the inviscidity temperature. The temperature separating the nontransport and transport regions is termed the transport temperature. Both temperatures are functions of the characteristic time of a particular event. For instance, for a month of steady operation, the inviscidity and transport temperatures are currently held at $1300^{\circ} \mathrm{C}$ and $1600^{\circ} \mathrm{C}$, respectively. For events lasting a fraction of a second, such as a scram or transient over-power condition, the inviscid boundary uccurs at or close to the temperature of fuel melting; the transport temperature is in excess of the center temperature, eliminating the transport region from these very rapid events altogether. ${ }^{\dagger}$

\subsection{ASSUMPTION OF FUEL-CLADDING GAP CLOSURE}

Another assumption used in the model concerns the disposition of the as-fabricated fuel-cladding gap. At the first application of a small amount of power to a fresh fuel pin, thermal stresses crack the fuel into a large number of pie-shaped segments (Figure 2-2). The exact position in space of each segment at low linear power and the start of life is, in fact, indeterminate; any segment can be touching the cladding, can remain in toward the fuel center, or can be at some intermediate radial position. Most previous models have assumed that the fuel segments reside as far inward as possible, providing a maximum fuel-clạdding gap.

For both calculational and physical reasons, BEHAVE-2 makes the alternate assumption that the fuel segments are, for all times after the initial application of power, as far out as possible, thus producing a configuration in which there is no fuel-cladding gap. Thus, at the start of a BEHAVE-2 problem, as power is initially applied to the pin, the fuel segments are translated radially outward without deformation to the inner surface of the cladding. This movement produces a pattern of radial cracks and a central void, as shown in Figure $2-2{ }^{\dagger+}$ The assignment of the fuel segments to their maximum nnssible outward position corresponds to the assumption of rapid gap closure. The assumption is quite arbitrary at low center temperature, there being no physical process which particularly favors this contıguration. However, with increasing center temperature, interior fuel cracks heal and tabrication and fission gases terid to pressurize this hot plastic core of fuel. The force developed should be sufficient to push the fuel segments outward into intimate contact with the cladding. Thus, the model's assumption on the position of the fuel segments is arbitrary at

\footnotetext{
"See subsection 3.2.7 for further discussion of cracking.

" * Crack closure in the inviscid region is discussed in subsection 3.2.6.

1 Boundary temperatures arte distissed further in subcections 3.2 .1 and 3.2.2.

tt The number of fuel segments, shown in figure 2-2 to be six, is immaterial to the calculations. Cracks are treated as a continuum, representing a "void strain" or crack width per unit distance "normal to the crack plane. Stress is assumed to be zero in directions normal to cracks. These assumptions approach reality as the actual number of cracks increases.
} 


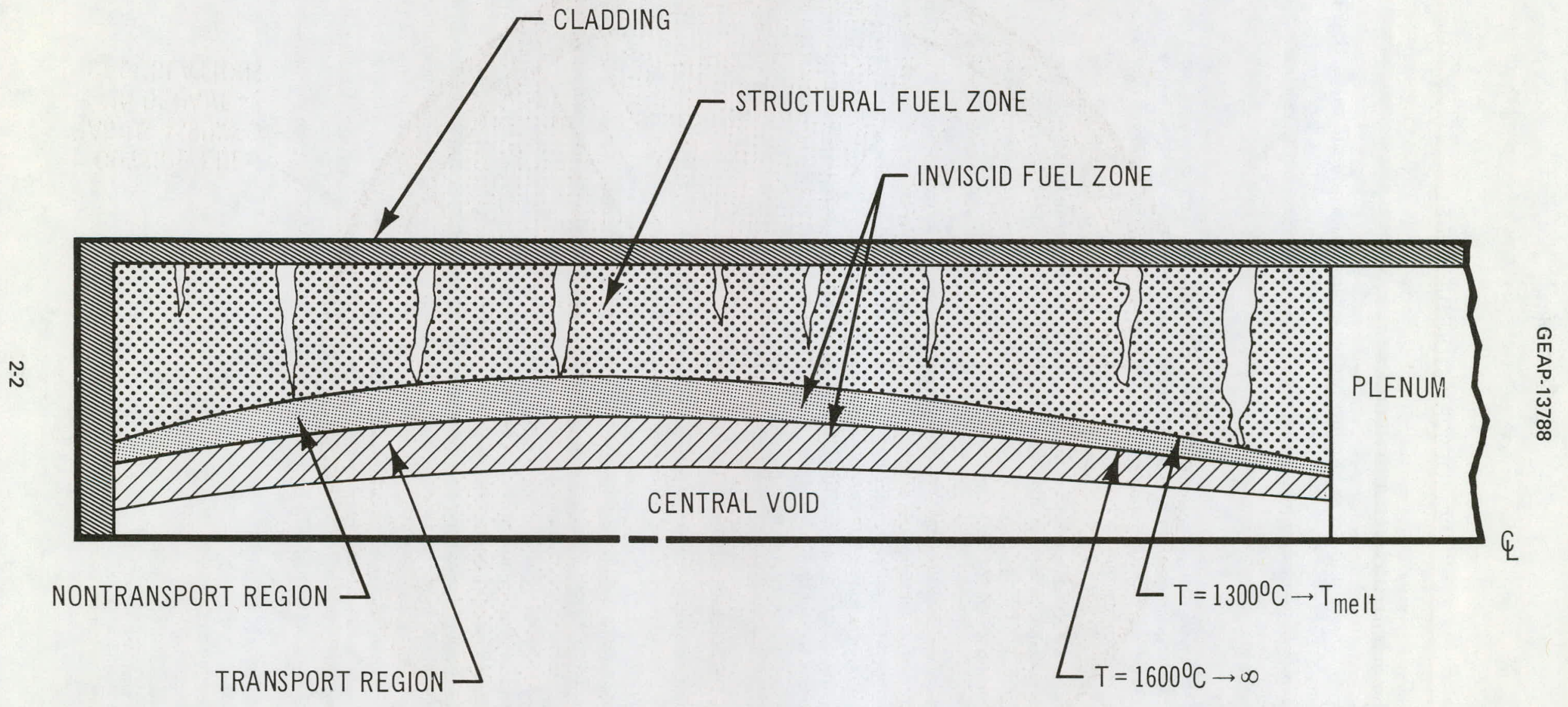

Figure 2-1. Division of Fuel into Structural and Inviscid Zones; Subdivision of Inviscid Fuel into Nontransport and Transport Regions 


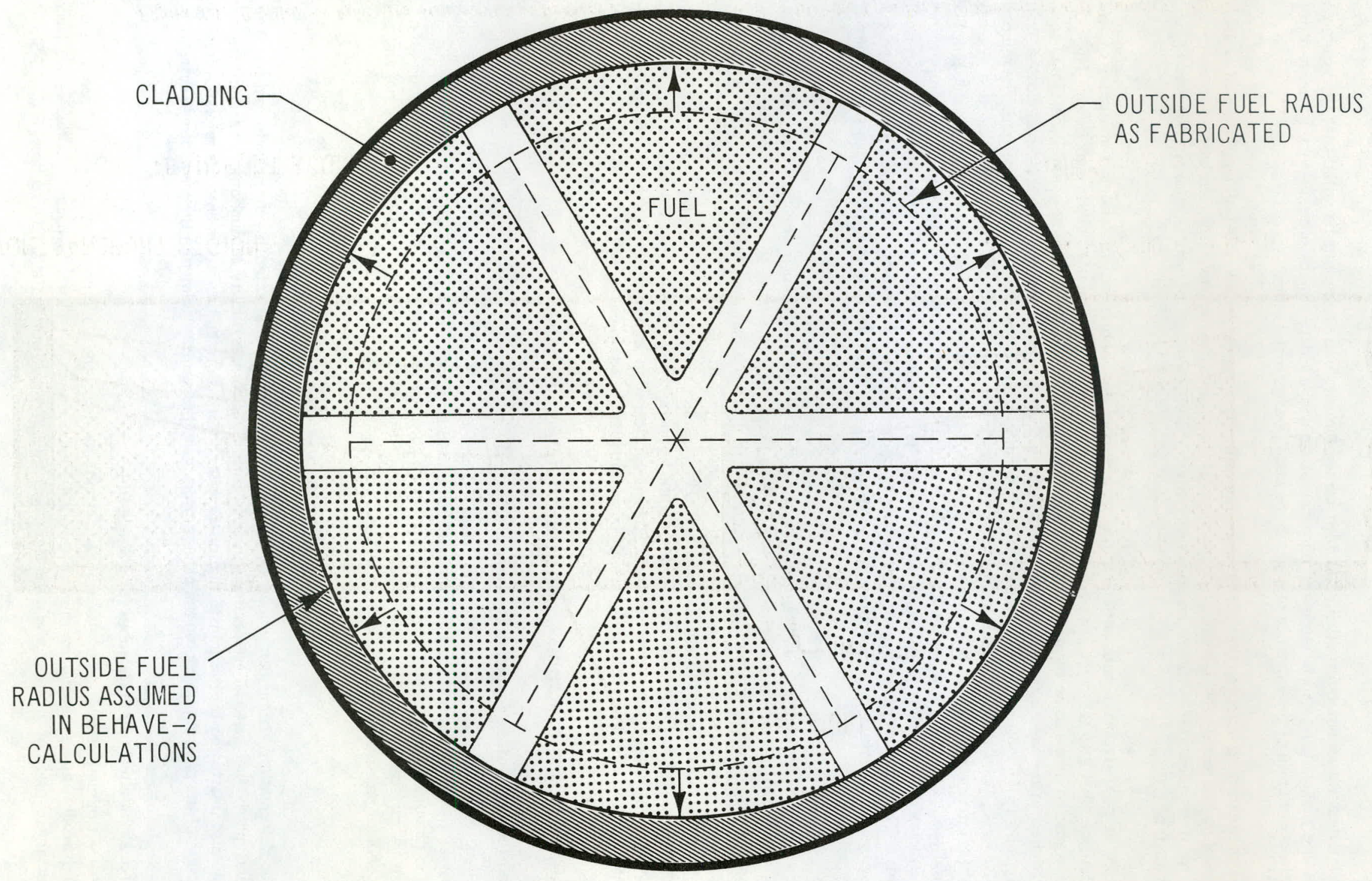

Figure 2-2. Assumed Fuel Configuration at Zero Power, Start of Life 
low center temperatures but quite credible at high center temperatures. It should be noted that the assumption of closure of the fuel-cladding gap is made for purposes of assigning a determinate position to the fuel and does not preclude the assumption of the existence of a gap in the code's heat transfer section.

It is of interest to compare the BEHAVE-2 assumption that no gap exists under all conditions after the initial application of power to the available data. Investigations of gap closure kinetics invariably rely upon photomicrographic evidence from shutdown fuel. Such investigations offer mixed evidence of gap closure in the "cold" or room temperature state.

Rabin, et al., ${ }^{10}$ reported substantial closure of the cold gap upon postirradiation examination of five pins irradiated in the EBR-2 to 0.2 at. \% peak burnup. The five pins operated at about $16 \mathrm{~kW} / \mathrm{ft}$ peak power. The F-2 series of pins ${ }^{11}$ irradiated in the same rear.tor to 5 at. \% poak burnup at $15-10 \mathrm{~kW} / \mathrm{ft}$ peak power all show closed cold gaps. A pin irradiated in the same experiment at $9 \mathrm{~kW} / \mathrm{ft}$ peak to 3 at. \% burnup did not show cold gap closure. Neimark, et al., have reported ${ }^{12}$ closure of a very large 14-mil fabricated gap in pin SOPC-5 at 3 at. \% burnup. The pin operated at $12 \mathrm{~kW} / \mathrm{ft}$ peak. Wide radial cracks remain at the outside rim of fuel in this pin after irradiation but all cracks are closed in the interior region, a state in qualitative agreement with the BEHAVE-2 assumption. A sister pin, SOPC-3, vivilı a 4-mil fabricated gap also showed cold gap closure after irradiation at $14.8 \mathrm{~kW} / \mathrm{ft}$ peak. The same report indicates that pins irradiated at $16 \mathrm{~kW} / \mathrm{ft}$ to 4.7 at. \% burnup had cold fuel-cladding gaps at the ends of the pins but not in the middle third. The problem of interpreting such data is compounded by the fact that fission products or cladding corrosion products are often removed during metallographic preparation, leaving an apparent gap where none existed during irradiation.

The validity of the code's assumption of zero gap is much more important in the "hot" or operating condition where the significant thermal and mechanical effects take place. Unfortunately, there is no direct evidence available concerning the magnitude of the hot gap. As Figure 2-3 illustrates, a gap may form during shutdown, where none existed at power. Furthermore, the uncracked fuel at moderate burnups has a tendency to shrink away from the cladding less than radially cracked low burnup fuel. The resultant closure of the cold gap is often misintcrprcted as implylng closure of the hot gap with burnup, whereas the hot gap may in actuality have closed early in life. The rate of hot gap closure, which must be deduced from detailed consideration of the mechanics of shutdown in addition to measurements of post-shutdown cold gaps, has not been systematically studied.

\subsection{MECHANICS OF THE CLADDING AND STRUCTURAL FUEL ZONES}

\subsubsection{Transformation of the Boundary Pressures}

In the stress.analysis of the cladding and structural fuel zones the assumption is made that fuel pores and cracks contain gas at the plenum pressure. The analysis is simplified by subtracting at each point in the fuel pin a pressure equal to the plenum pressure. The transformed system has zero pressure in the fuel cracks and pores and in the fission gas plenum. A surface traction is applied to the outside of the cladding equal in magnitude to the plenum pressure minus the coolant pressure.

$$
\sigma_{\text {ST }}=P_{\text {plenum }}-P_{\text {coolant }}
$$

Shear deformations, being determined by deviatoric stresses, are unaffected by the transformation. Also, the cladding and matrix fuel material are assumed to possess no bulk compressibility throughout the analysis, so material volumes are also unaffected by the transformation. Stresses are transformed back to an absolute reference frame in the output section of the program by adding the plenum pressure to pressures calculated in the transformed system.

\subsubsection{Force-Displacement Rate Relations for a Single Ring}

To permit numerical solution of the stress and strain rate fields, the cladding and structural fuel zones are divided radially and axially into a number of rings (Figure 2-4). Each ring is permitted to have three degrees of freedom: uniform radial expansion of the inner and outer radii, and uniform expansion in the axial direction (Figure 2-5). 

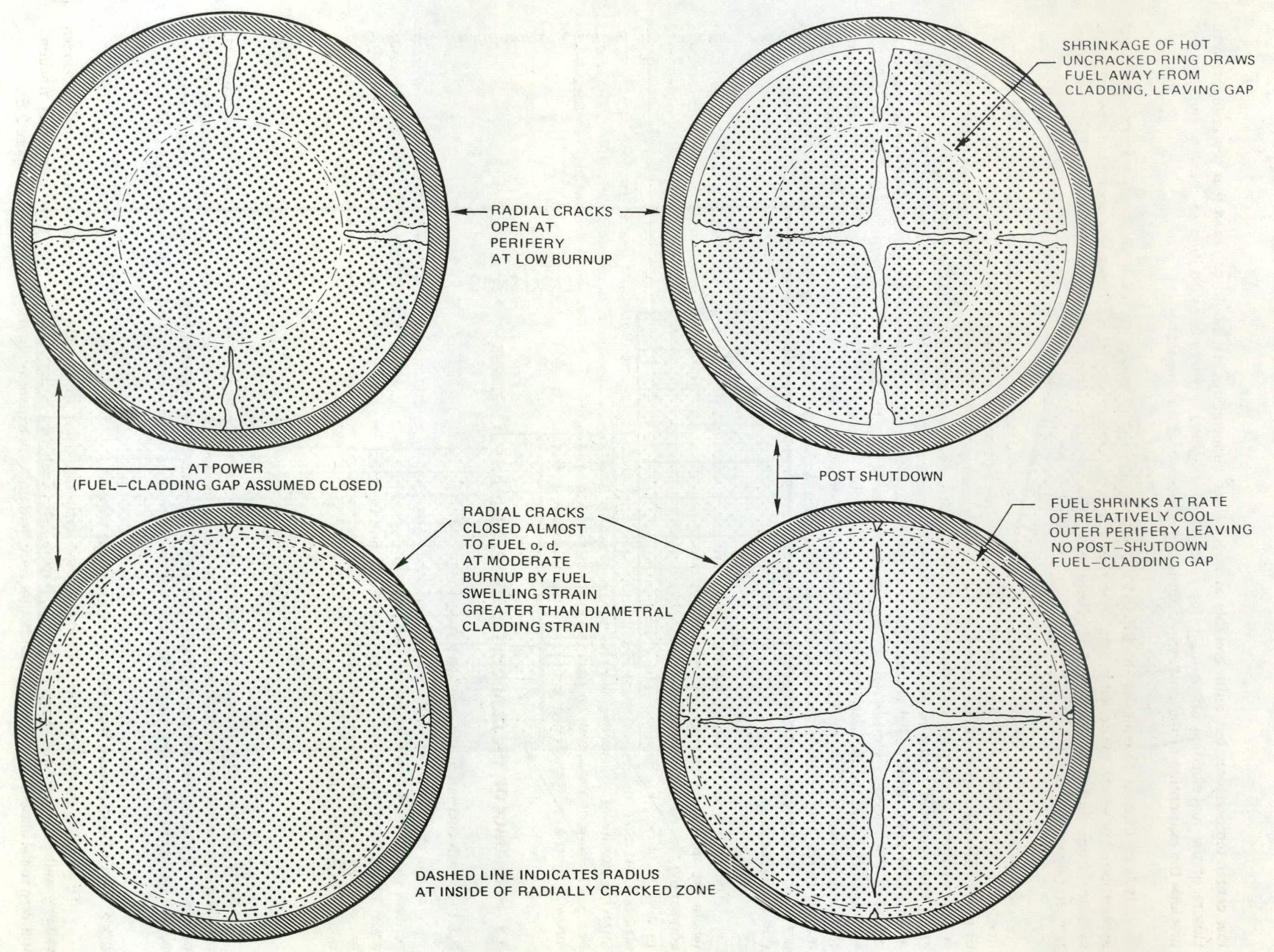

Figure 2-3. Fuel-Cladding Gap Formation During Shutdown 


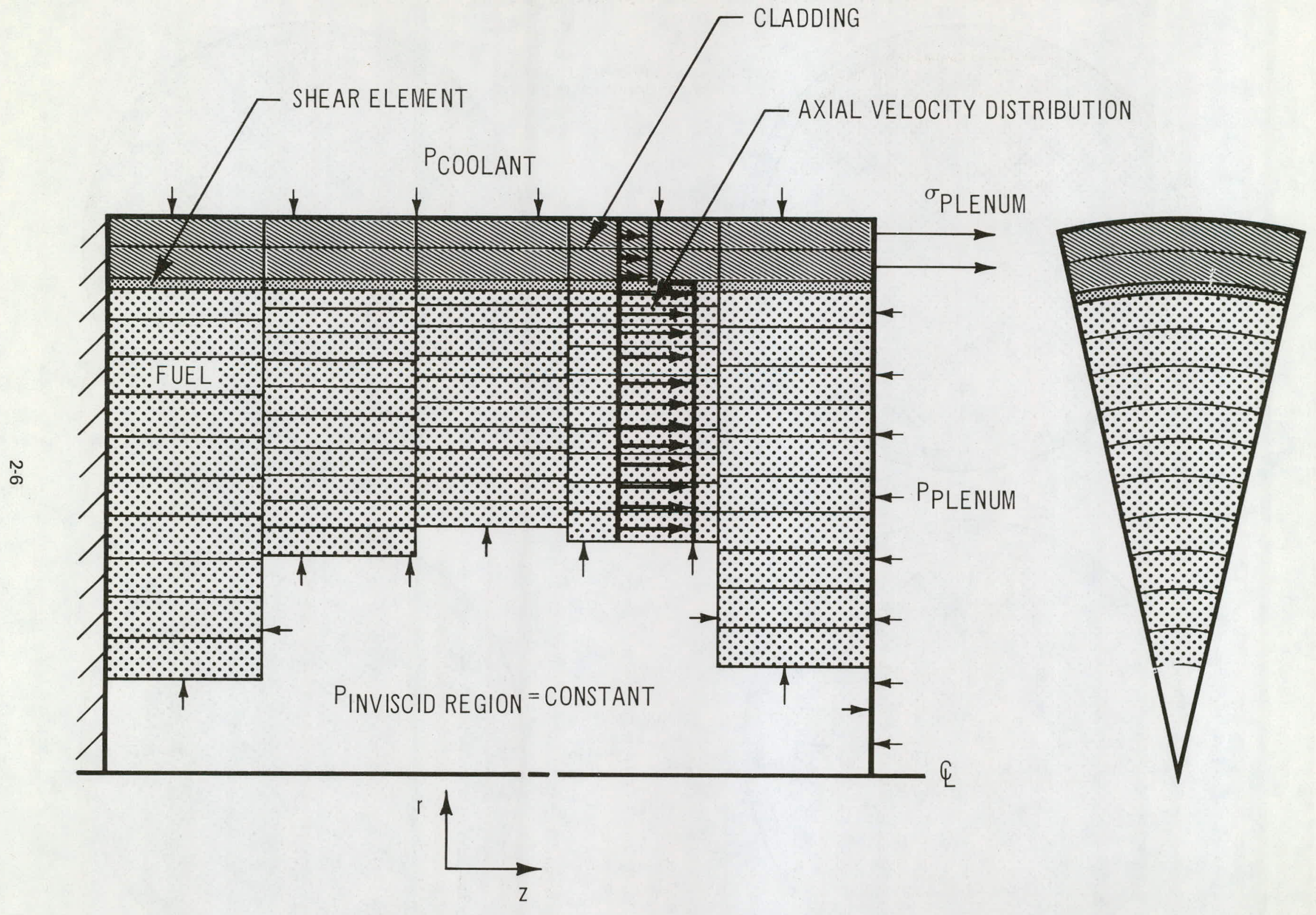

Figure 2-4. Idealization of Cladding and Structural Fuel Zones 
$\mathrm{k}_{\mathrm{ij}}=\mathrm{k}_{\mathrm{ij}}\left(\dot{\epsilon}^{*}\right.$, CRACK PATTERN $)$

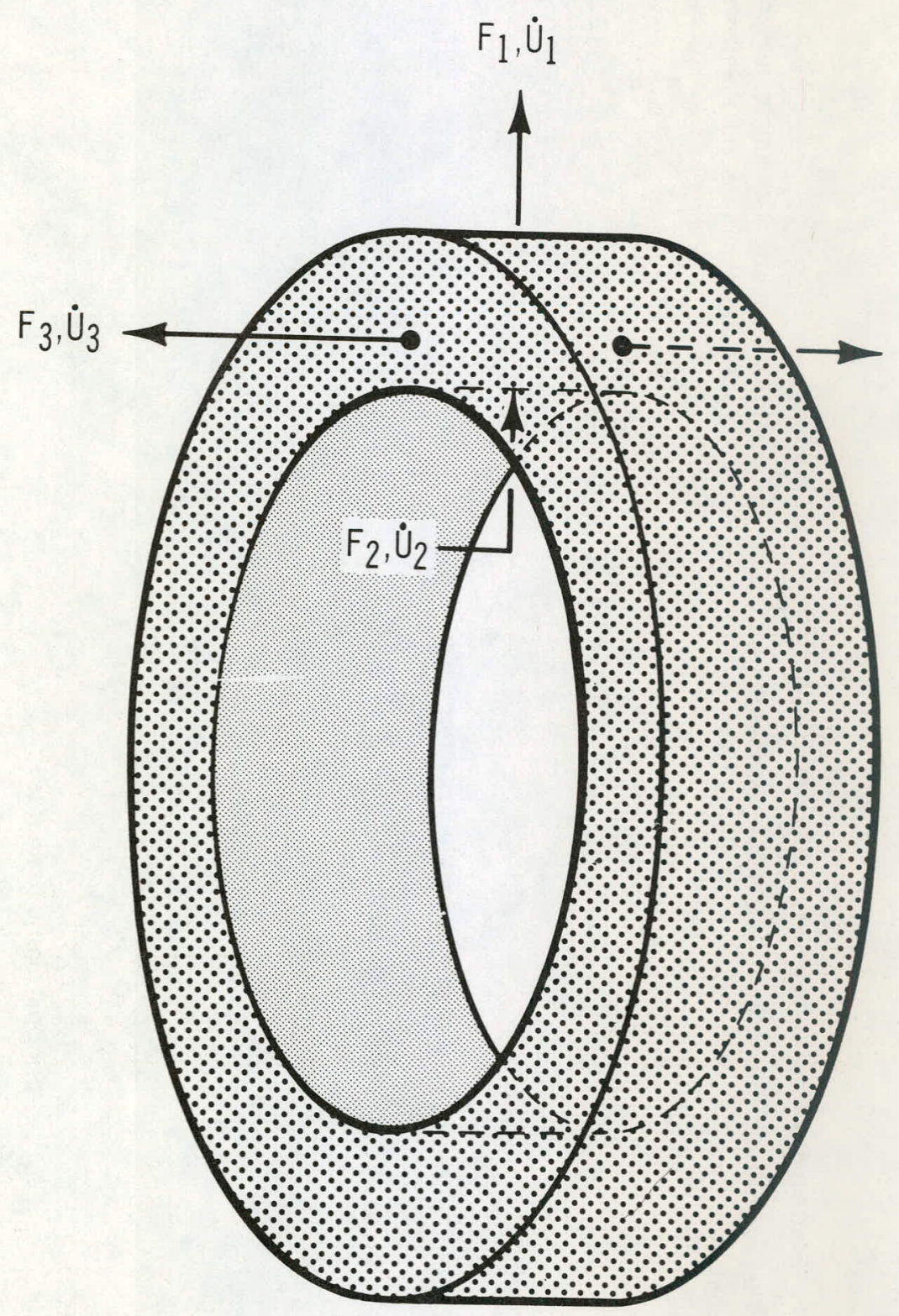


The magnitudes of the coefficients $k_{i j}$ and $G_{i}$ of the matrix equation in Figure $2-5$ depend on whether the ring is uncracked, radially cracked, transversely cracked, or cracked in both directions. Depending on this "crack pattern," one of the matrix equations derived below represents the fuel or cladding ring and may be put in the standard form of Figure 2-5.

\subsubsection{Relationship of the Components of Stress and Strain Rate}

The strain-rate component of an elastic-plastic solid in one of the three principal stress directions may be expressed in terms of Hooke's law for the elastic portion and the analogous Prandtl-Reuss flow rules for the plastic portion in the following form:

$$
\dot{\epsilon}_{1}=\frac{\dot{\epsilon}_{\mathrm{p}}^{*}}{\sigma^{*}}\left[\sigma_{1}-\nu_{\mathrm{p}}\left(\sigma_{2}+\sigma_{3}\right)\right]+\frac{1}{\mathrm{E}}\left[\dot{\sigma}_{1}-\nu_{\mathrm{e}}\left(\dot{\sigma}_{2}+\dot{\sigma}_{3}\right)\right]+\dot{\epsilon}_{\mathrm{d}} \text {, }
$$

where

$$
\begin{aligned}
& \dot{\epsilon}_{1}=\text { total strain rate in principal stress direction } 1 \\
& \sigma_{1}, \sigma_{2}, \sigma_{3}=\text { principal stresses } \\
& \dot{\sigma}_{1}, \dot{\sigma}_{2}, \dot{\sigma}_{3}=\text { principal stress rates } \\
& \dot{\epsilon}_{\mathrm{p}}=\text { effective plastic strain rate } \\
& =\sqrt{\frac{2}{3}} \sqrt{\left(\dot{\epsilon}_{p_{1}}-\dot{\epsilon}_{p_{2}}\right)^{2}+\left(\dot{\epsilon}_{p_{2}}-\dot{\epsilon}_{p_{3}}\right)^{2}+\left(\dot{\epsilon}_{p_{3}}-\dot{\epsilon}_{p_{1}}\right)^{2}} \\
& \dot{\epsilon}_{\mathrm{p}_{1}}, \dot{\epsilon}_{\mathrm{p}_{2}}, \dot{\epsilon}_{\mathrm{p}_{3}}=\text { principal plastic strain rates } \\
& \sigma^{*}=\text { effective stress } \\
& =\frac{1}{\sqrt{2}} \sqrt{\left(\sigma_{1}-\sigma_{2}\right)^{2}+\left(\sigma_{2}-\sigma_{3}\right)^{2}+\left(\sigma_{1}-\sigma_{3}\right)^{2}} \\
& \dot{\epsilon}_{\mathrm{d}}=\text { material dilatation rate }=\text { thermal expansion rate }+ \text { inexorable swelling rate } \\
& E=\text { Young's modulus } \\
& \nu_{\mathrm{e}}=\text { elastic Poisson's ratio } \\
& \nu_{p}=\text { plastic Poisson's ratio }
\end{aligned}
$$

During a timestep of finite length $\Delta t$, the approximation may be adopted that

$$
\dot{\sigma}_{i}=\frac{\sigma_{i}-\sigma_{i}^{\prime}}{\Delta t}
$$

where now $\sigma_{i}$ and $\sigma_{i}^{\prime}$ denote stresses at the end and at the beginning of the timestep, respectively. 
A significant simplification may be obtained by assuming that stresses are proportional to stress rates

$$
\frac{\dot{\sigma}_{1}}{\sigma_{1}}=\frac{\dot{\sigma}_{2}}{\sigma_{2}}=\frac{\dot{\sigma}_{3}}{\sigma_{3}}
$$

and by assuming that the elastic and plastic Poisson's ratios are equal

$$
\nu_{\mathrm{e}}=\nu_{\mathrm{p}}=\nu
$$

Introducing these approximations into (2-2),

$$
\dot{\epsilon}_{1}=\left(\frac{\dot{\epsilon}_{\mathrm{p}}^{*}}{\sigma^{*}}+\frac{1}{\mathrm{E} \Delta \mathrm{t}}\right)\left[\sigma_{1}-\nu\left(\sigma_{2}+\sigma_{3}\right)\right]-\frac{1}{\mathrm{E} \Delta \mathrm{t}}\left[\sigma_{1}^{\prime}-\nu\left(\sigma_{2}^{\prime}+\sigma_{3}^{\prime}\right)\right]
$$

And, defining the "creep modulus" $\xi$ as,

$$
\xi=1 /\left(\frac{\dot{\epsilon}_{\mathrm{p}}^{*}}{\sigma^{*}}+\frac{1}{E \Delta \mathrm{t}}\right) \text {. }
$$

Equation (2-6) becomes

$$
\dot{\epsilon}_{1}=\frac{1}{\xi}\left\{\left(\sigma_{1}-\frac{\xi}{\mathrm{E} \Delta \mathrm{t}} \sigma_{1}^{\prime}\right)-\nu\left[\left(\sigma_{2}-\frac{\xi}{\mathrm{E} \Delta \mathrm{t}} \sigma_{2}^{\prime}\right)+\left(\sigma_{3}-\frac{\xi}{\mathrm{E} \Delta \mathrm{t}} \sigma_{3}^{\prime}\right)\right]\right\}+\dot{\epsilon}_{\mathrm{d}} .
$$

Equation (2-8) is in the same form as Hooke's law for an elastic solid but with strains replaced by strain rates, Young's modulus replaced by the creep modulus and stresses replaced by the reduced stress $\left[\sigma-(\xi / E \Delta t) \sigma^{\prime}\right]$. Hence, solutions derived from elastic analysis may be directly applied to the present elastic-plastic analysis.

It should be noted that Equation $(2-8)$ is exact for either primarily elastic behavior $(E \Delta t \ll \xi)$ or primarily plastic behavior $(\mathrm{E} \Delta \mathrm{t} \gg \xi)$ if $\nu$ is taken to be $\nu_{\mathrm{e}}$ or $\nu_{\mathrm{p}}$, respectively. Values for $\nu$ used in the code are discussed in subsection 2.3.2.6.

\subsubsection{Matrix Equation for a Cladding Ring or Unbroken Fuel Ring}

The exact Lame solution ${ }^{*}$ for an elastic thick-walled cylinder under internal pressure $P_{2}$ and external pressure $P_{1}$, when generalized to include material dilatation $\epsilon_{\mathrm{d}}$ and axial stress $\sigma_{\mathrm{z}}$ gives

$$
\begin{aligned}
& U_{r}=\frac{1-\nu}{E} \frac{r_{2}{ }^{2} P_{2}-r_{1}{ }^{2} P_{1}}{r_{1}{ }^{2}-r_{2}{ }^{2}} r+\frac{1+\nu}{E} \frac{r_{2}{ }^{2} r_{1}{ }^{2}\left(P_{2}-P_{1}\right)}{\left(r_{1}{ }^{2}-r_{2}{ }^{2}\right) r}+\epsilon_{d} r-\frac{\nu \sigma_{z}}{E} r \\
& U_{z}=\frac{1}{E}\left[\sigma_{z}-2 \nu\left(\frac{r_{2}{ }^{2} P_{2}-r_{1}{ }^{2} P_{1}}{r_{1}{ }^{2}-r_{2}{ }^{2}}\right)\right] \ell+\epsilon_{d} l
\end{aligned}
$$

*See for instance, Timoshen ko and Goodier, Theory of Elasticity, 2nd ed., McGraw Hill, New York. 
where

$$
\begin{aligned}
U_{r} & =\text { radial displacement, } \\
U_{z} & =\text { axial displacement, } \\
r_{1}, r_{2} \cdot r & =\text { outer, inner, local radii, and } \\
\ell & =\text { length of cylinder. }
\end{aligned}
$$

Defining the nodal forces $F_{1}=-2 \pi r_{1} \ell P_{1}$,

$$
\begin{aligned}
& F_{2}=2 \pi r_{2} \ell P_{2}, \\
& F_{3}=\pi\left(r_{1}{ }^{2}-r_{2}{ }^{2}\right) \sigma_{z} .
\end{aligned}
$$

evaluating Equations (2-9) and (2-10) at $r_{1}$ and $r_{2}$, and replacing displacements with displacement rates, dilatation with dilatation rate, Young's modulus with the creep modulus, and stresses with reduced stresses, a matrix equation is obtained relating radial forces to the displacement rates at the inside and outside of the ring and axial forces to the displacement rates of the axial boundaries of the ring.

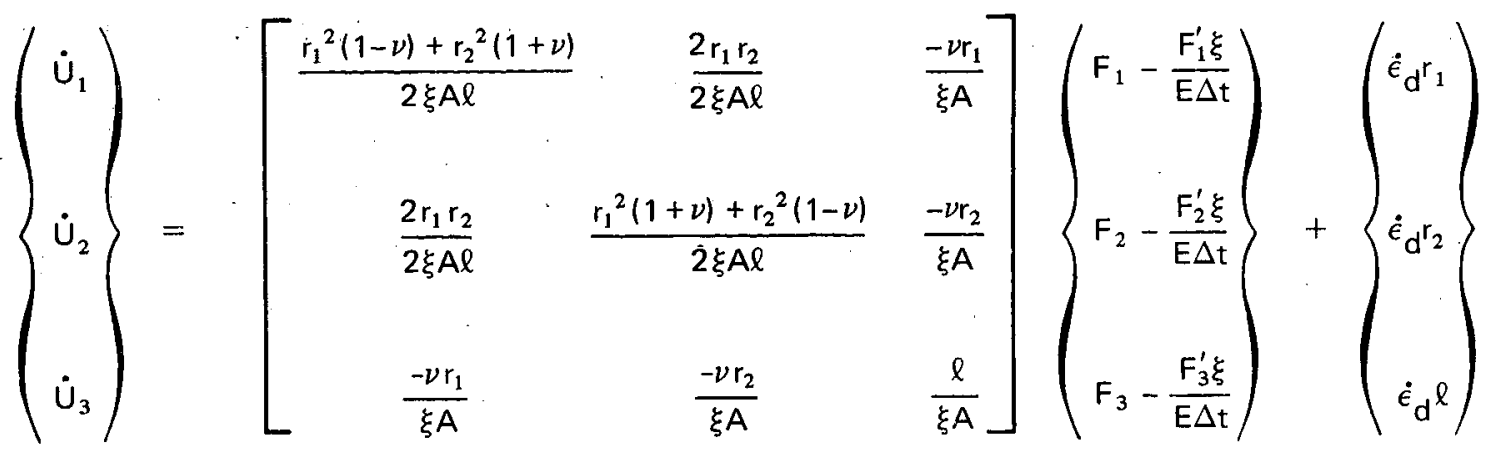

where

$$
\begin{aligned}
F_{1}^{\prime}, F_{2}^{\prime}, F_{3}^{\prime} & =\text { known nodal forces at the beginning of the timestep, } \\
A & =\pi\left(r_{1}{ }^{2}-r_{2}{ }^{2}\right) \text {, and } \\
\dot{U}_{1}, \dot{U}_{2}, \dot{U}_{3} & =\text { displacement rates. }
\end{aligned}
$$

\subsubsection{Matrix Equation for a Radially Cracked Fuel Ring}

In a radially cracked ring, the hoop stress, $\sigma_{\theta}$, is equal to zero and for equilibrium

$$
F_{1}=-F_{2}
$$

For a thin ring, the radial stress is approximately constant and given by

$$
\sigma_{r}=\frac{F_{1}}{\pi\left(r_{1}+r_{2}\right) \ell f}
$$

where $f$ is the fraction of the ring volume that is not in the form of radial or transverse cracks. 
Applying an axial stress

$$
\sigma_{z}=\frac{F_{3}}{A}
$$

using the strain rate-displacement rate relations,

$$
\begin{aligned}
& \dot{\epsilon}_{r}=\frac{\partial \dot{U}_{r}}{\partial r} \\
& \dot{\epsilon}_{z}=\frac{\partial \dot{U}_{z}}{\partial z}
\end{aligned}
$$

and a constitutive equation of the form of Equation (2-8), yields

$$
\left\{\begin{array}{c}
F_{1}-\frac{F_{1}^{\prime} \xi}{E \Delta t} \\
F_{2}-\frac{F_{2}^{\prime} \xi}{E \Delta t} \\
F_{3}-\frac{F_{3}^{\prime} \xi}{E \Delta t}
\end{array}\right\}=\left[\begin{array}{lll}
\frac{\pi f \xi \ell\left(r_{1}+r_{2}\right)}{\left(1-\nu^{2}\right)\left(r_{1}-r_{2}\right)} & \frac{-\pi f \xi \ell\left(r_{1}+r_{2}\right)}{\left(1-\nu^{2}\right)\left(r_{1}-r_{2}\right)} & \frac{\pi \nu f \xi\left(r_{1}+r_{2}\right)}{\left(1-\nu^{2}\right)} \\
\frac{-\pi f \xi \ell\left(r_{1}+r_{2}\right)}{\left(1-\nu^{2}\right)\left(r_{1}-r_{2}\right)} & \frac{\pi f \xi \ell\left(r_{1}+r_{2}\right)}{\left(1-\nu^{2}\right)\left(r_{1}-r_{2}\right)} & \frac{-\pi \nu f \xi\left(r_{1}+r_{2}\right)}{\left(1-\nu^{2}\right)} \\
\frac{\pi \nu f \xi\left(r_{1}+r_{2}\right)}{\left(1-\nu^{2}\right)} & \frac{-\pi \nu f \xi\left(r_{1}+r_{2}\right)}{\left(1-\nu^{2}\right)} & \frac{f \xi A}{\left(1-\nu^{2}\right) \ell}
\end{array}\right]\left\{\begin{array}{c}
\dot{U}_{1} \\
\dot{U}_{2} \\
\dot{U}_{3}
\end{array}\right\}+\left\{\begin{array}{c}
\frac{-\pi f \xi \ell\left(r_{1}+r_{2}\right) \dot{\epsilon}_{d}}{1-\nu} \\
\frac{\pi f \xi \ell\left(r_{1}+r_{2}\right) \dot{\epsilon}_{d}}{1-\nu} \\
\frac{-f \xi A \dot{\epsilon}_{d}}{1-\nu}
\end{array}\right\}
$$

\subsubsection{Matrix Equation for a Transversely Cracked Fuel Ring}

The matrix equation representing a transversely cracked ring may be obtained directly from Equation (2-11) for an uncracked ring by setting the axial force, $F_{3}$, equal to zero and by increasing radial strain rates by the ratio of $1 / f$ to account for the diminished load bearing area clue to the presence of cracks.

$$
\begin{aligned}
& \left\{\begin{array}{l}
\dot{U}_{1} \\
\dot{U}_{2}
\end{array}\right\}=\left[\begin{array}{cc}
\frac{r_{1}^{2}(1-\nu)+r_{2}^{2}(1+\nu)}{2 f \xi A l} & \frac{2 r_{1} r_{2}}{2 f \xi A l} \\
\frac{2 r_{1} r_{2}}{2 f \xi A l} & \frac{r_{1}^{2}(1+\nu)+r_{2}^{2}(1-\nu)}{2 f \xi A l}
\end{array}\right]\left\{\begin{array}{c}
F_{1}-\frac{F_{1}^{\prime} \xi}{E \Delta t} \\
F_{2}-\frac{F_{2}^{\prime} \xi}{E \Delta t}
\end{array}\right\}+\left\{\begin{array}{l}
\dot{\epsilon}_{d} r_{1} \\
\dot{\epsilon}_{d} r_{2}
\end{array}\right\} \\
& F_{3}=0
\end{aligned}
$$




\subsubsection{Matrix Equation for a Radially and Transversely Cracked Fuel Ring}

The matrix equation for a radially and transversely cracked ring may be obtained directly from Equation (2-17) for a radially cracked ring by setting the axial force, $F_{3}$, equal to zero.

$$
\begin{aligned}
\left\{\begin{array}{c}
F_{1}-\frac{F_{1}^{\prime} \xi}{E \Delta t} \\
\left.F_{2}-\frac{F_{2}^{\prime} \xi}{E \Delta t}\right)
\end{array}\right\}=\left[\begin{array}{ll}
\frac{\pi f \xi \ell\left(r_{2}+r_{2}\right)}{\left(r_{1}-r_{2}\right)} & \frac{-\pi f \xi \ell\left(r_{1}+r_{2}\right)}{\left(r_{1}-r_{2}\right)} \\
\frac{-\pi f \xi \ell\left(r_{1}+r_{2}\right)}{\left(r_{1}-r_{2}\right)} & \frac{\pi f \xi \ell\left(r_{1}+r_{2}\right)}{\left(r_{1}-r_{2}\right)}
\end{array}\right]\left(\begin{array}{l}
\dot{u}_{1} \\
\dot{U}_{2}
\end{array}\right\}+\left\{\begin{array}{l}
\left.-\pi f \xi \ell\left(r_{1}+r_{2}\right) \dot{\epsilon}_{d}\right) \\
\pi f \xi \ell\left(r_{1}+r_{2}\right) \dot{\epsilon}_{d}
\end{array}\right\} \\
F_{3}=0
\end{aligned}
$$

\subsubsection{Determination of Creep Modulus and Poisson's Ratio}

The creep modulus, $\xi$, is initially determined in the cladding from the nonlinear constitutive equation (see subsection 3.1 .2$)$ by assuming a value of the effective strain rate, $\dot{\epsilon}^{*}$, and solving for the effective stress, $\sigma^{*}$, knowing the effective stress during the last timestep, $\sigma^{* \prime}$. The creep modulus is then given by

$$
\xi=\frac{\sigma^{*}\left(\dot{\epsilon}^{*}, \sigma^{* \prime}\right)}{\dot{\epsilon}^{*}}
$$

In evaluating this property, the mean temperature during the timestep is used. After solving the complete set of structural equations for the fuel pin, an improved estimate is available for $\dot{\epsilon}^{*}$ which, on the next iteration, provides for an improved estimate of the creep modulus. From four to six iterations are used to converge the creep modulus to acceptable accuracy.

A similar convergence procedure is used in the fuel to determine a creep modulus. from the nonlinear constitutive equation (see subsection 3.1.1). However, in view of the steep temperature gradient across the fuel and the exponential variation of creep rate with temperature, it is not adequate to evaluate the property at the mean temperature of the ring when the temperature difference across a ring is $>50^{\circ} \mathrm{C}$. Under many loading conditions, the effective strain rate within the ring is approximately constant but the stress varies exponentially due to the temperature gradient. Using the assumption of constant effective strain rate, a mean effective stress for the ring is derived as.

$$
\bar{\sigma}^{*}=\frac{1}{T_{2}-T_{1}} \int_{T_{1}}^{T_{2}} \sigma^{*}\left(\dot{\epsilon}^{*}, \sigma^{*}, T\right) d T,
$$

where $T_{1}$ and $T_{2}$ are temperatures at the outside and inside of the ring, respectively. Then the creep modulus for the ring is given by

$$
\xi=\frac{\bar{o}^{*}}{\dot{\epsilon}^{*}}
$$


A Poisson's ratio of 0.5 , equivalent to material incompressibility, renders the matrix Equation (2-11) singular. Thus, a lower value must be employed for mathematical reasons. A value of $\nu=0.4$ is used in the cladding, giving the cladding a small amount of compressibility that is at variance with the code's assumption of material incompressibility. However, the small residual volume created during a particular timestep by this compressibility is eliminated during the next timestep by reducing thermal expansion volume by the amount of the residual compressibility volume.

In the fuel, two different Poisson's ratios are used. Where the material is in a primarily elastic regime defined by $\xi / E \Delta t \geqslant 0.5$, the value

$$
\nu=0.3
$$

is employed. The fuel matrix material is considered incompressible and the slight volume expansion due to the material (matrix material plus pores) compressibility is taken up in a small increase in pore volume under a tensile hydrostatic load. The material is so highly deformation resistant in the elastic regime that negligible error is introduced in the fuel porosity under realistic stresses.

In the primarily plastic regime defined by $\xi / E \Delta t<0.5$, the ability of the fuel to be compressed into its own porosity may have considerable effect on the calculated stresses. Since Poisson's ratio is determinant of the compressibility of the material, it must be accurately stated in the plastic regime. BEHAVE-2 uses a value dependent on the porosity, $p$, given by:

$$
\nu=\frac{2-p}{4+p}
$$

The equation is based ${ }^{13}$ upon deformation of a linearly viscous material into spherical pores. Its applicability to the nonlinear stress-strain rate regime is assumed without proof.

Concurrently with the iterations to determine $\xi\left(\dot{\epsilon}^{*}\right)$, the crack pattern in the fuel is also determined. A ring is considered cracked in one of the two possible categories of cracking planes during an iteration if either the stress is positive normal to the cracking plane during the present timestep or cracks in that category existed at the end of the previous timestep.

\subsubsection{Formulation of the Matrix Equation Representing the Overall Structure}

Having determined the matrix equations describing each ring, the program proceeds to couple them together into a matrix equation representing the whole structure as illustrated in Figure 2-6. In step 1, the fuel rings in a given axial section are coupled together. Force equilibrium and displacement compatibility are maintained between rings and a constant axial velocity profile is imposed on all rings in the axial section. In step 2, the coupled equations representing the force-displacement rate relations for $n$ rings are condensed into 3 nodal equations representing the inner, outer, and axial boundaries of the fuel section.

$$
\left\{\begin{array}{l}
F_{0} \\
F_{i} \\
F_{z}
\end{array}\right\}=\left[\begin{array}{lll}
K_{11} & K_{12} & K_{13} \\
K_{21} & K_{22} & K_{23} \\
K_{31} & K_{32} & K_{33}
\end{array}\right]\left\{\begin{array}{l}
\dot{u}_{0} \\
\dot{U}_{i} \\
\dot{U}_{z}
\end{array}\right\}+\left\{\begin{array}{l}
G_{0} \\
G_{i} \\
G_{z}
\end{array}\right\}
$$




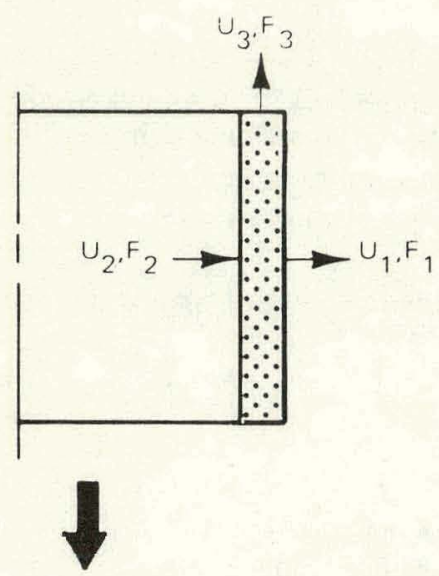

STEP 1. COUPLE FUEL (OR CLADDING) RINGS INTO AXIAL SECTION MATRIX EQUATION
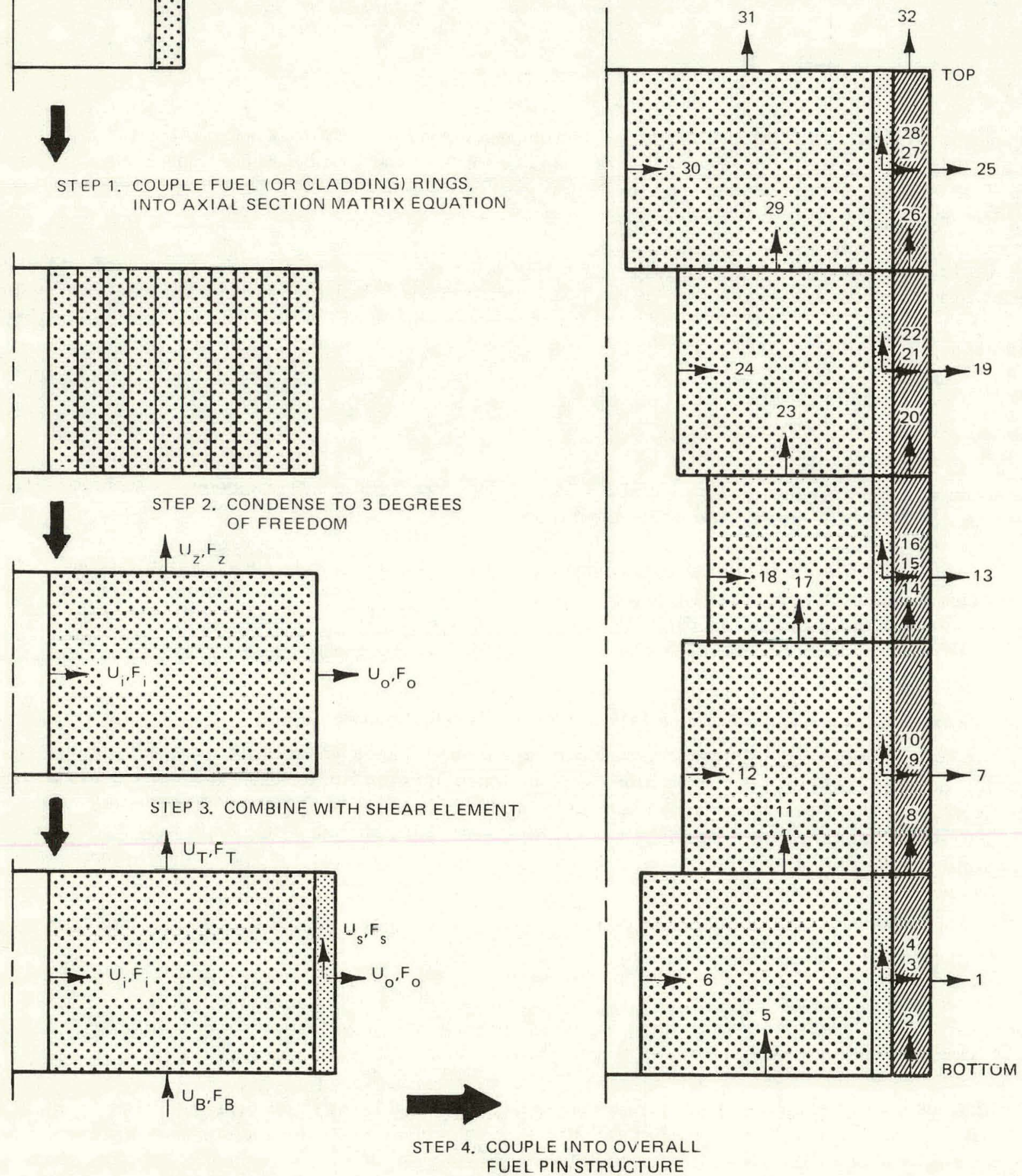

Figure 2-6. Assembly of Individual Ring Elements and Shear Elements into Overall Fuel Pin Structure 
Fuel-cladding friction is simulated by coupling a so-called "shear element" to the outside of the fuel, as shown in step 3. The shear element, analogous to a layer of viscous lubricant, exerts an opposing shear stress on the fuel which is proportional to the difference between the mean velocity of the fuel section and the velocity of the shear element's outer face. This results in a matrix equation for the coupled fuel-shear element ensemble of the form

$$
\left\{\begin{array}{c}
F_{0} \\
F_{i} \\
F_{T} \\
F_{B} \\
F_{S}
\end{array}\right\}=\left[\begin{array}{ccccc}
K_{11} & K_{12} & K_{13} & -K_{13} & 0 \\
K_{21} & K_{22} & K_{23} & -K_{23} & 0 \\
K_{31} & K_{32} & \frac{C}{4}+K_{33} & \frac{C}{4}-K_{33} & -\frac{c}{2} \\
-K_{31} & -K_{32} & \frac{C}{4}-K_{33} & \frac{C}{4}+K_{33} & -\frac{C}{2} \\
0 & 0 & -\frac{C}{2} & -\frac{C}{2} & C
\end{array}\right] \quad\left\{\begin{array}{c}
\dot{U}_{0} \\
\dot{U}_{i} \\
\dot{U}_{t} \\
\dot{U}_{b} \\
\dot{U}_{S}
\end{array}\right\}+\left\{\begin{array}{c}
G_{0} \\
G_{i} \\
G_{z} \\
-G_{z} \\
0
\end{array}\right\}
$$

where $\dot{U}_{t}$ and $\dot{U}_{b}$ represent the absolute velocities of the upper and lower faces of the fuel section, respectivelv, and replace $U_{z}$, the relative velocity between the two faces, in Equation (2-25).

The shear element property, $C$, represents the ratio between the shear force, $F_{S}$, generated at the fuel-cladding interface and the shear rate, $U_{s}-\left(U_{t}+U_{B}\right) / 2$. To simulate sliding friction, an algorithm converges on the unknown value of $\mathrm{C}$ during iteration of the stress-strain rate solution by attempting to make the following equality hold true

$$
C^{\prime}=\mu \frac{F_{o}}{F_{s}}
$$

where

$$
\begin{aligned}
& C^{\prime}=\text { value of } C \text { to be used next iteration, } \\
& F_{O}=\text { normal force at fuel-cladding interface calculated last timestep, } \\
& F_{S}=\text { shear force at fuel-cladding interface, and } \\
& \mu=\text { friction coefficient. }
\end{aligned}
$$

Sliding friction is simulated whenever the equality is realized. However, under two conditions the equality cannot be fulfilled for mathematical or physical reasons. First, when the normal force is zero, Equation (2-27) calls for $\mathrm{C}=0$. However, application of this value would result in singularity of the force-displacement rate relations for the whole structure. To circumvent the problem, a low value is assigned to $\mathrm{C}$ which provides a small shear force between the fuel and cladding even when the normal force is zero. Second, under some conditions the shear force will remain small compared to the normal force regardless of the magnitude of $\mathrm{C}$. Under successive iterations, the magnitude of $\mathrm{C}$. calculated by Equation (2-27) will continue to increase. This situation mathematically indicates that physically a "stick" condition (i.e., no fuel-cladding sliding) has been reached. To preclude an infinite C, which would present numerical problems, the algorithm sets a large but finite upper limit on $\mathrm{C}$ which allows negligible relative movement and approximates a true stick condition.

The identical procedure outlined in steps 1 through 3 is followed in each cladding section. Then, in step 4 , all of the fuel and cladding sections are coupled together, maintaining force equilibrium and displacement compatibility in the radial and axial directions, into the matrix equation representing the overall structure. Frictionless shearing is permitted between adjacent fuel or cladding sections in the $(r, \theta)$ plane and compatibility is not maintained between radial displacements of points in adjacent fuel or cladding sections, a negligible error considering the large length/ diameter ratio in most problems. 
The nodal scheme at this point is as shown in Figure 2-6. For a 5-axial-section case, the structure has 32 degrees of freedom. Thus, 32 simultaneous equations must be solved by the computer, a tractable number in terms of computer time.

\subsubsection{Application of Boundary Conditions to Structural Fuel and Cladding}

The structure is fixed in space iy setting the axial displacement rates of the bottommost fuel and cladding nodes (nodes 5 and 2 in Figure 2-6) equal to zero. Then the transformed surface traction given by Equation (2-1) is applied to the outside of the cladding. One of two boundary conditions is applied to the inner surface of the structural fuel zone. In $M O D E=1$, the inviscid fuel zone has remaining void and acts in a compressible manner. In this case, the pressure in the inviscid zone is equal to the plenum pressure; in the transformed system the plenum pressure is zero, so there is no boundary pressure.

In MODE $=2$, all voidage within the inviscid zone above a residual $1 \%$ porosity has been exhausted and the zone is considered incompressible. The expanding inviscid zone fuel inexorably imposes its volumetric expansion rate upon the structural zone-inviscid zone boundary. The program manipulates the force-displacement rate relations so that the inviscid zone expansion rate is imposed on the boundary while a constant but unknown pressure is maintained on the boundary. The program assumes that a membrane extends over the top of the fuel column, preventing inviscid zone fuel from flowing out the end. Physically, such a barrier may be formed at the top of the fuel column by a blanket or insulator pellet which cools the top of the fuel column below the temperature of the adjoining fuel and thus forms a creep-resistant "cork."

A final boundary condition deals with axial restraint of the fuel column. When the top of the fuel column has moved upward relative to the cladding by an amount equal to the input quantity "axial expansion length." further upward movement of the fuel relative to the cladding is prevented by setting the axial displacement rate of the top fuel node (node 31 in Figure 2-6) equal to the axial displacement rate of the top ciadding node (node 32 in Figure 2-6). This simulates the presence of a rigid fuel column restraint. Contact with the axial restraint is indicated in the printout by IAXRE=1.

\subsubsection{Calculation of the New Configuration in Space}

Having determined a converged set of force-displacement rate relations and applied boundary conditions, the final solution of the equations provides a set of forces and displacement rates in the overall fuel pin nodal scheme of Figure 2-6. By essentially reversing the calculational steps, the forces and displacement rates can be found at the boundaries of each individual ring and shear element. These forces are then used to determine the stresses at the centroid of each ring. Displacement rates are multiplied by $\Delta t$ to obtain displacements. Finally, the new configuration in space is calculated.

In determining the new configuration in space, it may be determined that cracks in a particular ring have proceeded past closing up, producing a calculated negative fraction of crack volume within the ring. This occurs because the logic is unaware of the closure of a crack in a ring until the volume in the form of that type of crack has become negative. During the next timestep, the crack will be considered closed and the negative crack volume will be annihilated by adding it to the amount by which the ring thermally expands.

\subsection{FUEL MOVEMENT WITHIN THE INVISCID FUEL ZONE}

Fuel movement within the inviscid zone (see Figure 2-7) is affected by a variety of diffusional and fission product effects as well as by the mechanical effects found in the structural zone. The distribution of fuel mass within the inviscid zone is uniquely determined by the rules listed below:

1. No cracks exist within the inviscid zone.

2. Axial velocity is constant and equal to that of the adjoining structural zone fuel except in the innermost ring where a non-uniform axial velocity, equivalent to axial mass transfer between adjacent fuel sections, is possible under certain conditions. 


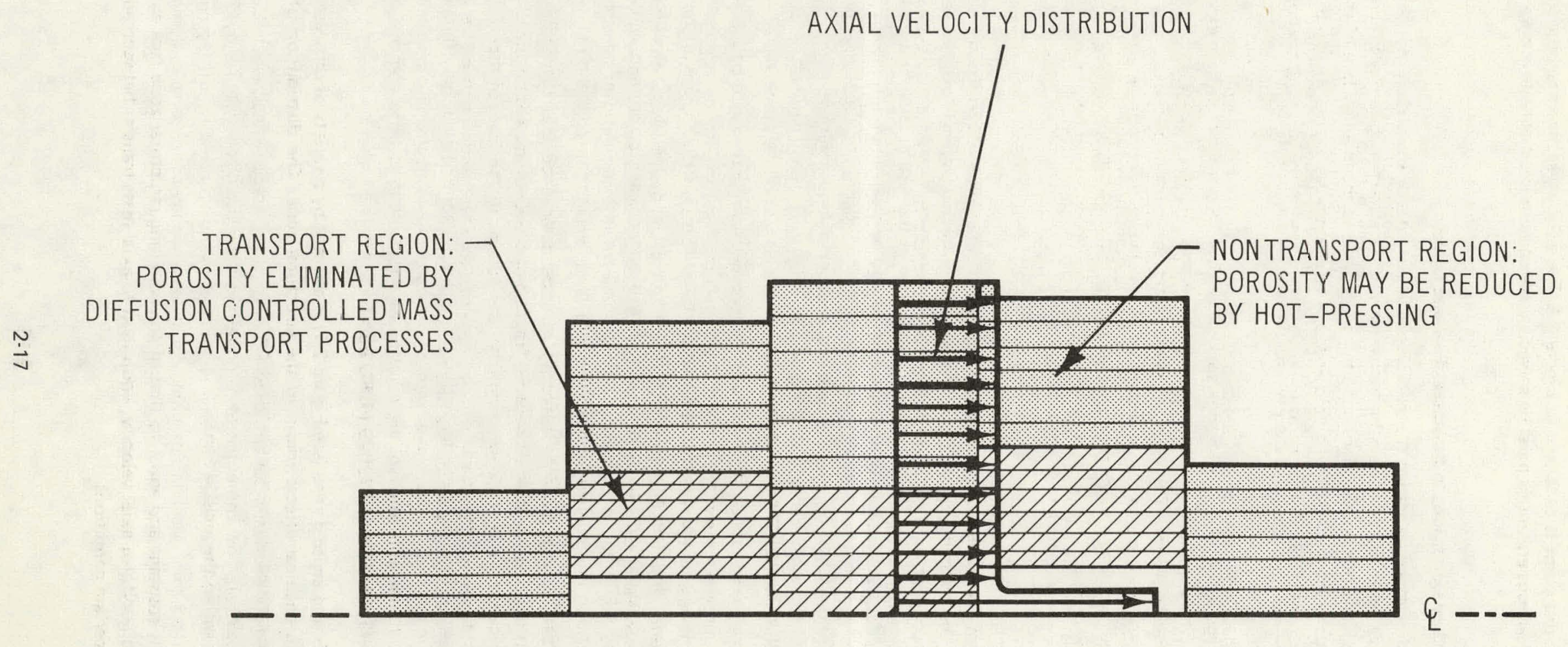

Figure 2-7. Idealization of Inviscid Fuel Zone 
3. Porosity in the inner "transport region" is removed, except for a residual $1 \%$, by pore sweeping.

4. Where center void exists anywhere in the pin during a timestep, hot pressing does not occur in the inviscid region.

5. Whein all center void is exhausted throughout the pin, expansion of fuel matrix material in excess of the space available causes hot pressing of the nontransport region fuel. Proceeding in approximately inverse order of temperature without regard to axial location, the program reduces the porosity in a ring down to a residual $1 \%$ before going on to the next ring. This procedure would be expected to be closely matched physically where a constant hydrostatic pressure prevails throughout the length of the pin.

6. Steps 4 and 5 provide space for the fuel to occupy within the inviscid region as a whole without regard for space available within a given axial section. Excess fuel within a given axial section is transferred from the section's innermost ring to the innermost ring of the nearest section having space available.

As discussed in subsection 2.7.1, the ease of axial fuel movement is somewhat exaggerated by these rules. Further, the rules implicitly assume that axial fuel flow to a section having remaining center void is favored over hot pressing of fuel; this latter assumption is probably accurate for a short section of fuel, but inaccurate for $L / D \gg 1$.

\subsection{REDEFINITION OF THE NODAL GRID}

\subsubsection{Fuel}

The boundaries between axial fuel sections remain embedded in the structural zone fuel throughout a problem. The radial boundaries between the structural and inviscid zones and between the nontransport and transport regions, however, change in radius as the temperatures characteristic of the boundaries and the temperature distribution within the fuel change independently with time. Since a constant number of equal-thickness rings is assumed within each region, the nodal grid changes in space radially (see Figure 2-8) every timestep. The identity of each ring is therefore lost and the properties of the new ring are taken to be the weighted average of the properties of those rings from which it is made.

At low temperatures or during rapid events the transport and nontransport regions are not present; the fuel acts in an almost elastic manner so that property variations across the radius are not large. When, at higher temperatures and lower strain rates, there is a large gradient in viscosity, the other two regions are present and a greater number of rings is brought into play. Property variations across each ring are thus kept low, a significant advantage of this method. $A$ disadvantage lies in the fact that the averaging process.smooths variations in properties and in essence introduces a false diffusion of each property value. The error thus introduced is not expected to be large, however.

\subsubsection{Cladding}

Axial boundaries are embedded permanently within the structural zone fuel but only temporarily, during a single timestep, within the cladding material. When relative motion occurs the fuel and cladding grids are axially offset. Before starting the next timestep, the axial boundaries are adjusted in the cladding so as to coincide with those in the fuel. Radial boundaries are embedded permanently in the cladding.

\subsubsection{Crack Closure}

When the inviscid region boundary sweeps outward with time, cracks which existed in the structural zone (allowed by the program logic) are now computed to be present in the inviscid zone (denied by the program logic). The code now tentatively assumes that the crack volume eliminated by this process is entirely converted into spherical porosity volume in the inviscid zone. Mechanisms which could cause such porosity generation include the formation of large fission gas bubbles on grain boundaries displacing the crack volume and the mismatch of jagged crack surfaces during healing of a crack. This topic is further discussed in subsection 3.2.6. 


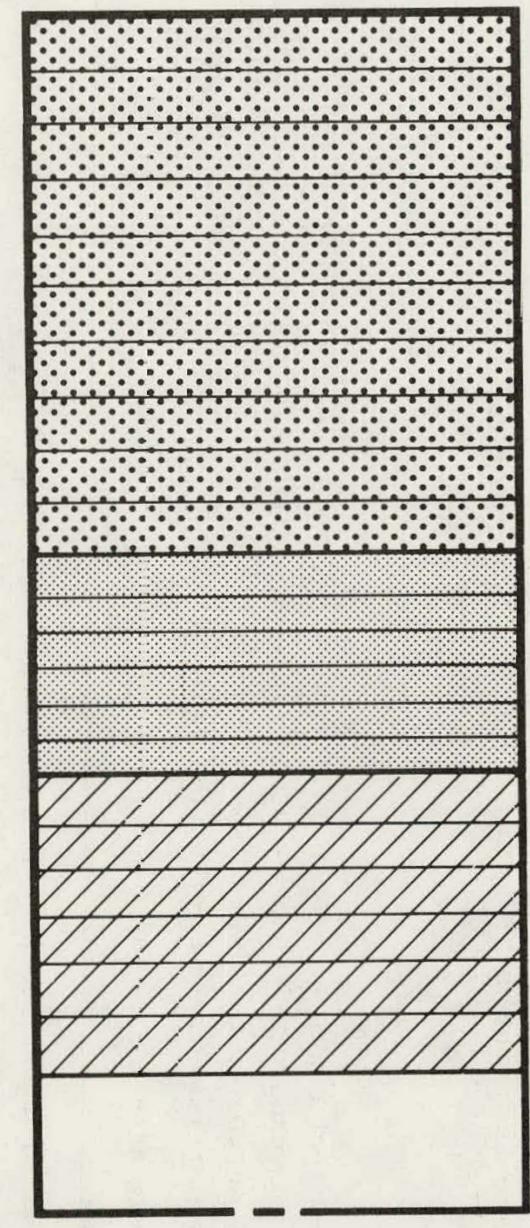

NODAL STRUCTURE OF FUEL SECTION BEFORE REDEFINITION
OUTSIDE OF FUEL

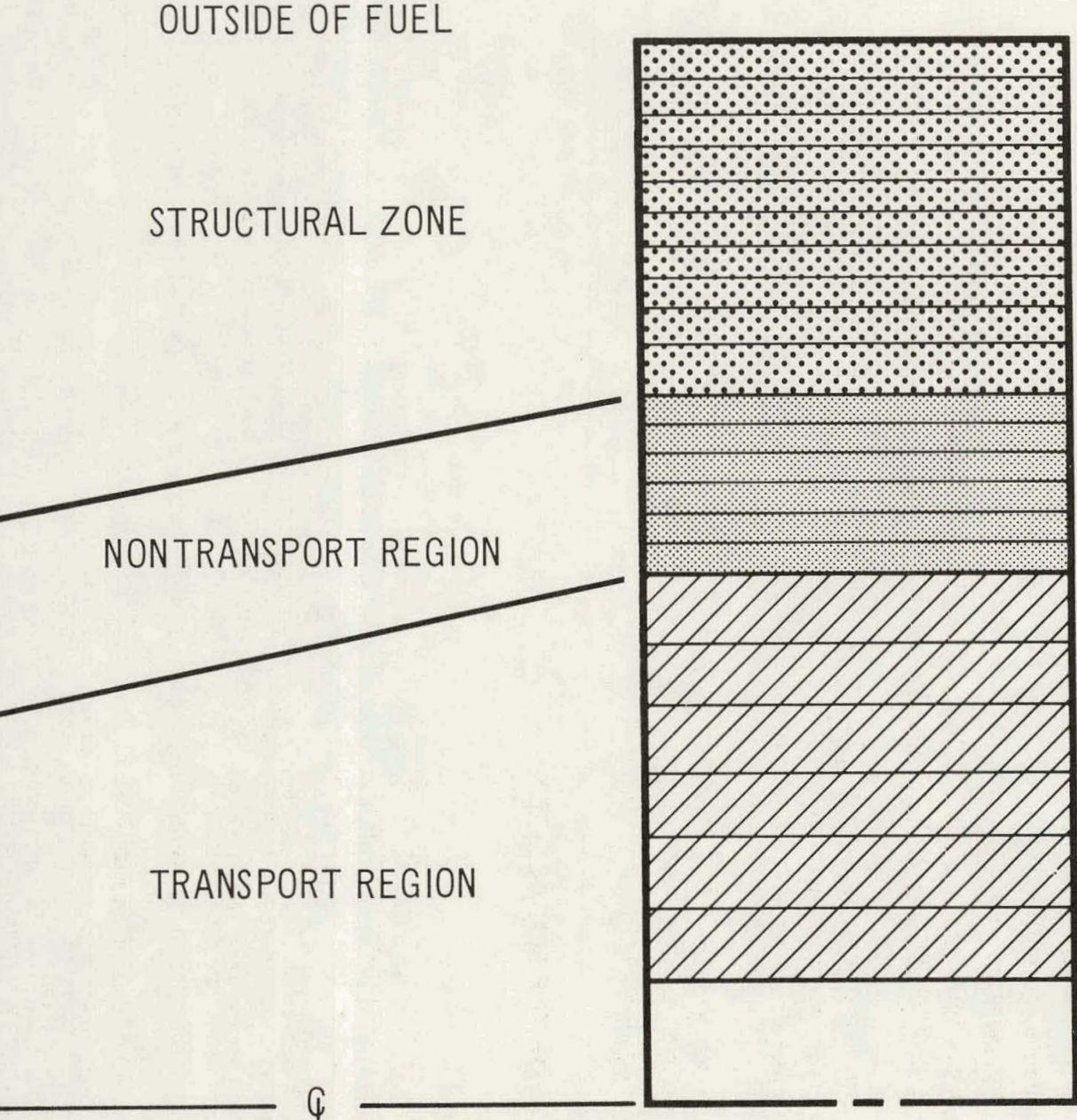

NODAL STRUCTURE OF FUEL SECTION AFTER REDEFINITION 


\subsection{CALCULATION OF THE TEMPERATURE DISTRIBUTION}

User selection of the option 3 temperature calculation results in temperatures being calculated by a onedimensional quasi-steady-state heat transfer subroutine. Radial and transverse cracks are assumed to possess no heat conductance in the subroutine. The temperature-and-density-dependent thermal conductivity expression described in subsection 3.1 .5 is employed in the fuel. The thermal conductivity within a ring is evaluated at the surface temperature of that ring rather than at the more accurate mid-ring temperature. Negligible error is incurred when 30 rings are employed in the calculation.

Since thermal expansion is an important forcing function for the change in structure occurring during a timestep, a temperature distribution must be established before the new structure can be calculated. To meet this requirement the program logic uses the structure at the beginning of the timestep but the linear power at the end of the timestep to calculate the temperature distribution at the end of the timestep. If the structure changes substantially during the timestep, some error will be incurred in the calculated temperatures. Such errors are likely to be negligible, with the exception that center temperatures are often noticeably out of line with the final structure when a center void is formed during a timestep.

Options providing transient heat-transfer capability have been developed for use in simulations of transient overpower or undercooling experiments. However, these options are not included in this version of the code and therefore are not discussed in this report.

\subsection{DISCUSSION OF MODEL MECHANICS}

\subsubsection{Axial Fuel Flow}

BEHAVE-2's treatment of axial fuel flow assumes that plane strain (a uniform axial velocity profile) is maintained within the structural fuel zone and all relative axial fuel flow occurs within the inviscid zone. No relative axial fuel flow can take place under low center temperature-high strain rate conditions because no inviscid zone exists. In the following analysis, it is shown that the axial velocity profile under an axial pressure gradient is uniform except at the center, as assumed. Moreover, under low center temperatures where the code disallows relative axial fuel movement, little such movement is in fact possible. However, the code's assumption of negligible axial pressure gradient under axial flow conditions is violated under some conditions, the assumption becoming less valid as the length to diameter ratio of the fuel increases.

The assumption of constant hydrostatic pressure and negligible shear stresses inside a certain radius is well justified at any given axial position. Furthermore, if the fuel center contains molten fuel or molten fission products, the same hydrostatic pressure will clearly be maintained throughout the length of the pin. However, when the fuel center contains solid rather than molten fuel, the resistance to axial flow over long distances may be large and the model's assumption of axially invariant hydrostatic pressure in the inviscid zone may be violated; this latter case is considered below.

A feel for the physical problem may be obtained by considering the length through which a moderate pressure difference ( $400 \mathrm{psi}$ ) will extrude a uniformly dilating fuel out the end of a rigid open-ended cylinder as shown in Figure 2-9. The hypothetical problem approximates the case in which a temperature or stress peak causes yielding to occur primarily in a localized axial zone. If no available voidage exists within the fuel, inexorable growth of the fuel material through thermal expansion or fission product swelling is relieved by flow toward the region of localized yielding. The open end of the rigid tube in the hypothetical problem approximates the region of localized yielding in the physical problem.

Assume that pressure is a function of axial position only. Then a force ba!ance on a cylinder of fuel of radius $r$ gives for the shear stress on the outside

$$
\tau=-\frac{d P}{d z} \frac{r}{2}
$$

where $\frac{d P}{d z}$ is the axial pressure gradient. 
AXIAL FLOW OF DILATING FUEL UNDER. THERMAL CREEP

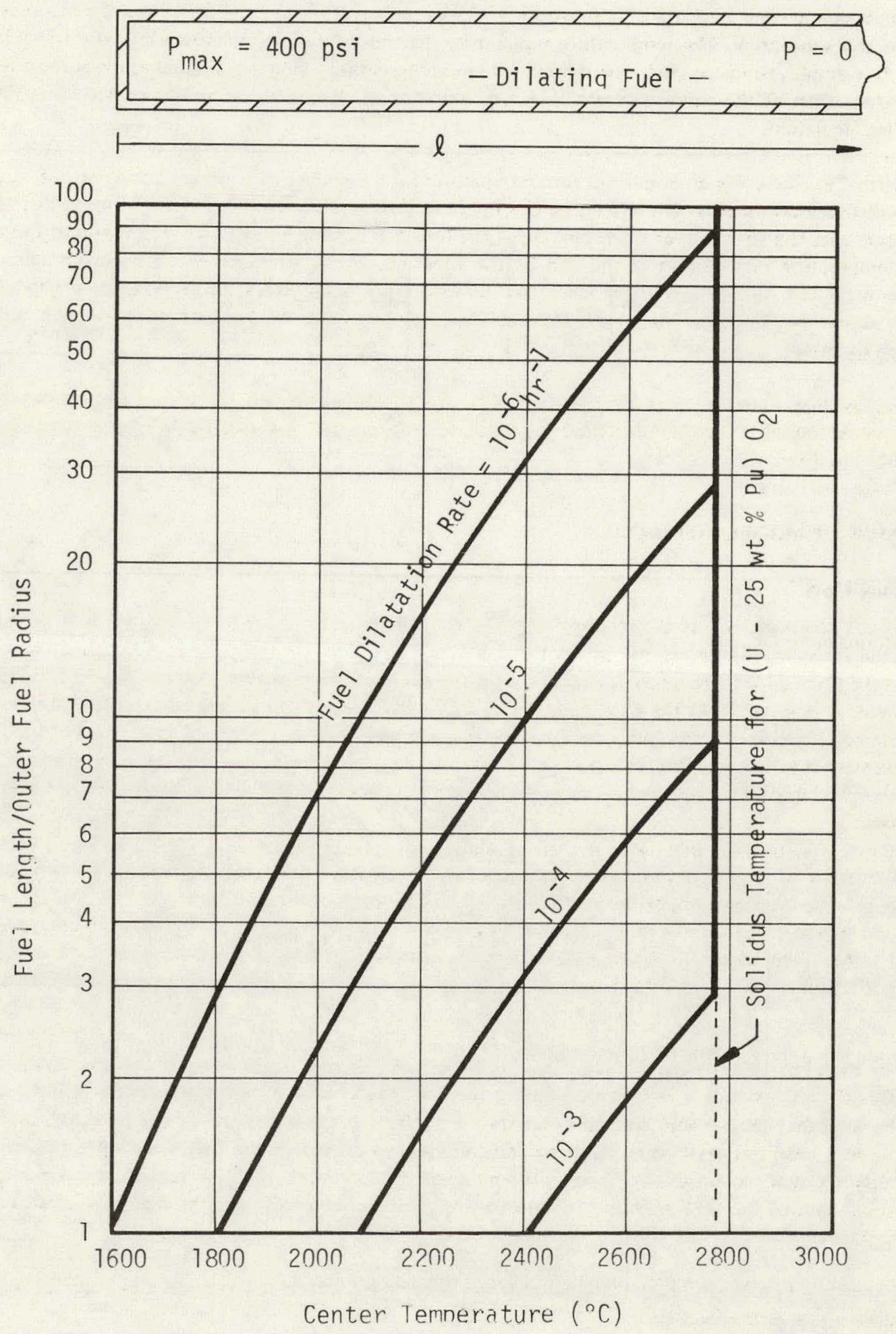

Figure 2-9. Length Through Which $\mathrm{UO}_{2}$ Will Flow in an Axial Direction Under a 400 psi Pressure Difference, Assuming a Uniform Volumetric Dilatation Rate of the Fuel as Shown 


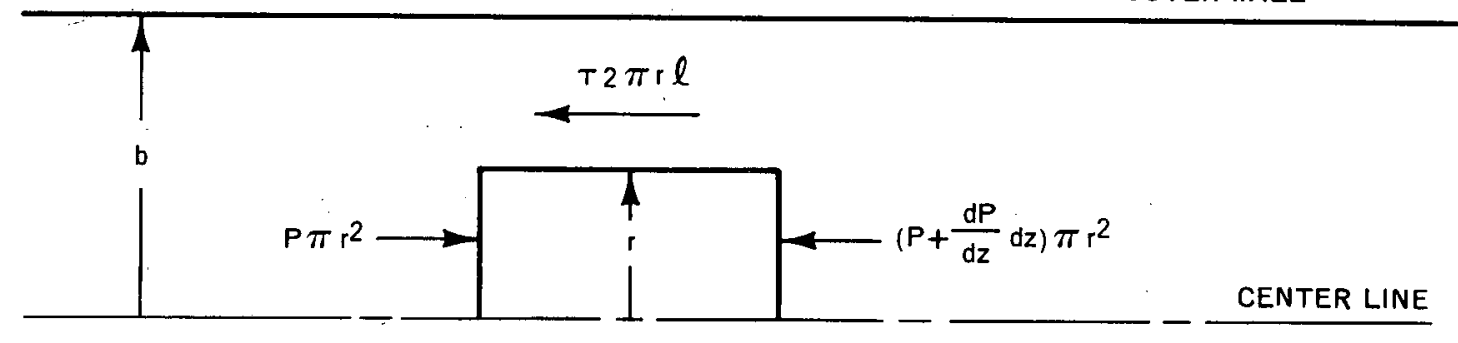

For a viscous material,

$$
\tau=-\mu \frac{\mathrm{du}}{\mathrm{dr}}
$$

where $u(r)$ is the axial velocity.

The viscosity may be described by an Arrhenius relation:

$$
\mu=\mu_{0} e^{Q / R T}
$$

where $\mu_{0}$ is a constant.

Combining Equations (2-28), (2-29), and (2-30).

$$
u(r)=\frac{1}{2 \mu_{0}} \frac{d P}{d z} \int_{r}^{b} r e^{-Q / R T} d r
$$

The temperature distribution may be taken as approximately parabolic:

$$
\frac{T-T_{s}}{T_{c}-T_{s}}=1-\frac{r^{2}}{b^{2}}
$$

where $T_{S}$ is the fuel surface temperature and $T_{C}$ is the fuel center temperature. 
Combining Equations (2-31) and (2-32):

$$
u(r)=\frac{1}{4 \mu_{0}} \frac{d P}{d z} \frac{b^{2}}{T_{c}-T_{S}} \int_{T}^{T_{S}} e^{-Q / R T} d T .
$$

Equation (2-33) may be integrated by an approximate method assuming a local temperature well above the fuel surface temperature, yielding

$$
u(r)=\frac{1}{4 \mu_{0}} \frac{d P}{d z} \frac{b^{2}}{T_{c}-T_{s}} \frac{R T_{c}^{2}}{Q} e^{-Q / R T}
$$

Equation (2-34) indicates that the axial velocity varies exponentially with the local temperature. This extreme temperature dependence causes an axial velocity distribution that is highly peaked at the center of the fuel.

The mean axial velocity is given by:

$$
\bar{u}=\frac{1}{\pi b^{2}} u(r) 2 \pi r d r
$$

Inserting (2-34) and performing an approximate integration, assuming a center temperature well above the surface temperature gives

$$
\bar{u}=-\frac{1}{4 \mu_{0}} \frac{d P}{d z} \frac{b^{2}}{\left(T_{c}-T_{s}\right)}\left(\frac{R T_{c}^{2}}{Q}\right)^{2} e^{-Q / R T_{c}}
$$

Now, assuming the fuel is dilating at a volumetric rate $\dot{\theta}$ which can be accommodated only by axial flow, the variation in mean axial velocity with distance from the closed end of the surrounding cylinder is given by:

$$
\bar{u}=\dot{\theta}_{z} .
$$

Equating (2-35) and (2-36) and integrating between limits:

$$
-\frac{1}{4 \mu_{0}} \frac{b^{2}}{\left(T_{c}-T_{s}\right)^{2}}\left(\frac{R T_{c}^{2}}{Q}\right)^{2} e^{-Q / R T_{c}} \int_{\Delta P \max }^{0} d P=\dot{\theta} \int_{0}^{\ell} z d z
$$

or,

$$
\Delta \mathrm{P} \max =2 \mu_{0} \dot{\theta}\left(\frac{\ell}{b}\right)^{2}\left(1-\frac{T_{s}}{T_{c}}\right)^{2}\left(\frac{Q}{R T_{c}}\right)^{2} e^{Q / R T_{c}}
$$

Equation (2-37) is plotted in Figure 2-9, with values for the constants $\mu_{0}$ and $Q$ derived from the work of Bohaboy. ${ }^{14}$

Figure 2-9 indicates that at low fuel dilatation rates and high center temperatures fuel can transfer over considerable distances. In this case, the code's assumption is justified. In the opposite situation of low center temperatures and high fuel expansion rates the fuel has little ability to flow axially. The code correctly models this lack of axial mobility by causing the inviscid zone to vanish and no axial fuel flow can occur. However, in an intermediate region of moderate center temperatures and expansion rates the inviscid region will exist and axial fuel flow may be overpredicted. 
However, only in the case of a fully densified inviscid zone acting as a displacement boundary condition on the structural fuel is serious error likely. In this latter condition, fuel transferred into a local area directly affects local strain. Therefore, where a MODE $=2$ (fully densified inviscid region) condition is indicated in the printout during a moderate rate of power increase, the output should be analyzed to test the validity of the constant pressure assumption.

\subsubsection{Convergence}

The program converges, by iteration, the three nonlinear properties-creep modulus, crack pattern, and shear element viscosity. Rather than iterate all these quantities until several convergence criteria are fulfilled, a number of iterations (4 to 6 ) is employed which experience has shown to provide adequate accuracy. The scheme used to determine the nonlinear creep modulus provides rapid convergence in primarily strain-rate controlled processes in which loading is due to differential dilatation of the materials. Slower convergence is to be expected in primarily stress controlled processes such as high plenum pressure loading. Proper convergence of the cladding creep modulus may be inferred from the reasonableness of the effective stress at which yielding occurs. While problems with convergence of the cladding creep modulus have not been met in past runs of the code, if encountered they may be dealt with by increasing the number of timesteps in the time spans involved.

Accuracy of calculation of some other quantities is controlled by the length of timesteps input by the user. Particularly noteworthy is the problem of negative crack volumes. As noted in subsection 2.3.5, the program does not sense crack closure until crack volume has become negative. During the next timestep, the negative crack volume is annihilated by thermally expanding the ring by the amount of the negative volume. If timesteps are too large, this false thermal expansion can cause anamolous strain of the cladding. Significant errors are particularly likely when a long timestep during steady-state operation is followed by a rapid power change. A large negative crack volume can result from the long timestep during steady-state operation which then causes false thermal expansion of the fuel during the next timestep at the high strain rates characteristic of a rapid power change. Under high strain rates, the fuel is stronger than the cladding and anamolous plastic strain can result. The problem may be alleviated by increasing the number of timesteps, thereby directly reducing the magnitude of the false thermal expansion. As a general guideline it is recommended that timestep lengths be held to under one month and power increases per timestep to less than $2 \mathrm{~kW} / \mathrm{ft}$.

\subsubsection{Effects Not Considered}

The effects of gravity on fuel motion are not considered by the program. A result may be the post-shutdown presence of finite width transverse cracks passing all the way through the fuel column. Such cracks would in reality close up at the point of minimum axial separation. In practice, the width of the separation has been found to be small and the error of minor magnitude. Also, the downward flow of molten fuel in a gravitational field is not simulated by the code.

Other effects of potential importance not included in the present version of the code include axial fuel vapor transport in the axial direction, plutonium redistribution, and migration of solid and liquid fission products.

\subsection{FLOW DIAGRAM}

A flow diagram presenting broad aspects of the program is given in Figure 2-10. 


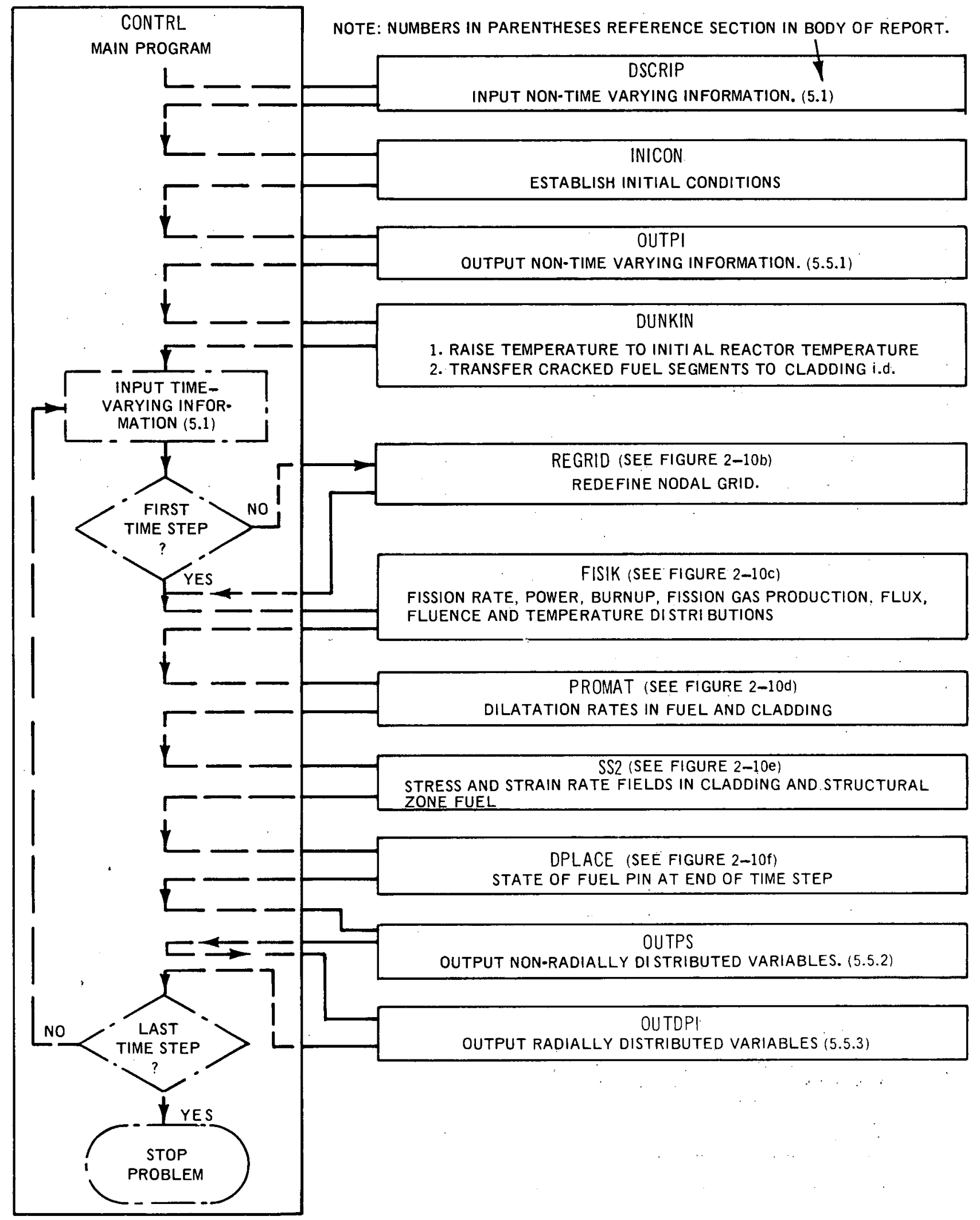

Figure 2-10a. Flow Diagram of BEHAVE-2 Control Program and Major Subroutines 


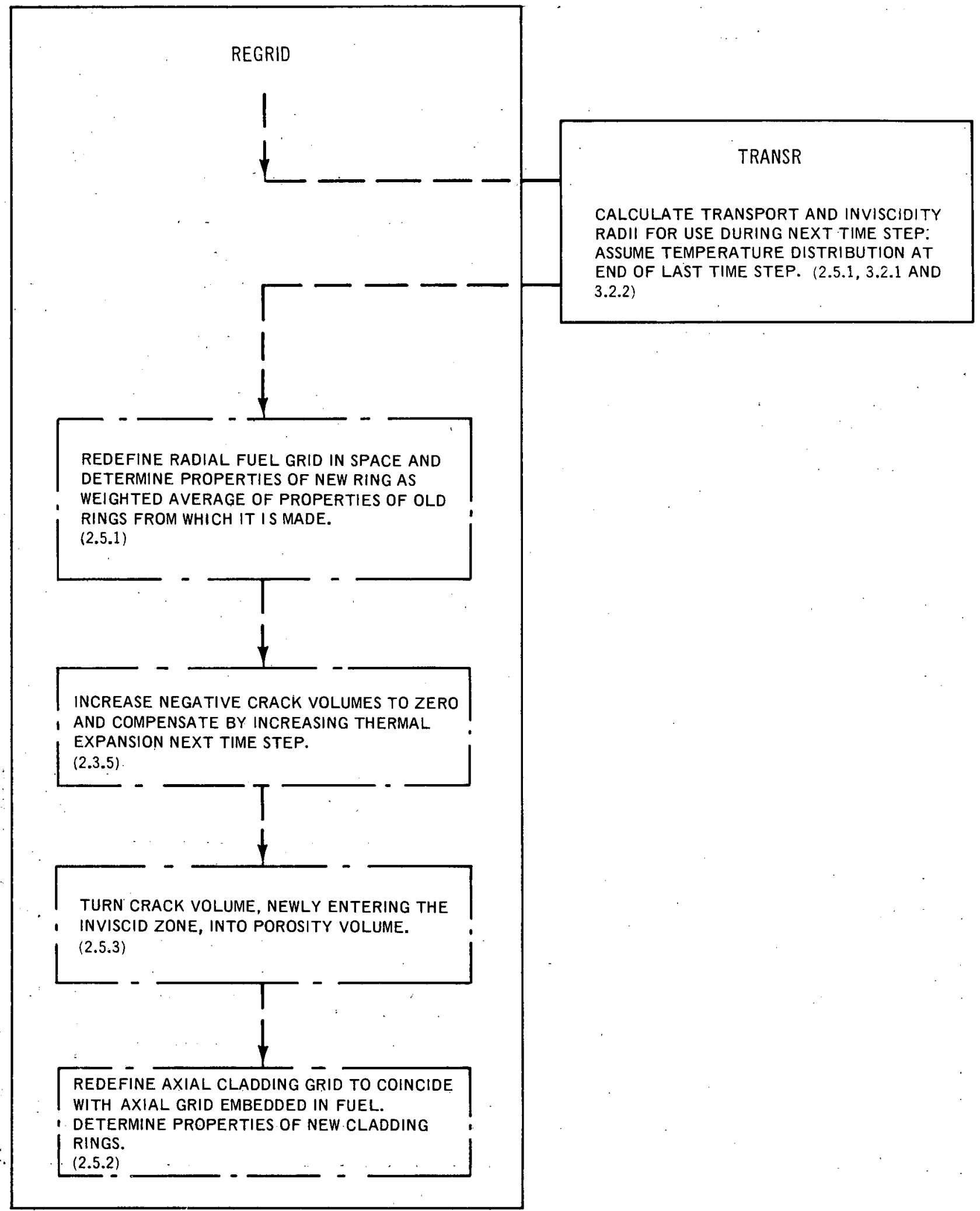

Figure 2-10b: Subroutine REGRID and Associated Subroutine 


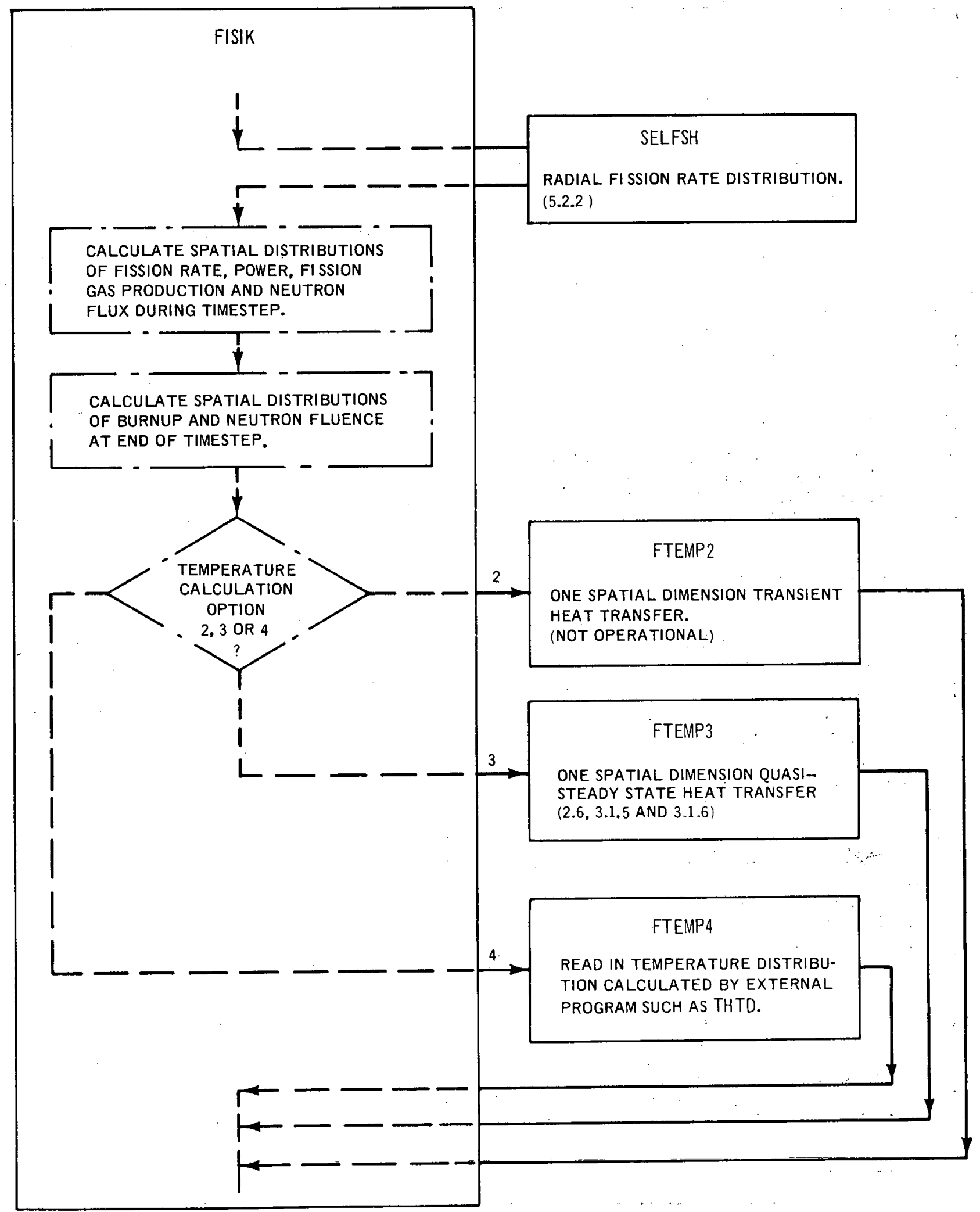

Figure 2-10c. Subroutine FISIK and Associated Subroutines 


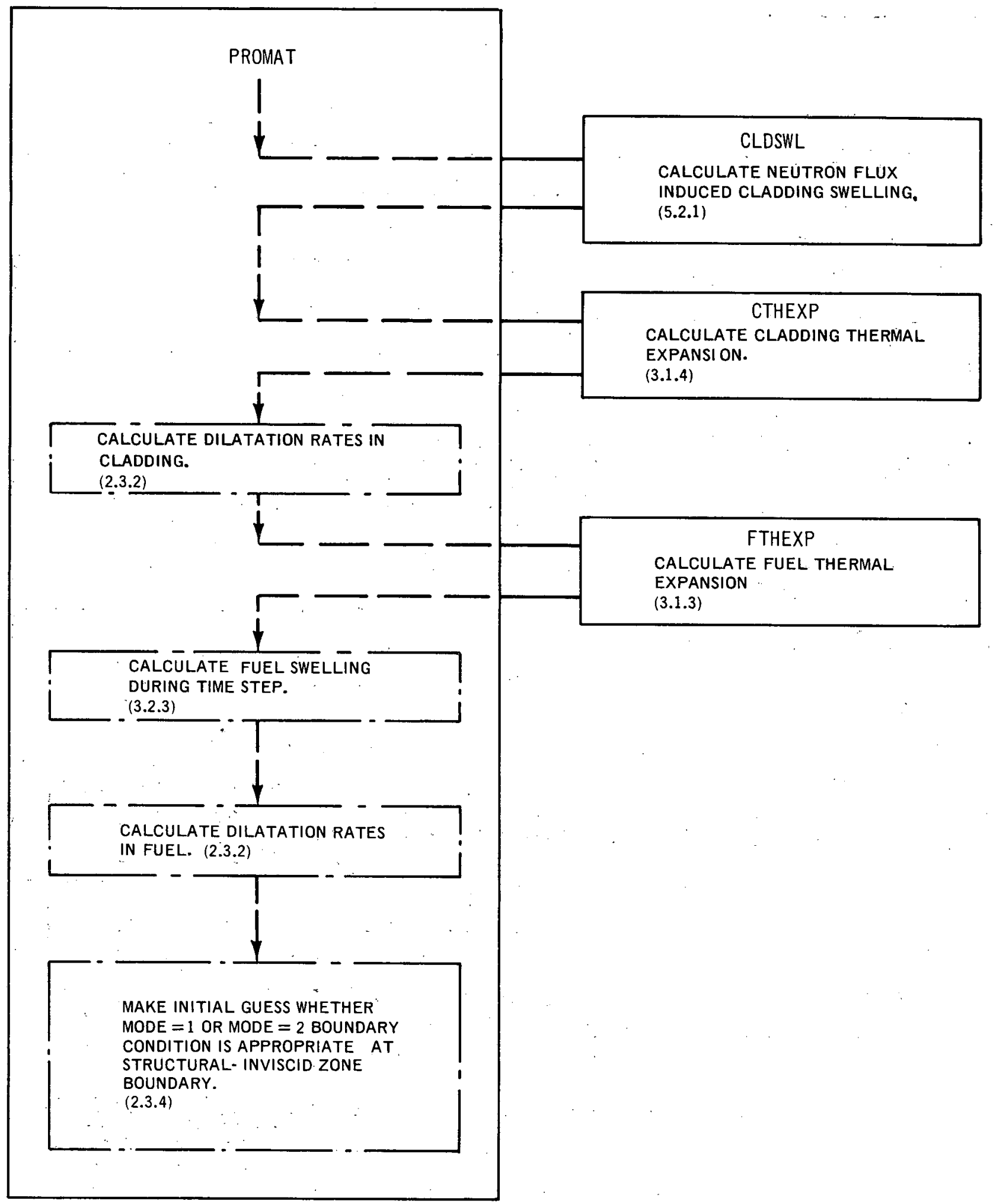

Figure 2-10d. Subroutine P.ROMAT and Associated Subroutines 


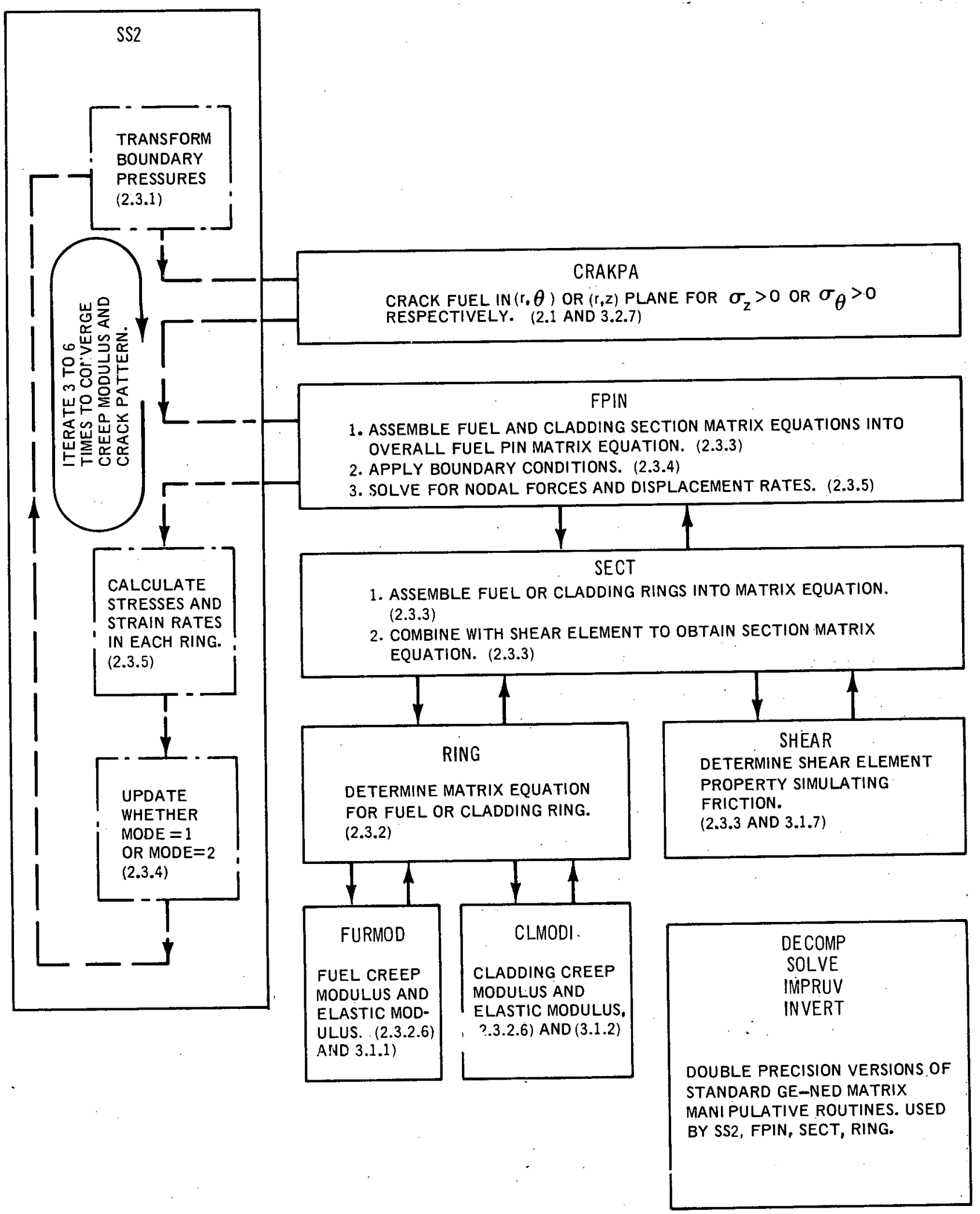

Figure 2-10e. Subroutine SS2 and Associated Subroutines 


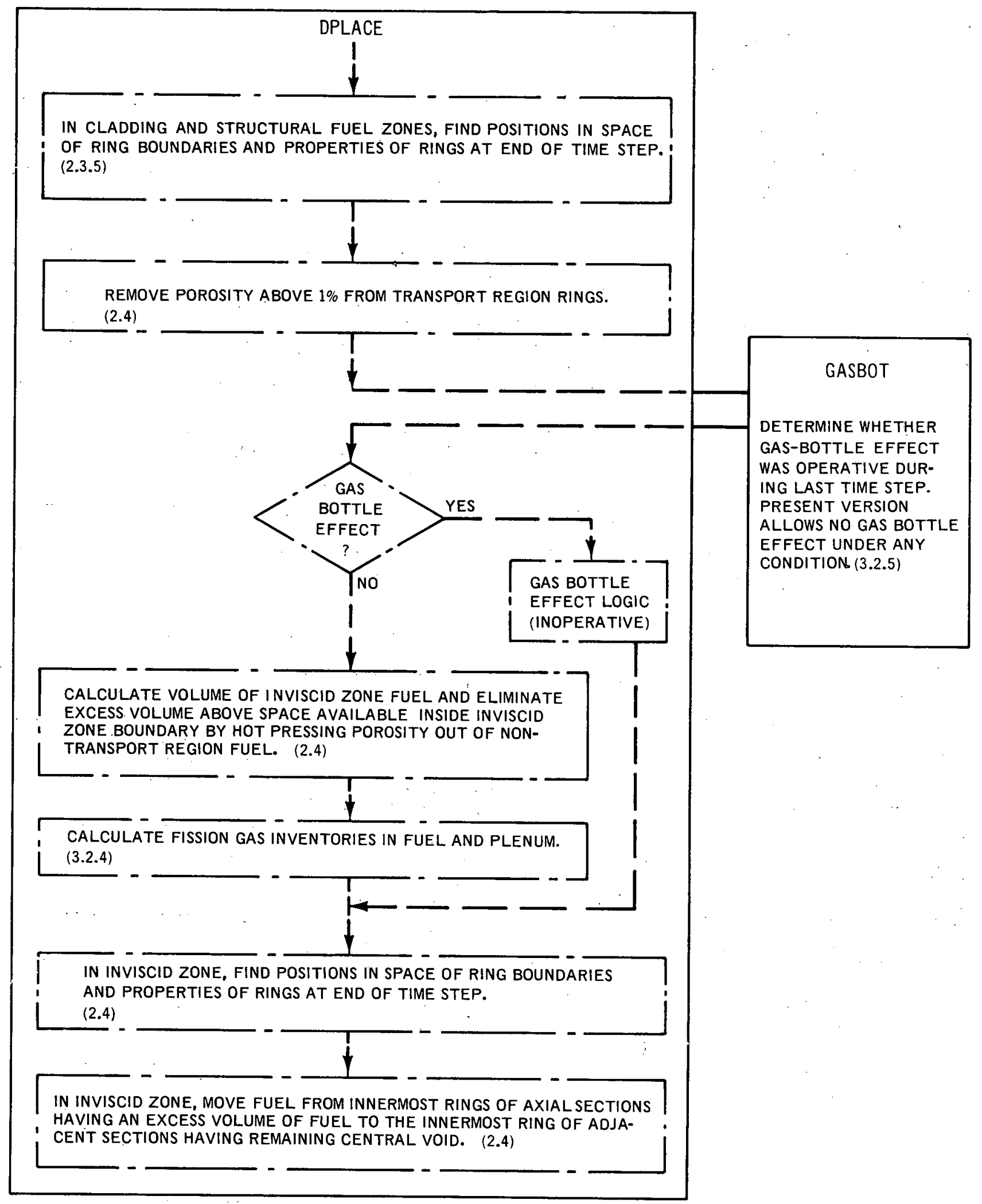

Figure 2-10f. Subroutine DPLACE and Associated Subroutine 


\section{MATERIAL PROPERTIES}

For purposes of discussion, the material properties used in the code are broken down into two categories. The term "primary properties" refers to quantities which have been directly measured. "Secondary properties" are simplified representations of nature. These latter "properties" describe, in general, incompletely understood phenomena; they are, therefore, tentative and subject to verification through comparisons of model predictions with data.

Material properties are in general the easiest parts of a program to change. It is to be anticipated that the properties described below will be superseded as better primary property data become available and as more insight into secondary properties is achieved.

\subsection{PRIMARY PROPERTIES}

\subsubsection{Fuel Constitutive Equation}

The fuel is assumed to be deformable in both elastic and steady-state creep modes

$$
\begin{aligned}
& \dot{\epsilon}^{*}=\dot{\epsilon}^{*} \text { elastic }+\dot{\epsilon}_{\text {thermal }}^{*}+\dot{\epsilon}_{\text {creep }}^{*} \text { fission }: \\
& \dot{\epsilon}^{*} \text { elastic }=\frac{1}{\Delta t}\left(\frac{\sigma^{*}}{E}-\frac{\sigma^{* \prime}}{E}\right) \\
& \begin{array}{l}
\dot{\epsilon}_{\text {thermal }}^{*} \\
\text { creep }
\end{array}=A \sigma^{*} \exp (-90,000 / R T)+B \sigma^{*}{ }^{4.5} \exp (-132,000 / R T)
\end{aligned}
$$

where

$$
\begin{aligned}
\dot{\epsilon}^{*} & =\text { effective strain rate }\left(\mathrm{sec}^{-1}\right), \\
\sigma^{*} & =\text { effective stress at the end of a timestep (psi), } \\
\sigma^{*^{\prime}} & =\text { effective stress at the end of the previous timestep, } \\
E & =\text { Young's modulus }=27,500,000 \mathrm{psi}, \\
\Delta t & =\text { length of timestep }(\mathrm{sec}), \\
A & =\frac{2.702 \times 10^{3}}{(\mathrm{D}-87.8) \mathrm{G}^{2}}, \\
\mathrm{~B} & =\frac{3.822 \times 10^{-7}}{\mathrm{D}-90.5}, \\
\mathrm{R} & =1.986 \mathrm{cal} / \mathrm{mole}^{\circ} \mathrm{K}, \\
\mathrm{T} & =\text { temperature }\left({ }^{\circ} \mathrm{K}\right), \\
D & =\text { theoretical density }(\%), \text { and } \\
\mathrm{G} & \text { grain size (microns). }
\end{aligned}
$$


Equation (3-3) is from the creep studies of Bohaboy, et al., ${ }^{14}$ on stoichiometric $\mathrm{UO}_{2}$. A constant fuel density of $96 \%$ is used in determining the constants $A$ and $B$ due to the fact that the constants behave unrealistically in the vicinities of $90.5 \%$ and $87.8 \%$ density. A constant grain size of 30 microns is employed regardless of the fabricated grain size since grain growth in the hotter regions renders the fabricated grain size in these regions meaningless. A more accurate method would be to include the kinetics of grain growth in the code and use actual grain sizes.

$$
\dot{\epsilon}_{\substack{\text { fission } \\ \text { creep }}}=\dot{C} \dot{f} \sigma^{*}
$$

where

$$
\begin{aligned}
& \dot{f}=\text { fission rate (fissions } / \mathrm{cc}-\mathrm{sec} \text { ) and } \\
& \mathrm{C}=1.45 \times 10^{-26} \mathrm{~cm}^{3} / \text { fission-psi. }
\end{aligned}
$$

Fission-induced creep rate is frequently assumed to follow the law posed in Equation (3-4). However, experiments to date have shown several decades variation in the constant $A$, perhaps indicating a more complex phenomenon. An early value of $6.9 \times 10^{-26}$ for $\mathrm{C}$ was inferred ${ }^{15}$ from the in-pile porosity collapse rate in $\mathrm{UO}_{2}$ plate-type fuel under a high hydrostatic pressure. The value of $1.45 \times 10^{-26}$ is based on the following simple theory. Assume a cylindrical specimen of cross-sectional area $A$ and length $\ell$ creeping under an axial compressive stress at a strain rate $\dot{\epsilon}$. The work done on the specimen by the external load per unit time is

$$
\dot{\mathrm{W}}_{\mathrm{e}}=\dot{\epsilon} \ell \sigma \mathrm{A} .
$$

The mean strain energy is given by $\left(\sigma^{2} / 2 E\right)$ where $E$ is Young's modulus. According to Lustman, ${ }^{16}$ approximately $60,500 \mathrm{UO}_{2}$ atoms are displaced per fission. This represents an affected volume, $v$, of about $0.81 \times 10^{-18} \mathrm{cc} / \mathrm{fission}$. Assume that all the elastic strain energy in this volume is destroyed by the atom displacements. Then, the mean rate of elastic energy dissipation is given by

$$
\dot{W}_{d}=A l \dot{f} v \frac{\sigma^{2}}{2 E}
$$

Equating the rate of energy dissipation within the system to the rate of work done on the system,

$$
\dot{\epsilon}=\frac{\mathrm{v}}{2 \mathrm{E}} \dot{\mathrm{f}} \sigma .
$$

The constant $C$ is given by $v / 2 E$. Applying $E=27.5 \times 10^{6}$, the value $C=1.45 \times 10^{-26}$ is obtained. This value is in excellent agreement with recent data ${ }^{17}$ from an in-pile compressive creep experiment at 350 to $600^{\circ} \mathrm{C}$ from which a value for $\mathrm{C}$ of $1.4 \times 10^{-26}$ may be derived. The same experiment verified the assumption of linear stress dependence of . strain rate.

The elastic modulus of $27,500,000$ psi is from temperature-dependent data reported for $\mathrm{UO}_{2},{ }^{18}$ evaluated at a temperature of $1000^{\circ} \mathrm{C}$. That value is assumed in the code to apply at all temperatures.

Evidence suggests that in addition to the three deformation mechanisms of Equation (3-1), an additional mechanism of interparticle slippage is present vibrocompacted powder fuel. The evidence is derived from the lack of cladding strain on first-startup of powder fuel pins. Were only the three mechanisms of Equation (3-1) operative, plastic cladding strain would be predicted becuase of differential thermal expansion, due to the minimal fuel-cladding gap in powder pins. Data are apparently unavailable on deformation of $\mathrm{UO}_{2}$ or mixed oxides by this mechanism. It is suggested that in order to use BEHAVE-2 for simulations of powder pins a pseudo-initial fuel-cladding diametral gap amounting to $1 \%$ of the fuel diameter be provided to preclude erroneous calculation of plastic strain during the first startup. After long periods of operation, sintering may produce a material better represented by Equation (3-1). 


\subsubsection{Cladding Constitutive Equation}

The cladding is assumed to be deformable in elastic, short-term plastic, thermal creep, and irradiation creep modes.

$$
\dot{\epsilon}^{*}=\dot{\epsilon}_{\text {elastic }}^{*}+\dot{\epsilon}^{*} \text { short-term }+\dot{\epsilon}^{*} \text { thermal }+\dot{\epsilon}^{*} \text { irradiation }
$$

where

$$
\dot{\epsilon}_{\text {elastic }}^{*}=\frac{1}{\Delta t}\left(\frac{\sigma^{*}}{E}-\frac{\sigma^{* \prime}}{E}\right) .
$$

For $\phi \mathrm{t}<(\phi \mathrm{t})_{\text {sat }}$ :

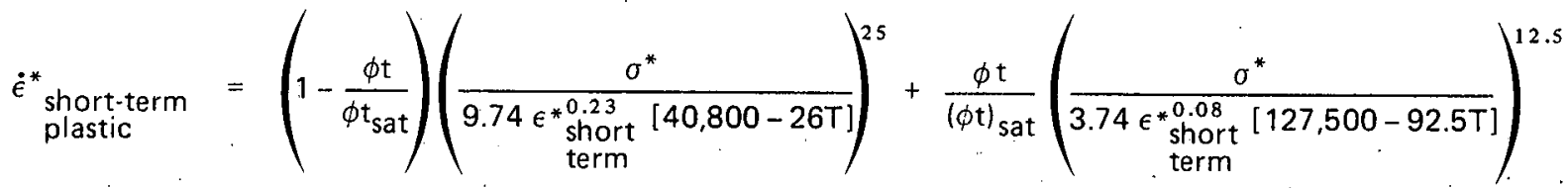

For $\phi \mathrm{t} \geqslant(\phi \mathrm{t})_{\text {sat }}$ :

$$
\begin{aligned}
\dot{\epsilon}^{*} \begin{array}{c}
\text { short-term } \\
\text { plastic }
\end{array} & =\left(\frac{\sigma^{*}}{3.74 \epsilon^{* 0.08} \begin{array}{c}
\text { short } \\
\text { term }
\end{array}}\right)^{12.5} \\
\dot{\epsilon}_{\text {thermal }}^{*} & \left.=\frac{\left(1.79 \times 10^{-5} \sigma^{*}\right)^{8.23} \exp (62.48-5800-92.5 \mathrm{~T}]}{3600}\right)^{1.57)} \\
\dot{\epsilon}_{\text {irradiation }}^{*} & =1.87 \times 10^{-30} \phi \exp (1.405-0.0027 \mathrm{~T}) \sigma^{*}
\end{aligned}
$$

where

$$
\begin{aligned}
& \dot{\epsilon}^{*}=\text { effective strain rate }\left(\sec ^{-1}\right) \text {, } \\
& \phi=\text { fast flux }\left(\mathrm{n} / \mathrm{cm}^{2}-\sec [E>0.1 \mathrm{MeV}]\right), \\
& \phi t=\text { fast fluence }\left(\mathrm{n} / \mathrm{cm}^{2}[E>0.1 \mathrm{MeV}]\right) \\
& (\phi \mathrm{t})_{\text {sat }}=\text { saturation fast fluence }=3 \times 10^{22} \mathrm{n} / \mathrm{cm}^{2}(\mathrm{E}>0.1 \mathrm{MeV}) \\
& \mathrm{T}=\text { temperature }\left({ }^{\circ} \mathrm{K}\right) \text {, } \\
& \sigma^{* \prime}=\text { effective stress, last timestep (psi), } \\
& \sigma^{*}=\text { effective stress, this timestep (psi), } \\
& \Delta \mathrm{t}=\text { length of timestep (sec), } \\
& E=\text { Young's modulus }=23 \times 10^{6} \mathrm{psi} \text {, and } \\
& \epsilon_{\substack{\text { short } \\
\text { term }}}^{*}=\text { accumulated effective short term plastic strain }=\int_{0}^{t} \dot{\epsilon}_{\substack{\text { short-term } \\
\text { plastic }}}^{*} \mathrm{dt} .
\end{aligned}
$$


The thermal creep portion is a minor modification* of an equation derived ${ }^{19}$ from data for unirradiated, annealed Type-316 stainless steel. The irradiation creep portion is based on the equation reported in Reference 20 and assumes that irradiation creep rate is proportional to fast fluence ( $\mathrm{E}>0.1 \mathrm{MeV}$ ).

BEHAVE-2 conducts stress analysis in a stress-strain rate domain and all strains must occur at a finite strain rate. Therefore, the usual assumption in elastic-plastic analysis of instantaneous deformations is not applicable. To derive Equations (3-9a) and (3-9b), tensile test data reported by Lauritzen, et al., ${ }^{21}$ for irradiated and unirradiated, annealed Type-316 stainless steel were fit to an equation of the form

$$
\sigma=A \epsilon^{m} \dot{\epsilon}^{n}\left(k_{1}-k_{2} T\right) \text {. }
$$

Equation (3-12) was then solved for $\dot{\epsilon}$. Constants were determined for both unirradiated material and for material irradiated to a fluence of $3 \times 10^{22} \mathrm{n} / \mathrm{cm}^{2}(E>0.1 \mathrm{MeV})$. Equations containing the two sets of constants were linked in the manner shown in Equation (3-9) to account for the hardening effects of fluence on strain rate.

Flgure 3-1 indicates the effect of fluence and strain rate on stress calculated by Equation (3-9). The abrupt change in properties near. the assumed "saturation fluence" of $3 \times 10^{22} \mathrm{n} / \mathrm{cm}^{2}$ ( $\mathrm{E}>0.1$ MeV) is undoubtedly unrealistic. Analysis of new data should help to better define the shape. Of interest is the much greater strain rate sensitivity of the yield stress at high fluence compared to the unirradiated state. Equation (3-9) is based on a cursory examination of the data and is intended as an example of the type of cladding representation needed in the code rather than as suggested design equations. Its use at present is warranted only because no similar equation representing plastic flow is available.

Figure 3-2 shows the thermal creep and short-term plastic flow portions of Equation (3-8) plotted at an instant in time in which the plastic strain is $0.1 \%$. Since the material is strain hardening, the curves in the short-term plastic flow dominated region will move upward to increasing stresses as plastic strain is accumulated.

Strain accumulated in the short-term plastic flow category is assumed to contribute to a permanent strain hardening effect regardless of the intervening temperature and irradiation history. A more realistic representation would allow strain hardening effects to decay as a function of time, temperature, and fluence. Strain accumulated in either of the creep categories is assumed to not contribute to strain hardening.

The elastic modulus of $23 \times 10^{6} \mathrm{psi}$ is taken from reference 22 for Type-316 stainless steel at $540^{\circ} \mathrm{C}$.

\subsubsection{Fuel Thermal Expansion}

An equation proposed by $\mathrm{Rubin}^{23}$ for $(\mathrm{U}-25$ wt \% $\mathrm{Pu}) \mathrm{O}_{2}$ represents fuel thermal expansion.

$$
\frac{\Delta \ell}{\ell_{0}}(\%)=4.41 \times 10^{-4}+6.765 \times 10^{-6} \mathrm{~T}+2.965 \times 10^{-9} \mathrm{~T}^{2}
$$

where

$$
\begin{aligned}
\frac{\Delta \ell}{\ell_{0}} & =\text { linear thermal expansion, } \\
\ell_{0} & =\text { length at } 0^{\circ} \mathrm{C} \text {, and } \\
T & =\text { temperature }\left({ }^{\circ} \mathrm{C}\right) .
\end{aligned}
$$

The phase change volume upen melting is assumed to be $9.6 \%$ after work by Christensen ${ }^{24}$ on $\mathrm{UO}_{2}$.

*The modification sets $\sinh \left(1.79 \times 10^{-5} \sigma\right)=1.79 \times 10^{-5} \sigma$, a good approximation for $\sigma<10^{5}$ psi. 


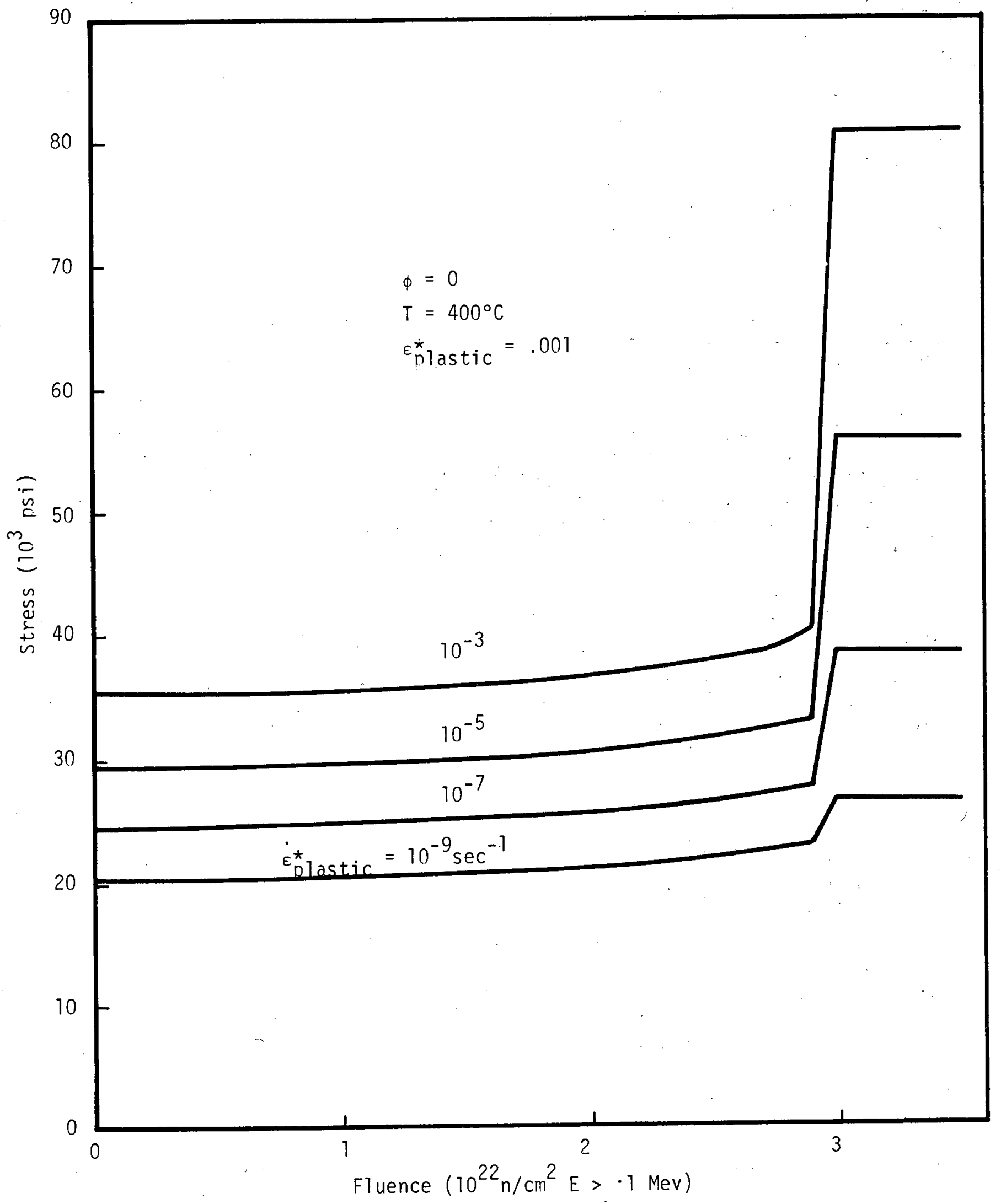

Figure 3-1. Stress-Plastic Strain Rate-Fluence Relation for Stainless Steel Employed in BEHAVE-2 
GEAP-13788

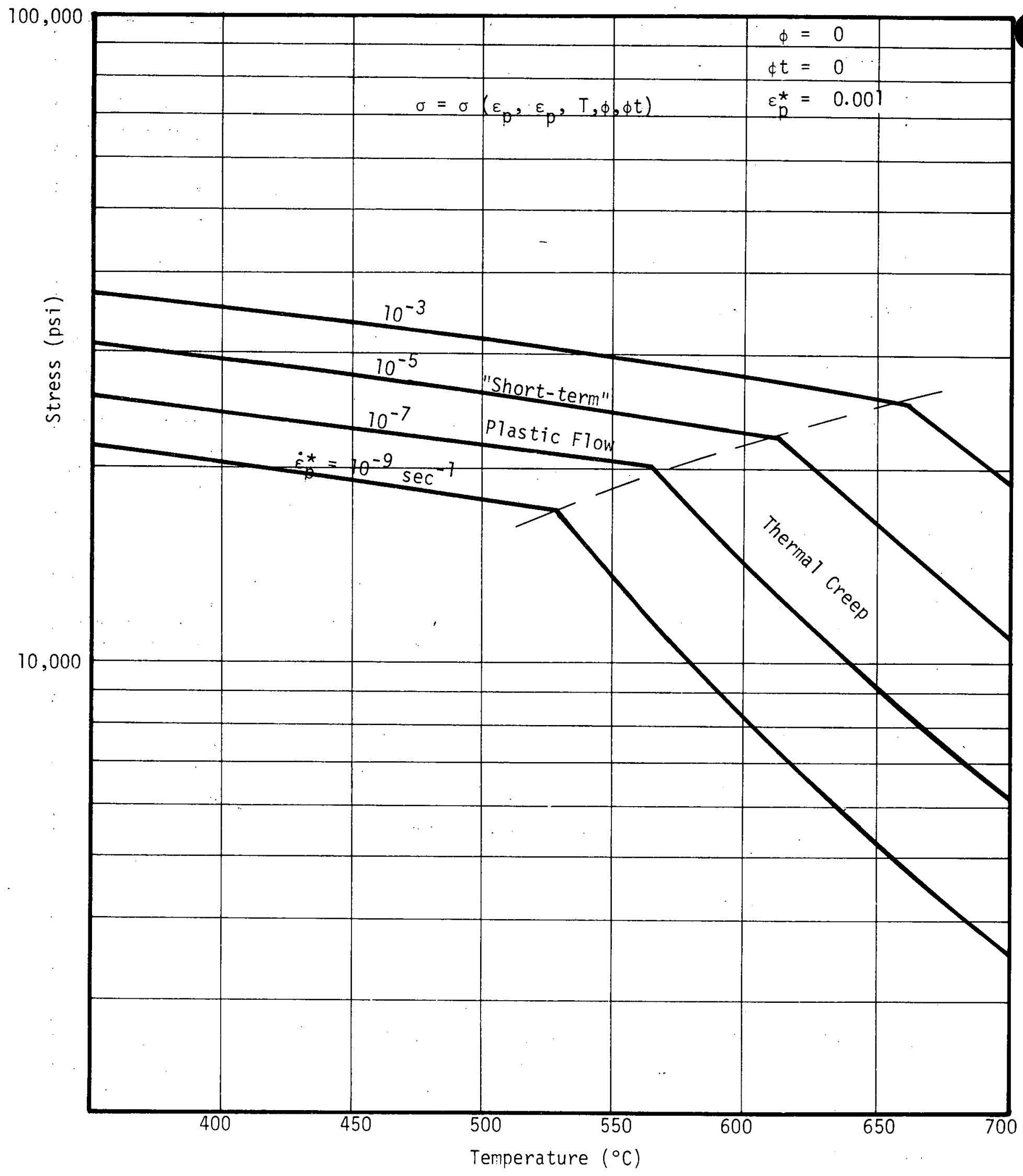

Figure 3-2. Stress-Plastic Strain Rate-Temperature Relation for Unirradiated Type-316 Stainless Steel 


\subsubsection{Cladding Thermal Expansion}

The equation is based on the average coefficient of expansion from $70^{\circ} \mathrm{F}$ to $1000^{\circ} \mathrm{F}$ for $18-8$ stainless steels. $^{22}$.

$$
\frac{\Delta V}{V}=55.1 \times 10^{-6} \mathrm{~T}
$$

where

$$
\mathbf{T}=\text { temperature }\left({ }^{\circ} \mathrm{C}\right)
$$

\subsubsection{Fuel Thermal Conductivity}

Equations reported in Reference 25 are used for fuel thermal conductivities. Temperature dependencies differ only by a constant in the following three equations.

For $\rho>0.95$

$$
k=(3 \rho-1)\left(\frac{1}{5.75+0.0503 \mathrm{~T}}+2.91 \times 10^{-13} \mathrm{~T}^{3}\right)
$$

For $0.85<\rho \leqslant 0.95$

$$
k=-\left(1-2.1 \rho+\rho^{2}\right)\left(\frac{1}{0.288+0.00252 \mathrm{~T}}+5.83 \times 10^{-12} \mathrm{~T}^{3}\right)
$$

For $\rho<0.85$ the density correction recommended by Kämpf and Karsten ${ }^{26}$ is employed with the temperature dependency of Equations (3-15) and (3-16).

$$
k=\left(\frac{1-p^{2 / 3}}{1-0.05^{2 / 3}}\right)\left(\frac{1}{3.11+0.0272 T}+5.39 \times 10^{-13} \mathrm{~T}^{3}\right)
$$

where

$$
\begin{aligned}
& \mathrm{k}=\text { thermal conductivity }\left(\mathrm{W} / \mathrm{cm}-{ }^{\circ} \mathrm{C}\right), \\
& \mathrm{T}=\text { temperature }\left({ }^{\circ} \mathrm{K}\right), \\
& \rho=\operatorname{density}(\text { fraction of theoretical), and } \\
& \mathrm{p}=1-\rho .
\end{aligned}
$$

\subsubsection{Cladding Thermal Conductivity}

The expression used for cladding thermal conductivity is based on data from Reference 22 for Type-316 stainless steel.

$$
k=0.132+0.00013 T\left(W / \mathrm{cm}-{ }^{\circ} \mathrm{C}\right)
$$

where

$$
T=\text { temperature }\left({ }^{\circ} \mathrm{C}\right) \text {. }
$$




\subsubsection{Fuel-Cladding Friction Coefficient}

A value of 1 for the static and sliding friction coefficient, $\mu$, is used in the program based on the work of Martin. ${ }^{27}$ At most points in time, the calculation is insensitive to the value of this parameter for the following reasons. When radial cracks are closed up well into the structural fuel zone, the fuel presses firmly on the cladding (due to fuel swelling or thermal expansion) with an interfacial normal stress, $\sigma_{N}$. Due to the large length/diameter ratio encountered in most practical problems, the average interfacial shear stress, $\tau$, needed to completely restrain sliding is small. Therefore, in this situation $\tau / \sigma_{N} \ll \mu$ and the value chosen for $\mu$ is unimportant. On the other hand, when radial cracks are not closed up in the structural fuel zone, $\sigma_{N}$ is small and relative sliding takes place. Here, $\tau=\mu \sigma_{N}$, but $\sigma_{N}$ is so small that the resulting small $\tau_{N}$ has negligible effect on the fuel. Cases in which sliding is occurring so that $\tau=\mu \sigma_{N}$, yet $\tau$ is large enough to significantly affect the fuel, are encountered relatively rarely in practice.

\subsection{SECONDARY PROPERTIES}

\subsubsection{Transport Temperature}

The intent of the transport temperature is to provide a single time-dependent temperature above which all existent fuel porosity can be considered to have been swept to the center by diffusion-controlled mass transport processes. According to Nichols, ${ }^{28}$ thermal-gradient-induced pore migration is dominated by the two mechanisms of surface diffusion and vapor transport. The former mechanism yields a radial pore velocity inversely proportional to the pore radius while the latter mechanism produces a velocity of migration that is independent of radius. Therefore, in small pores, the velocity will be determined by surface diffusion while in larger sizes the velocity is vapor-transport controlled. Nichols estimates a cross-over size in the vicinity of 10 to 100 microns. Pores smaller than this size will migrate at a velocity varying inversely with their radii, tending to segregate the bubbles according to size. Small pores are swept along most rapidly, leaving the larger pores behind.

Adopting 1 micron as a typical pore radius, surface diffusion is dominant and, according to Barnes and Nelson, ${ }^{29}$ the radial velocity is given by: ${ }^{*}$

$$
V=\frac{36 \Omega^{1 / 3} D_{s}\left(\frac{d T}{d x}\right)}{\pi^{2} r T}
$$

where

$$
\begin{aligned}
\Omega & =\text { atomic volume of diffusing species, } \\
D_{S} & =\text { surface diffusion coefficient, } \\
\frac{d T}{d x} & =\text { local temperature gradient, and } \\
r & =\text { pore radius. }
\end{aligned}
$$

$$
\begin{gathered}
\text { Substituting } D_{S}=D_{.0} e^{-Q / R T} \text { and } V_{0}=\frac{36 \Omega^{1 / 3} D_{o}\left(\frac{d T}{d x}\right)}{\pi^{2} r T} \text {, Equation (3-19) becomes } \\
V=V_{0} e^{-Q / R T}
\end{gathered}
$$

\footnotetext{
*A development by Nichols ${ }^{28}$ differs from this formula by a factor of about 7.5 .
} 
To calculate the time for a pore to reach the center of the fuel, the following substitutions are made.

$$
\begin{aligned}
& d t=\frac{d x}{V} \\
& T=T_{0}+\frac{d T}{d x} d x,
\end{aligned}
$$

obtaining

$$
\int_{t_{0}}^{t_{1}} d t=\int_{T_{0}}^{T_{1}} \frac{1}{v_{0} \cdot\left(\frac{d T}{d x}\right)} \frac{R T^{2}}{Q} d\left(e^{Q / R T}\right) .
$$

The integrand on the right hand side is approximated by considering all terms other than the exponential to be constant, yielding:

$$
\Delta t \simeq \frac{-R T_{0}^{2}}{Q v_{0}\left(\frac{d T}{d x}\right)_{0}}\left(e^{Q / R T_{1}}-e^{Q / R T_{0}}\right)
$$

The first exponential may be neglected in comparison to the second for reasonable temperature differences $\left(T_{1}-T_{0}>\right.$ $200^{\circ} \mathrm{C}$. This results in the final approximate form:

$$
\Delta t=\frac{R T_{o}^{2}}{Q V_{0}\left(\frac{d T}{d x}\right)_{0}} e^{Q / R T_{0}}
$$

Nichols ${ }^{28}$ has adopted the attitude that the time for a pore to be swept away from a particular radius is some effective distance, $\Delta \mathrm{x}_{\text {eff }}$, divided by its initial velocity. This quantity is essentially the physical width of the transport region boundary. The initial velocity derived above is $V_{0} e^{-O / R T_{0}}$ giving, for the effective distance

$$
\Delta x_{e f f}=\frac{R T_{0}^{2}}{Q\left(\frac{d T}{d x}\right)_{0}} .
$$

1f, for example,

$$
\begin{aligned}
& \mathrm{Q}=120,100 \mathrm{cal} / \mathrm{mole}^{30} \\
& R=1.986 \mathrm{cal} / \mathrm{mole}^{\circ}{ }^{\circ} \mathrm{C} \\
& \frac{d T}{d x}=10^{4}{ }^{\circ} \mathrm{C} / \mathrm{cm}, \text { and } \\
& T_{0}=2000^{\circ} \mathrm{K}
\end{aligned}
$$

Equation (3-25) gives a typical value of $\Delta x_{\text {effective }}=0.0066 \mathrm{~cm}$. 
Nichols ${ }^{2}$ has arbitrarily assumed that the effective distance is a constant $0.1 \mathrm{~cm}$. The value derived here varies inversely with the temperature gradient and is $\sim 150$ times smaller at a temperature gradient of $10^{4}{ }^{\circ} \mathrm{C} / \mathrm{cm}$.

Equation (3-24) can be solved for $T_{0}$ after inserting the definition of $V_{0}$. giving

$$
T_{0}=\frac{0}{R} \frac{1}{\ln \left[\frac{36 \Omega^{1 / 3} D_{0} Q \Delta t\left(\frac{d T}{d x}\right)_{0}^{2}}{\pi^{2} r T_{0}^{3} R}\right]}
$$

Approximating the right hand side of the transcendental equation, which varies slowly with temperature, by using a constant value $\mathrm{T}_{\mathrm{O}}=2000^{\circ} \mathrm{K}$ and taking

$$
\begin{aligned}
\Omega & =4.1 \times 10^{-23} \mathrm{~cm}^{3} .^{31} \\
\dot{D}_{\mathrm{O}} & =5.64 \times 10^{-7} \mathrm{~cm}^{2} / \mathrm{sec}^{28} \\
r & =10^{-4} \mathrm{~cm}
\end{aligned}
$$

Equation (3-26) becomes

$$
T_{0}=\frac{6.03 \times 10^{4}}{\ln \left[0.532\left(\frac{d T}{d x}\right)^{2} \Delta t\right]}
$$

Equation (3-27) is plotted versus time in Figure $3-3$, for an assumed value of $\mathrm{dT} / \mathrm{dx}=10^{4}{ }^{\circ} \mathrm{C} / \mathrm{cm}$. The temperature is seen to be a weak function of the time, $\Delta \mathrm{t}$. The equation defines a radius for each timestep inside which all porosity in excess of a residual $1 \%$ will be eliminated by the program logic. The time, $\Delta t$, in Equation (3-27) is set equal to the length of the timestep input by the user for a particular event. This formulation of the porosity migration problem in which porosity is assumed to be instantaneously eliminated from the transport region is only an approximation to reality since porosity migrating across that region does, in fact, occupy volume for a finite period of time. However, in view of the extremely rapid acceleration of the migrating pore, the time spent in the transport region will be very small compared to time spent near the outer boundary of the region and the approximation is well justified. The method puts the position of the boundary ultimately at the discretion of the program user since he controls the length of each timestep. For instance, a modeler who represents a 5000 -hour period of steady-state operation by five 1000-hour periods will calculate a transport region boundary some $25^{\circ} \mathrm{C}$ lower than a person choosing to represent the period by ten 500-hour periods. An economic penalty is paid for using an excessive number of timesteps so that in practice, large divergencies in timestep length between different users modeling the same power history are not anticipated. A factor-of-4 divergency in timestep length produces a 50 to $100^{\circ} \mathrm{C}$ difference in the position of the boundary which, for a temperature gradient of $10^{4} \mathrm{C} / \mathrm{cm}$, represents a radial distance of $0.01 \mathrm{~cm}$. This is of the order

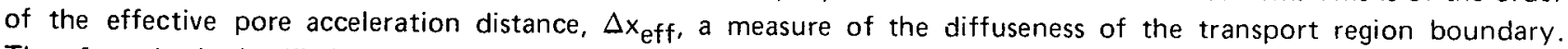
Therefore, both the likely variability in transport region boundary temperature and the geometrical consequences of that variability are small.

The transport region is defined as an area denuded of porosity due to diffusion of pores up the temperature gradient. Its maximum historical radius may be left as a microstructural artifact in the form of the columnar grain growth radius if theories linling pore sweeping to columnar grain growth are correct. While direct measurements of the radius at which porosity declines would be more useful in checking the model used in the code, in the absence of such measurements it is interesting to compare observations of columnar grain growth temperature to predictions made by using Equation (3-27). 


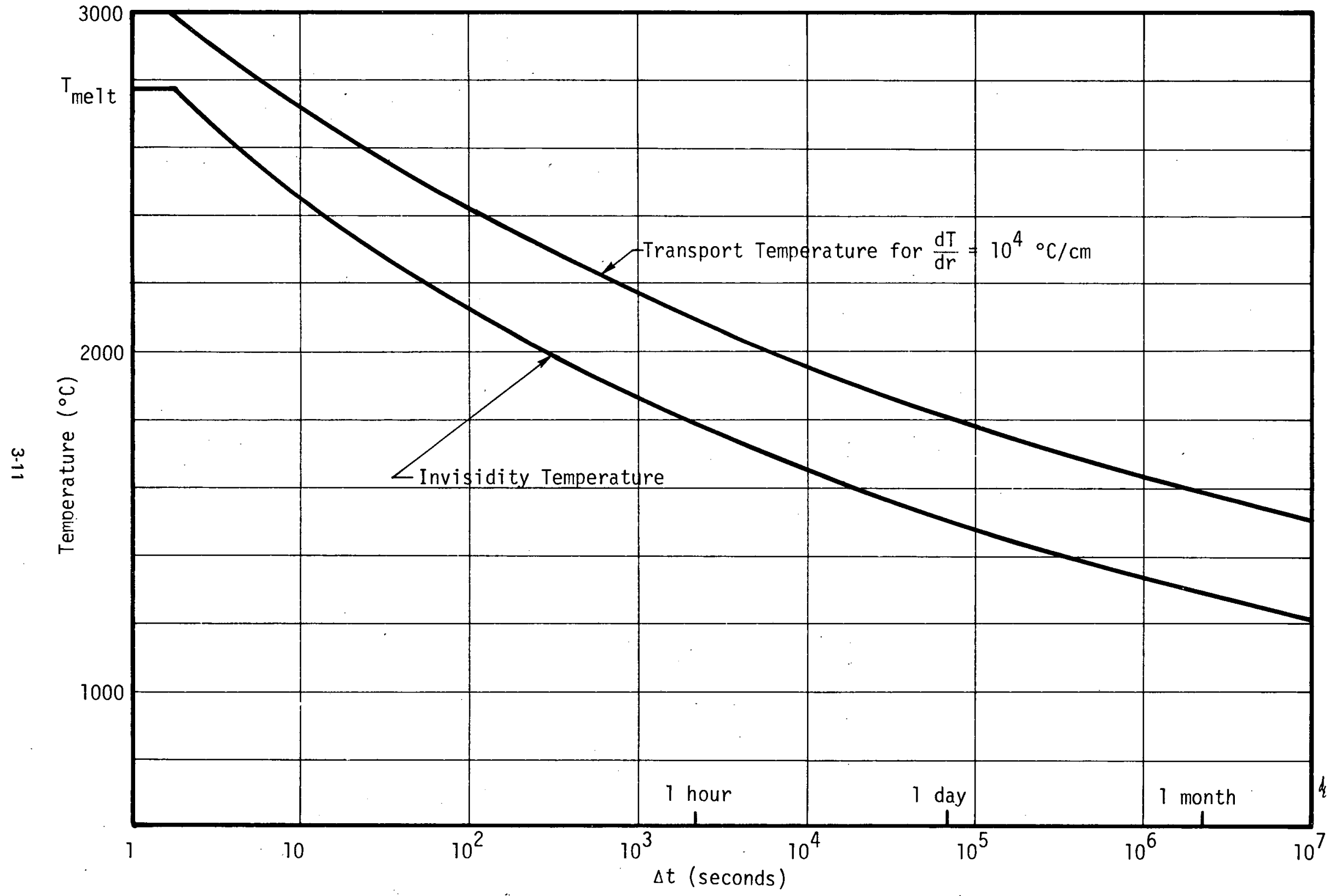

Figure 3-3. Inter-Regional Boundary Temperatures Employed in BEHAVE-2, versus Length of Timestep 


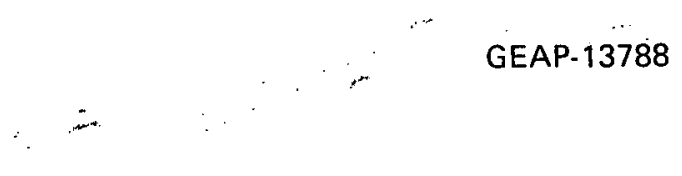

Potter and Elyard, ${ }^{32}$ in an out-of-pile experiment with pure $\mathrm{UO}_{2}$ observed columnar grain growth at $1800^{\circ} \mathrm{C}$ in 25 hours. The temperature gradient is not calculated in their paper, but is probably within a factor of 2 of $10^{4}{ }^{\circ} \mathrm{C} / \mathrm{cm}$. The $1797^{\circ} \mathrm{C}$ transport temperature for 25 hours at $10^{4}{ }^{\circ} \mathrm{C} / \mathrm{cm}$ from Equation (3-27) is very close to the experimental value.

MacEwan and Lawson ${ }^{33}$ in another out-of-pile experiment on $\mathrm{UO}_{2}$ reported incipient columnar grain growth at $1900^{\circ} \mathrm{C}$. Assuming a temperature gradient of near $10^{4}{ }^{\circ} \mathrm{C} / \mathrm{cm}$ in their experiment, the calculated value is $1840^{\circ} \mathrm{C}$, in excellent agreement with the experimental value. Hausner and Nelson, ${ }^{34}$ on the other hand, reported a temperature of $2140^{\circ} \mathrm{C}$ for columnar grain growth in 25 hours, greatly at variance with the calculated value of $1797^{\circ} \mathrm{C}$ and with the other two experimients. The reason for the divergency in values is unknown.

The assumption of $1 \%$ porosity in the columnar grain growth region has been made ${ }^{35}$ in heat transfer calculations but its universal validity is open to question. Post-irradiation examinations indicate that the columnar region often contains much more than $1 \%$ porosity. According to Christensen, ${ }^{36}$ a more realistic value is $5 \%$. Observations of high porosity in the columnar region are in apparent conflict with the pore sweeping theory of columnar grain growth. Due to the exponential relationship of diffusivity to temperature, a pore should accelerate in a steep temperature gradient so rapidly as to pass through the majority of the region in a very short period of time, leaving that region at close to $100 \%$ density. It is possible that the observed pore population is absent during operation but is formed upon shutdown of the reactor. Marlowe has noted ${ }^{37}$ that fission gas in dynamic solution in the fuel due to irradiation effects would come rapidly out of solution in the high-temperature region once the rate of fissioning was reduced. This precipitation due to fission rate reduction when combined with the hydrostatic tension on the columnar region fuel caused by differential thermal contraction shutdown might be enough to cause the observed voids.

\subsubsection{Inviscidity Temperature}

The inviscidity temperature defines the boundary inside which the fuel deforms significantly under relatively small stresses. More specifically, it is defined in BEHAVE-2 as the temperature at which fuel porosity volume is reduced by $10 \%$ under a hydrostatic pressure of 400 psi in $\Delta t$ seconds. A pressure of 400 psi at the cladding inner surface would produce stresses on the order of $4000 \mathrm{psi}$ in cladding with a radius/thickness ratio of 10 , a barely significant quantity in comparison to yield stresses of 20,000 psi or more. Assuming the material is represented by a strain-rate-independent viscosity, the rate of change of porosity in a material under hydrostatic pressure containing spherical porosity is given by

$$
\frac{d p}{d t}=\frac{-3}{4 \eta} P p
$$

where

$$
\begin{aligned}
\frac{d p}{d t} & =\text { rate of porosity increase, } \\
p & =\text { porosity } \\
\eta & =\text { viscosity, and } \\
P & =\text { hydrostatic pressure. }
\end{aligned}
$$

Integrating Equation (3-28) for a constant pressure hot pressing process,

$$
\ln \left(\frac{p_{1}}{p_{2}}\right)=\frac{3}{4 \eta} P_{t} .
$$


The temperature dependence of viscosity is assumed to be described by an Arrhenius relation with the activation energy taken from Bohaboy's relation ${ }^{14}$ for uniaxial viscous creep of $\mathrm{UO}_{2}$

$$
\eta=\eta_{0} \mathrm{e}^{90,000 / R T}
$$

Analysis of data from a hot pressing experiment ${ }^{38}$ on $\mathrm{UO}_{2}$ at $1850^{\circ} \mathrm{C}, 5600$ psi gives

$$
\eta_{0}=3.04 \times 10^{7} \text { psi-sec. }
$$

Introducing $\eta$ into Equation (3-29) and $\mathrm{p}_{1} / \mathrm{p}_{2}=1.1, \mathrm{P}=400 \mathrm{psi}$, gives

$$
\mathrm{T}\left({ }^{\circ} \mathrm{K}\right)=\frac{1}{5.72 \times 10^{-4}+2.21 \times 10^{-5} \ln \left(9.88 \times 10^{-6} \Delta \mathrm{t}\right)}
$$

Equation (3-31) is plotted in Figure 3-3; the temperature proves to be a weak function of the length of a timestep, $\Delta t$. As discussed previously, user selection of timestep length will result in some variability in the inviscidity temperature between users modeling identical power histories. If the differences in timestep lengths are within-a factor of 4 the variability of the calculated temperature is held within 50 to $100^{\circ} \mathrm{C}$.

\subsubsection{Fuel Swelling}

In BEHAVE-2, a unit volume of fuel is divided up into the three categories of matrix material, porosity, and crack volume. Pores are defined as spherical objects having a large enough radius that surface tension forces may be ignored. Pores are assumed to contain gas in pressure equilibrium with the pin's fission gas plenum. Cracks.are planar voids which likewise contain gas in pressure equilibrium with the fission gas plenum. The remaining category, matrix material volume, is made up of the mixed oxide, solid fission product volume, and gas containing bubbles of such small size that the gas pressure is controlled by surface tension and is independent of the local hydrostatic pressure. The matrix material is incompressible and swells at an inexorable rate. This is the rate termed "fuel swelling rate" in the program. However, the undensified fuel material is compressible since a hydrostatic pressure causes a diminution in the volume of pores and cracks by deformation of the matrix material. Thus, it is possible for a unit volume of fuel to be shrinking while the matrix material is swelling. Isotropy of swelling is assumed in the structural fuel zone while in the inviscid zone, the assumption is not made.

This definition of the fuel swelling rate is intended to be as independent as possible of specific assumptions concerning the nature of fuel swelling but it inevitably contains a few assumptions and idealizations. The picture of fuel swelling presented here is consistent with a common understanding of the phenomenon which suggests that fission gas bubbles remain in fairly small, surface-tension-dominated sizes $(<0.1$ microns) until they reach grain boundaries. Grain boundaries are thought to be in either continuous communication with the plenum, through grain boundary linkup, or intermittent contact. Thus large scale bubbles, which are pores in the BEHAVE-2 categorization, may well be close to being in pressure equilibrium with the plenum. Nevertheless, the following departures from the idealized model may physically exist.

1. Small fabricated pores which undoubtedly exist in practice will tend to sinter due to surface tension. The model considers pores to close only under hydrostatic pressure.

2. The model does not allaw for fuel swelling by relatively large fission gas filled bubbles such as the grain boundary bubbles frequently seen in the vicinity of the equiaxed region. (However, crack closure in the nontransport region may be interpreted as being due to fuel swelling induced by grain boundary bubbles. See subsection 3.2.6 for further discussion of this point.) 
3. There is no direct proof that large pores are in pressure equilibrium with the plenum. Indirect evidence lies in the fact that porosity in the unrestructured region remains fairly constant. In fuel having a large central void, pores would expand in volume if they were at a pressure substantially above the plenum pressure. In the hotter regions, a pore pressure substantially above the plenum pressure would result in an even more rapid bloating of the fuel as it moved in to fill the central void.

4. The assumption that the structural zone fuel swells at a gradual isotropic rate and has properties characteristic of the unirradiated mixed oxide is, to a certain extent, inconsistent with the observed presence of highly mobile and structurally weak fission products in this zone in some high burnup pins. ${ }^{39}$

The fuel swelling rate is not, in general, an intrinsic property of the material susceptible to tabulation as a function of temperature, fission rate, and other parameters, since fission products move throughout the pin so that every element of fuel is affected by every other element of fuel throughout the pin. The theoretical approach in principle offers the possibility of calculating fuel swelling rates taking into account the large number of influential variables. At present, however, there is no definitive model of fuel swelling. Accordingly, most fuel pin modellers have adopted an empirical approach, basing fuel swelling rates on observed dimensional changes of irradiated fuel pins.

Perhaps the most valuable experiment run to date in the determination of the inexorable portion of fuel swelling, required in the BEHAVE-2 concept of the phenomenon, has been the strong-radial-restraint experiment reported by Nelson, et al. ${ }^{40}$ In this experiment, four capsules were loaded with high-density mixed-oxide fuel and irradiated in a thermal flux to burnups of up to 33 at. \%. High burnups and high density are useful in swelling determination since corrections for void fractions such as fabricated porosity, initial fuel-cladding gap, and shutdown cracks assume a smaller fraction of the total volume increase. Furthermore, the fuel was surrounded by cladding thick enough that all fuel expansion had to take place in an axial direction. This latter feature would induce a high hydrostatic pressure in the fuel column, at least at low center temperature, which would reduce porosity in the compressible category to a minimum. Nelson estimated that the swelling rate corrected for consumption of initial porosity increased with burnup from $0.29 \% \Delta \mathrm{V} / \mathrm{V} /$ at. \% burnup at zero burnup to $0.56 \%$ at 33 at. \% burnup. Linear power was highly variable throughout the irradiation. Work reported by Oldberg and Hines ${ }^{9}$ showed that, based on cladding dimensional changes, the volume-averaged rate of fuel swelling for a group of 26 pins irradiated at end-of-life linear powers of 12 to $16 \mathrm{~kW} / \mathrm{ft}$ to burnups of up to 11 at. \% was no greater than $0.9 \% \Delta \mathrm{V} / \mathrm{V} /$ at. \% burnup. This latter value appears at present to be optimal for the correlation of cladding diameter increase data.

Fuel swelling models generally predict a considerable peaking of gaseous fission product swelling in the vicinity of the equiaxed grain growth region with low gaseous swelling in the cooler region and little or no gaseous swelling in the columnar region. Similarly, solid fission products are not uniformly distributed, the temperature gradient producing diffusion toward the hotter and colder regions. For example, cesium is much in evidence in the fuel-cladding gap of several $^{39}$ high-burnup mixed-oxide fuel pins in the form of the oxide while large metallic ingots are found in the central voids. Thus, fuel swelling is a more complex phenomenon than the idealized model assumed in BEHAVE-2. The validity of the model can only be ascertained by comparison of predictions of cladding dimensional changes and microstructural features such as crack distributions and porosity distributions to predictions of the code.

\subsubsection{Fission Gas Release}

The program is currently set up for a step-function gas release model. Below the "gas release temperature" fission gas produced is retained within the lattice. Above the gas release temperature, gas produced is available to the plenum (a so-called "gas bottle" option in which communication of gas released from the lattice is assumed cut off from the plenum is discussed in subsection 3.2.5). The gas release temperature is currently set equal to the transport region boundary temperature, producing a gas release temperature of 1500 to $1600^{\circ} \mathrm{C}$ for long-term irradiatiońs. This picture of gas release is in agreement with the pore-sweeping model of gas release. ${ }^{28}$ That model, however, is apparently incapable of explaining releases approaching $100 \%$ observed in some ${ }^{39}$ high burnup pins and saturation of retained fission gas inventory observed in other cases. ${ }^{40}$ The best interim solution is probably the introduction of an empirical, burnup-dependent gas release temperature into the program. This would require a very minor change in the coding. 


\subsubsection{Gas Bottle Effect}

Notley et al., ${ }^{41}$ and others ${ }^{42}$ have performed experiments in which plenum pressure was monitored periodically to determine the variation with time of the fission gas plenum's molar content. Pins having relatively low center temperatures were found to evolve gas into the plenum more or less continuously. However, in pins with high center temperatures gas was released from the fuel to the plenum on an intermittent basis, occurring during power changes. The phenomenon, termed the "gas bottle effect," is of potential importance since the fission gas pressure in the inviscid zone could build up to values high enough to strain the cladding during weeks or months of steady-state operation. Such a pressure, moreover, bearing on the surrounding structural zone fuel would tend to close up cracks in that zone by compressing the fuel in a radial direction and extruding it in the circumferential direction.

A BEHAVE-2 option has been written, but is not debugged, which treats the gas bottle effect. At the moment the option is called into play, communication between the inviscid zone and the plenum is cut off. Fission gas produced in the portion of the nontransport region above the gas release temperature remains in place and forms large gas-filled pores. Fission gas produced in the transport region is swept to the central void. The relative volume fractions of gas-filled pores and central void are uniquely determined by the moles of gas in each locality, the temperature distribution, and the fact that pressure throughout the inviscid zone is constant. Upon termination of the gas-bottle option communication with the plenum is immediately restored. However, the fission-gas-generated porosity remains.

\subsubsection{Crack Closure and the Central Uncracked Ring Effect}

The BEHAVE- 2 code predicts the production of a few tenths of a percent plastic cladding strain under conditions in which a long period of operation at $\checkmark 8$ to $11 \mathrm{~kW} / \mathrm{ft}$ is followed by a power increase. This results from the model's assumption of the formation of a central uncracked ring of fuel (CUR) extending from the central void boundary out to the inviscid zone boundary (see Figure 3-5). For a timestep length of 1 month, the inviscid zone boundary extends out to $1300^{\circ} \mathrm{C}$.

Relative fuel-cladding thermal expansion during a power increase may or may not plastically strain the cladding, depending on the deformation resistance of the CUR. The strength of the CUR is a function of several variables, including the temperature above which cracks are closed, the linear power prevailing during crack closure, the linear power to which the pin is subsequently raised and the central void radius. Figure 3.4 presents the results of a study in which the effects of variations in several of these variables were determined. Plastic strain induced in the cladding is plotted versus the steady-state power during formation of the CUR. The calculations have assumed a rise to a power greater than $13 \mathrm{~kW} / \mathrm{ft}$ at a rate of $2 \mathrm{~kW} / \mathrm{ft}-\mathrm{h}$. With no central void, a crack closure temperature of $1365^{\circ} \mathrm{C}$ produces $0.18 \%$ plastic strain; a temperature of $1465^{\circ} \mathrm{C}$ produces $0.08 \%$ plastic strain.

Clearly, the predicted plastic strain increment due to this effect is strongly dependent on the crack closure temperature. Therefore, in the case of long periods of steady-state operation, the temperature at the inside of the structural fuel zone ideally would be tied to the crack closure property rather than the viscosity property; the latter property is now controlling. Unfortunately, only Bain ${ }^{43,44}$ has systematically investigated crack closure. Bain's experiments, run with both $\mathrm{UO}_{2}$ and $\mathrm{ThO}_{2}-2 \mathrm{wt} \% \mathrm{UO}_{2}$, employed fabricated cracks splitting the fuel pellets into two hemicylindrical portions. Under irradiation, lasting about a month, the fabricated cracks were found to have healed out to a temperature estimated to be $1400 \pm 100^{\circ} \mathrm{C}$ in the experiment run with ${\cup O_{2}}_{2}$. The extent of crack closure and healing extended well beyond the equiaxed grain-growth region. No crack healing was found in low-linear-power experiments in which there was no equiaxed grain growth. A vestigial line of pores marked the former position of the fabricated crack.

The CUR effect is of primary importance if it occurs periodically, i.e., whenever a long period of operation at moderate power is followed by a power increase. Given a periodic effect and a large number of cycles, a substantial amount of plastic strain would accrue from the small amount of plastic strain per cycle. The periodic effect is illustrated in Figure 3-5. When the power is reduced from the higher power levels to the power at which the CUR develops, cracks are formed, due to differential contraction of the hotter inner fuel relative to the cooler outer fuel. For the uncracked annulus necessary to the effect to be formed, these cracks must be closed up. Potential mechanisms for achieving crack closure are gaseous fission product swelling, porosity generation due to healing of mismatched jagged crack surfaces, and the gas bottle effect. A fourth mechanism of void migration up the temperature gradient is also available for crack closure but at too high a temperature to be of interest here. 


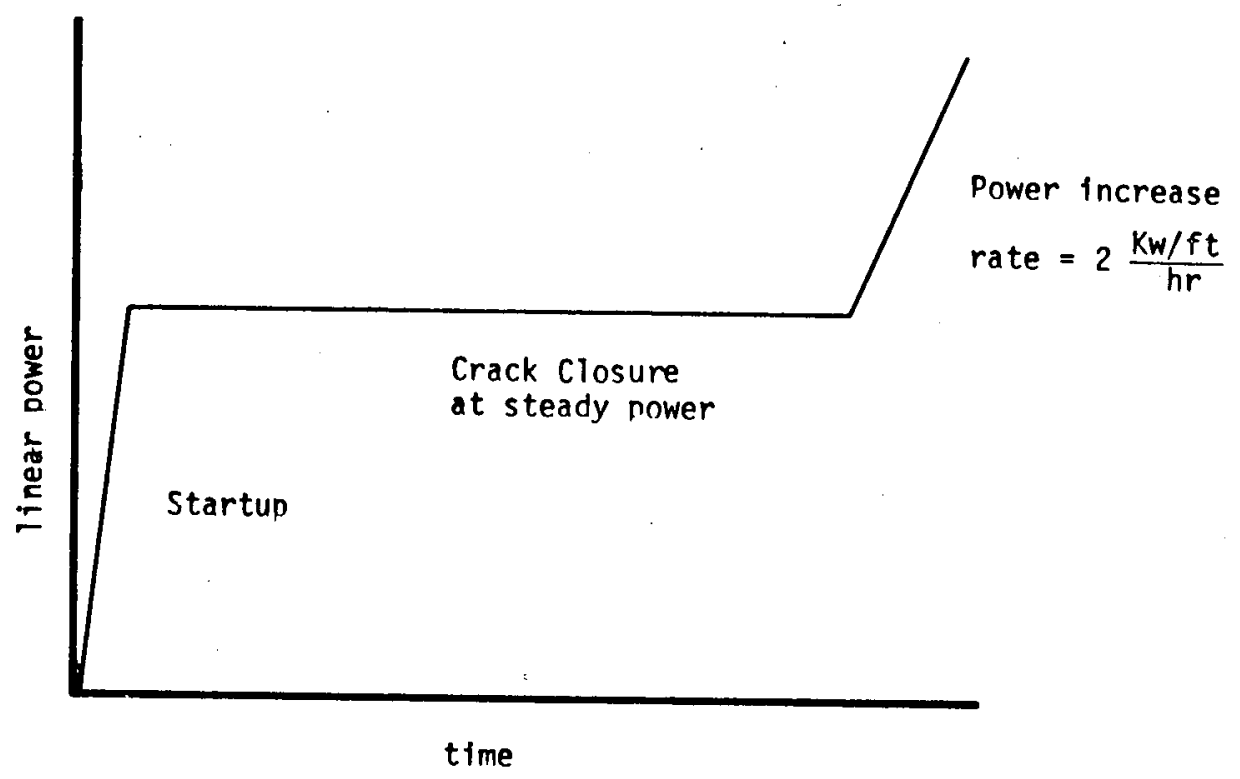

Power-Time History used to Investigate the CUR Effect

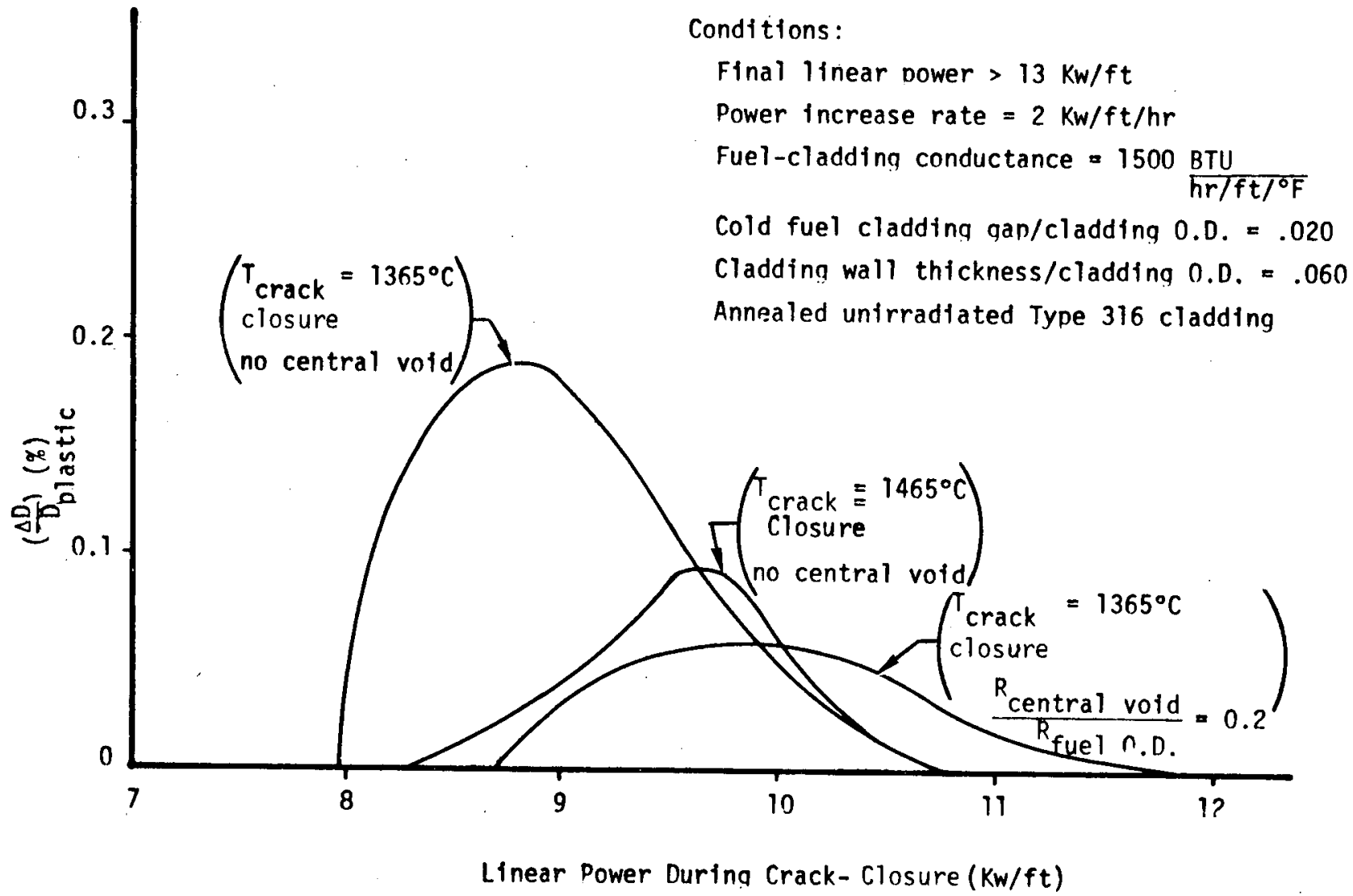

Figure 3-4. Permanent Cladding Diameter Increase Due to Plastic Strain versus Linear Power During Crack Closure 


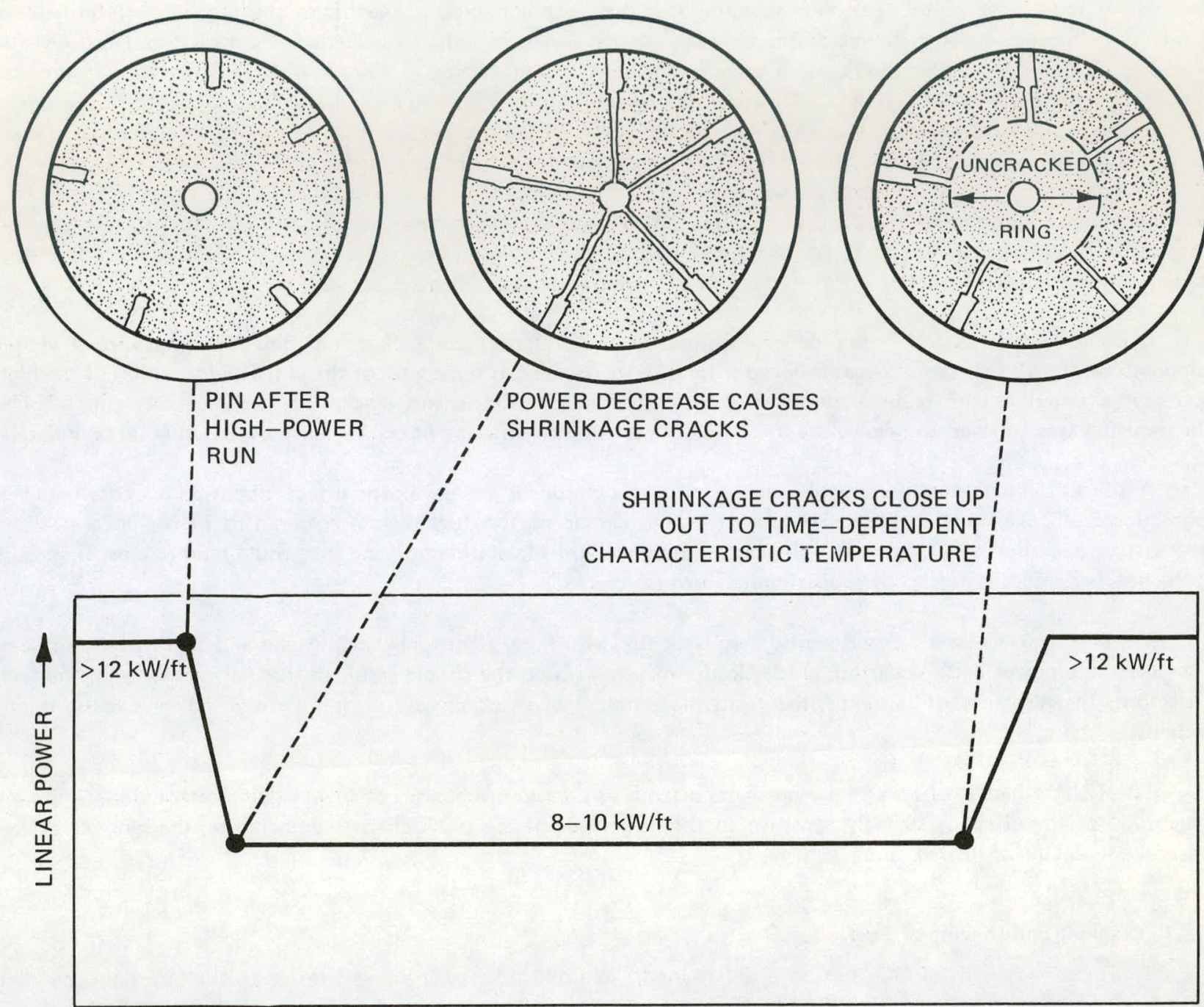

TIME $\longrightarrow$

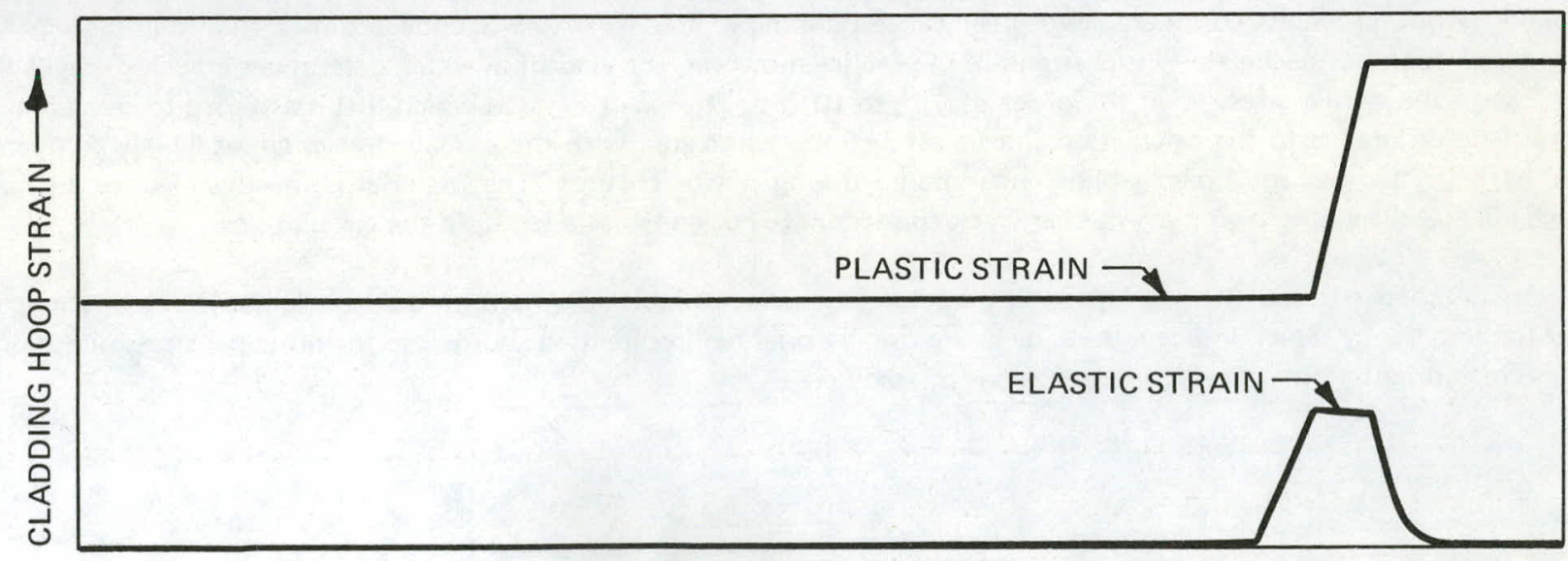

$\mathrm{TIME} \longrightarrow$

Figure 3-5. Schematic IIlustration of the Cyclical CUR Effect 
Many models of gaseous-fission-product-induced fuel swelling predict maximum swelling in an intermediate temperature regime in which temperatures are high enough for rapid bubble nucleation and growth but too low for sweeping of bubbles up the temperature gradient. Hilbert and coworkers ${ }^{45}$ have investigated fuel swelling in the temperature range of 1400 to $1600^{\circ} \mathrm{C}$. They report fuel swelling rates ranging from 4.3 to $6.0 \% \Delta \mathrm{V} / \mathrm{V} / \mathrm{at}$. \% burnup in experiments running to 0.7 at. \% burnup. Fuel swelling rates of this magnitude would cause rapid closure of cracks. However, temperature gradients in the experiments were much lower than prototypic values and the burnup is low by LMFBR standards. In an almost isothermal experiment, ${ }^{46}$ Grando, et al., have measured the rate of unrestrained fuel swelling. Rates of 5.7 and $10.3 \% \Delta V / V /$ at. \% burnup were measured at temperatures of 1365 and $1580^{\circ} \mathrm{C}$, respectively. The terminal burnup was $\mathbf{1 . 5}$ at. \%. In contrast, Michels, et al., have reported ${ }^{4}$ almost no fission gas bubbles were present in the equiaxed region of a prototypic LMFBR pin irradiated to 2.9 at. \% burnup.

Mustelier has reported ${ }^{48}$ the dedensification of the equiaxed zone in a fuel pin operating with a center temperature of $1650^{\circ} \mathrm{C}$. Density was reduced from $98 \%$ to $75-80 \%$ in the center of the pin. The formation of the high porosity, situated at the grain boundaries, was attributed to "crack and crack disappearance mechanics." The phenomenon was believed to involve the formation of porosity by sintering of cracks, leaving holes at grain boundaries.

A third effect potentially capable of causing crack closure is the gas bottle effect, discussed in more detail in subsection 3.2.5. The high pressures generated in the center of the fuel by the entrapment of fission gas during steady-state operation would compress the surrounding fuel in a radial direction and this would tend to close up cracks in the hot, low-viscosity region by squeezing fuel into the cracks.

Turning again to Bain's experiments, they were run with fairly tight fuel-cladding gaps and high fuel density and since only one power cycle occurred, crack closure may have been the simple result of thermal expansion of the fuel. Therefore, the relevance of the experiments to the problem of crack closure during periodic power cycling is not certain.

The CUR effect is of potentially great importance as a basic mechanism of fuel-cladding interaction. Since the magnitude of the eftect is strongly sensitive to the magnitude of the crack closure temperature, the kinetics of this effect are deserving of further study.

\subsubsection{Cracking and Healing of Fuel}

The tensile strength of $\mathrm{UO}_{2}$ has been determined, ${ }^{49}$ in unirradiated specimens tested by the four-point bending technique, to be in the range $15,000-28,000$ psi depending on strain rate and temperature. In irradiated fuel, the presence of cracks, fission product inclusions and fission gas bubbles on grain boundaries weakens the fuel to an unknown but probably consisıderable degree. Correspondingly. the BEHAVE.2 code assumes that the fuel in the structural zone has negligible tensile strength. In practice. however, the algorithm which determines cracking cracks the fuel when the tensile stress is on the order of $10^{3}$ to $10^{4}$ psi. The exact stress at which fuel is assumed to crack makes very little difference to the calculation since elastic strains associated with these small stresses are negligible compared to the large thermal and creep strains encountered during power changes. The material is ideally assumed to have negligible tensile strength so that whether crack surfaces have healed is not a factor in the calculations.

The code assumes that fuel does not fracture in shear; support for the assumption is lent by examinations of photomicrography which indicate that cracks are usually oriented in directions normal to the principal stress directions. This crack orientation indicates a tensile mode of fracture. 


\section{RESULTS OF A SAMPLE PROBLEM}

Presentation of results from a sample problem will illustrate the type of analysis which is possible using the program. Comparison of results with data from fuel pin irradiations will form the basis for future reports and is not undertaken here.

Described below are the results of a simulation of fuel pin $\mathrm{F} 2 \mathrm{H}$. This pin was clad in annealed Type-316 stainless steel and was irradiated in EBR-2 to a peak burnup of 7.3 at. \%. Features of the pin important to the calculated behavior include the high mean smeared density of $93.8 \%$, minimizing the void available for fuel swelling accommodation, and the fact that the fuel column was rigidly restrained from axial expansion.

The bottom of Figure 4-1 indicates the simplified power history which has been used to model this pin. Power is plotted versus timestep number. Numbers at the top of the graph indicate the elapsed time, in hours, associated with each event. The middle graph in the figure shows several categories of strain at the center-most of the five axial sections (the peak flux position) plotted versus timestep number. The curve $(\Delta D / D)_{\text {total }}-(\Delta D / D)_{\text {thermal expansion }}$ gives the diameter increase minus the thermal expansion from room temperature up to operating temperature. It provides a measure of the elastic, plastic, and steel swelling strain in the hoop direction of the cladding. The topmost graph gives the mean hoop stress plotted against timestep number.

Looking at the plot of hoop stress, plastic strain is seen to be accumulated at variable stress. The variability is due to the strain-rate sensitivity of yield stress which is accounted for in the cladding constitutive equation.

Figure 4-2 shows the same sort of hoop-stress plot but in this case broken down into stress at the inner and outermost of the 5 cladding rings used in this problem. The graph shows that cladding thermal stresses and differential swelling stresses are calculated by the program. Thus, thermal-stress-induced ratcheting effects in the cladding are modelled by the code.

Figure 4-3 shows the percentage length increase of the fuel column and an identical length of cladding relative to their room-temperature lengths during the first startup of the pin plotted versus time. The accompanying graph shows the power history. At zero power an axial gap exists between the axial barrier assumed to exist at the top of the cladding and the fuel. Zero axial gap was assumed at room temperature, but the cladding expands more than the fuel upon being raised to the $700^{\circ} \mathrm{F}$ EBR-2 tank temperature. As power is applied to the pin, the fuel column expands rapidly and overtakes the cladding, encountering the axial barrier at about $5 \mathrm{~kW} / \mathrm{ft}$. For the next $1 \mathrm{~kW} / \mathrm{ft}$, the fuel and cladding expand at the free expansion rate of the cladding as the transversely cracked fuel column is easily compressed by the cladding. A sharp upturn in the curve signifies that the fuel column has been compressed sufficiently to close up some of the transverse cracks. The fuel column has essentially become a rigid structure and the fuel and cladding expand upward at the free expansion rate of the fuel. Finally, a reduction in slope occurs as the interior of the fuel column becomes mushy due to its now high temperature and the fuel column loses its ability to impress its expansion rate on the cladding. Thenceforth, the fuel and cladding expand at the free expansion rate of the cladding. Excess fuel expansion is absorbed in hot pressing of porosity and closing down of previously produced fuel cracks.

Figure 4-4 shows the evolution of the microstructure at the peak flux position during the initial startup of the pin and a subsequent period of steady-state operation. The radii of several observable microstructural features are plotted versus timestep number. At low power, a very small central void is seen to exist. This is due to the assumed movement of pie-shaped fuel segments to the cladding inner surface which leaves a space between the apexes of the pie-shaped segments. As power is increased, thermal expansion closes up the initial central void. Above $10 \mathrm{~kW} / \mathrm{ft}$, the central void is closed and thermal expansion of the fuel causes hot pressing of the interior fuel. No columnar graingrowth region (here assumed to be coincident with the transport region) forms during the 5-hour startup. During the subsequent 204-hour period of steady-state operation, a columnar region forms. There is no additional thermal expansion at steady power and the porosity migration causes formation of a central void. 

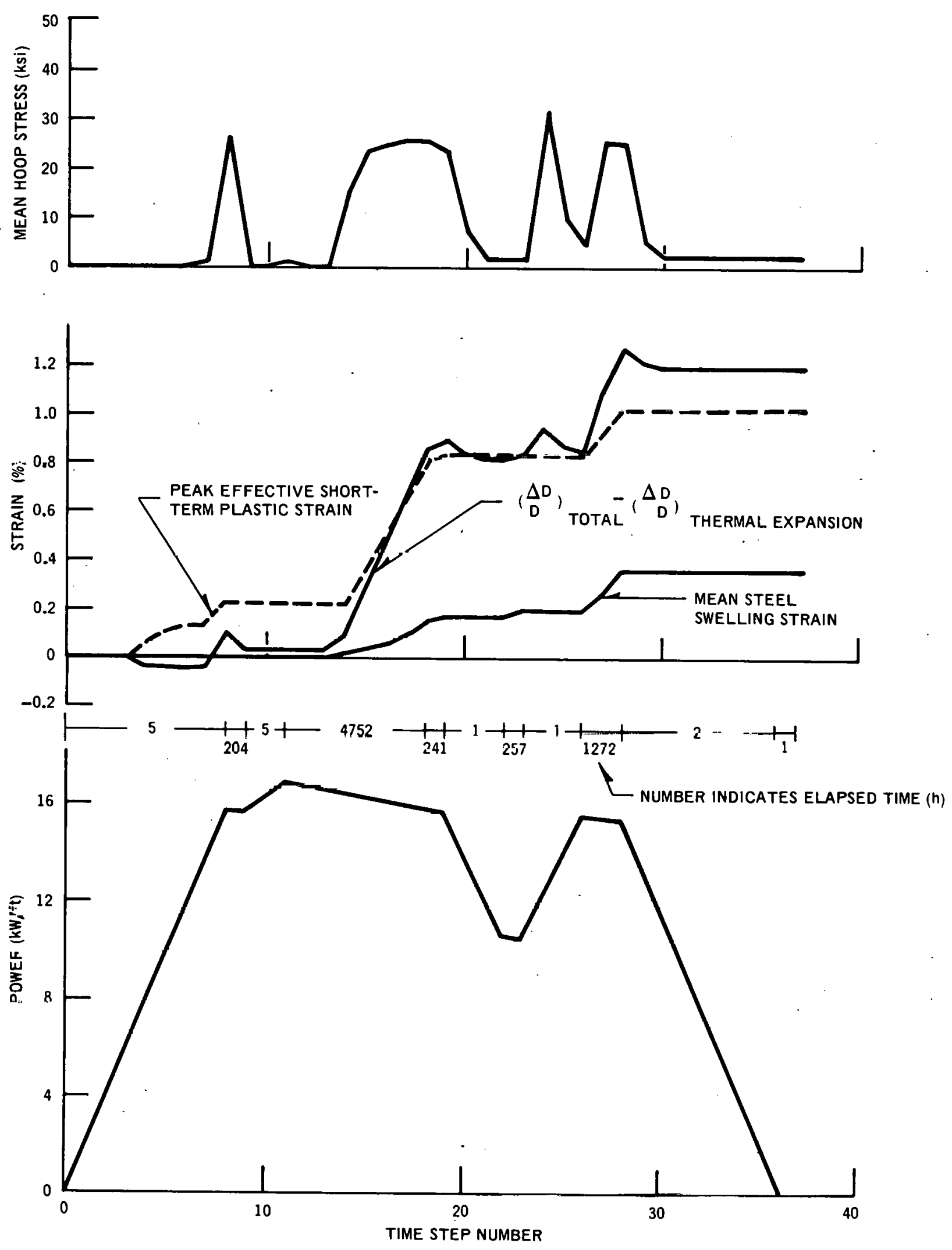

Figure 4-1. Power, Strain, and Hoop Stress Histories at the Peak Flux Position from a Simulation of Fuel Pin F2H 
PIN F2H

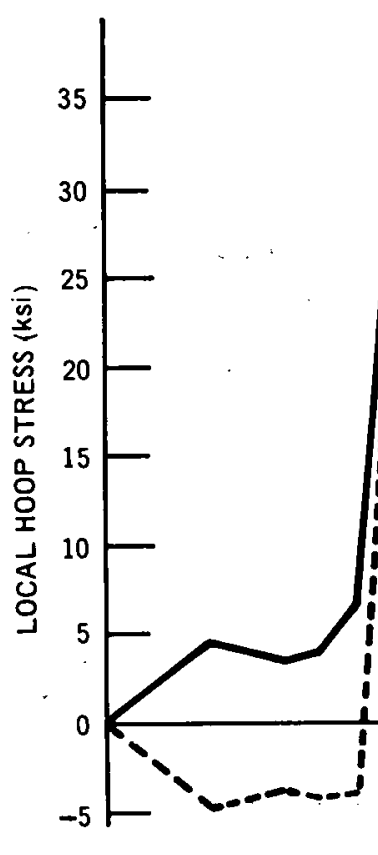

PEAK FLUX POSITION
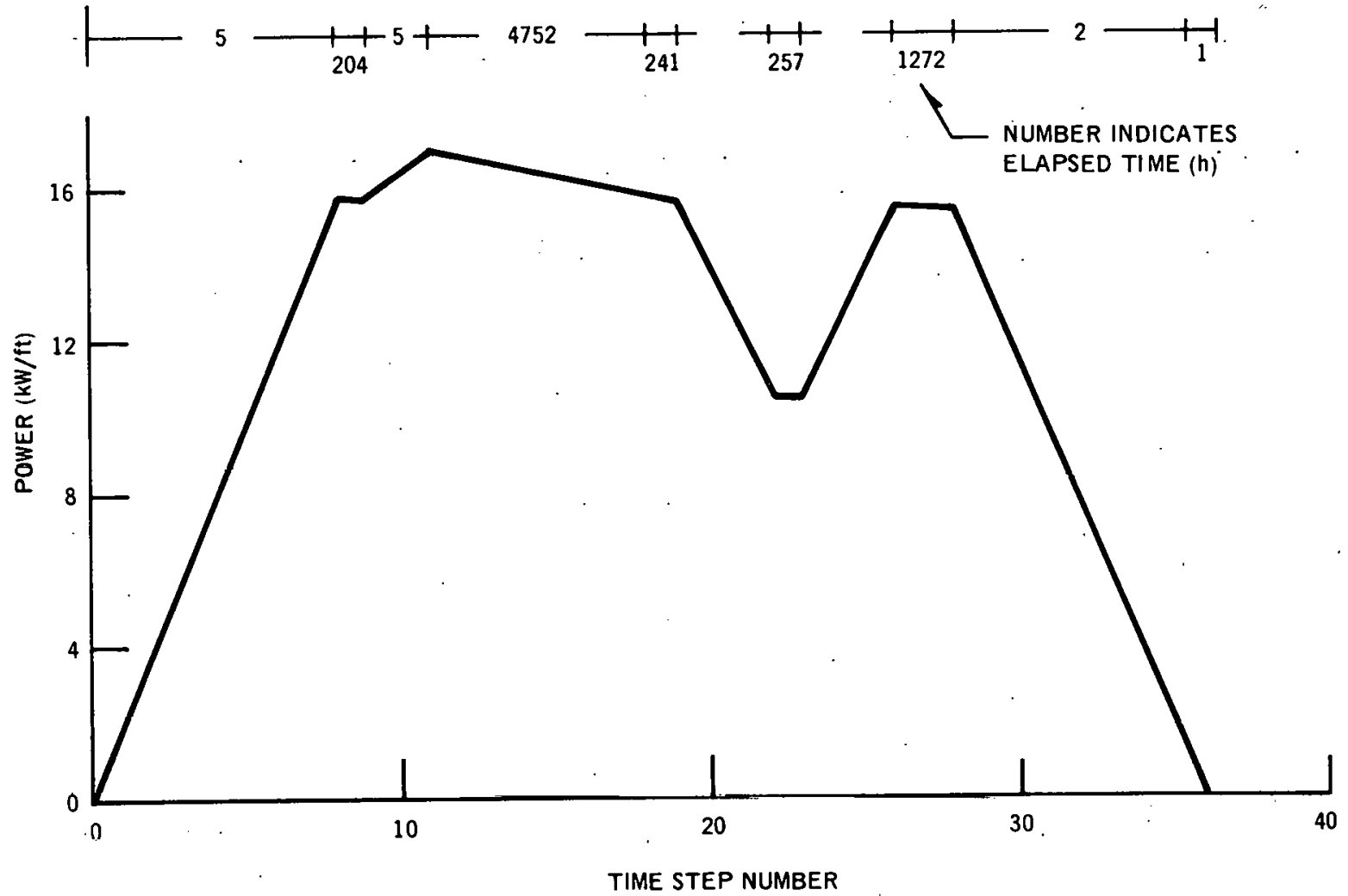

Figure 4-2. Cladding Hoop Stress at Inner and Outer Cladding Rings and Power Plotted versus Timestep Number 

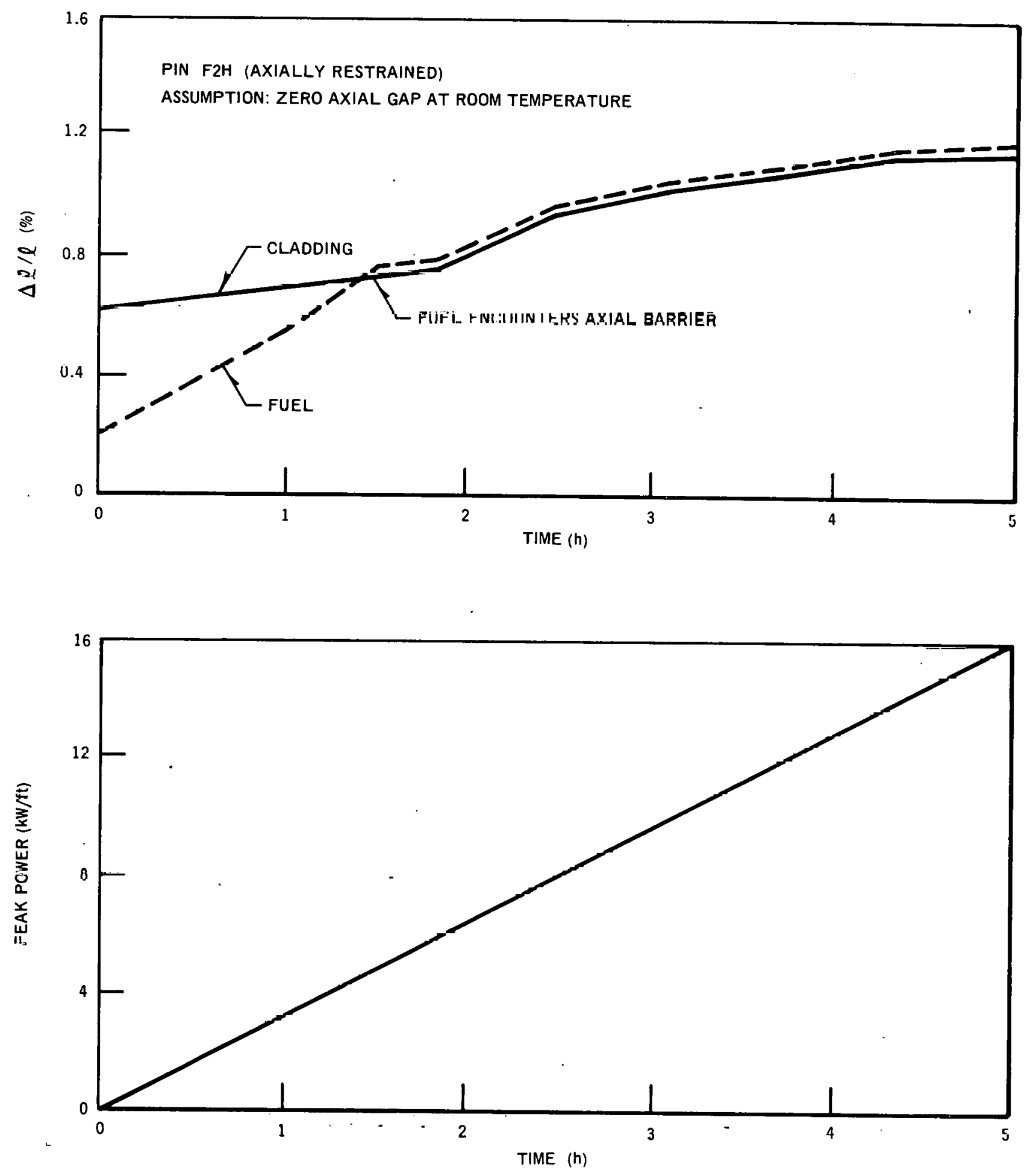

Figure 4-3. Length Increases of the Fuel and Cladding Relative to the Unirradiated, Room Tcmperature Lengths and Power Plotted versus Time 


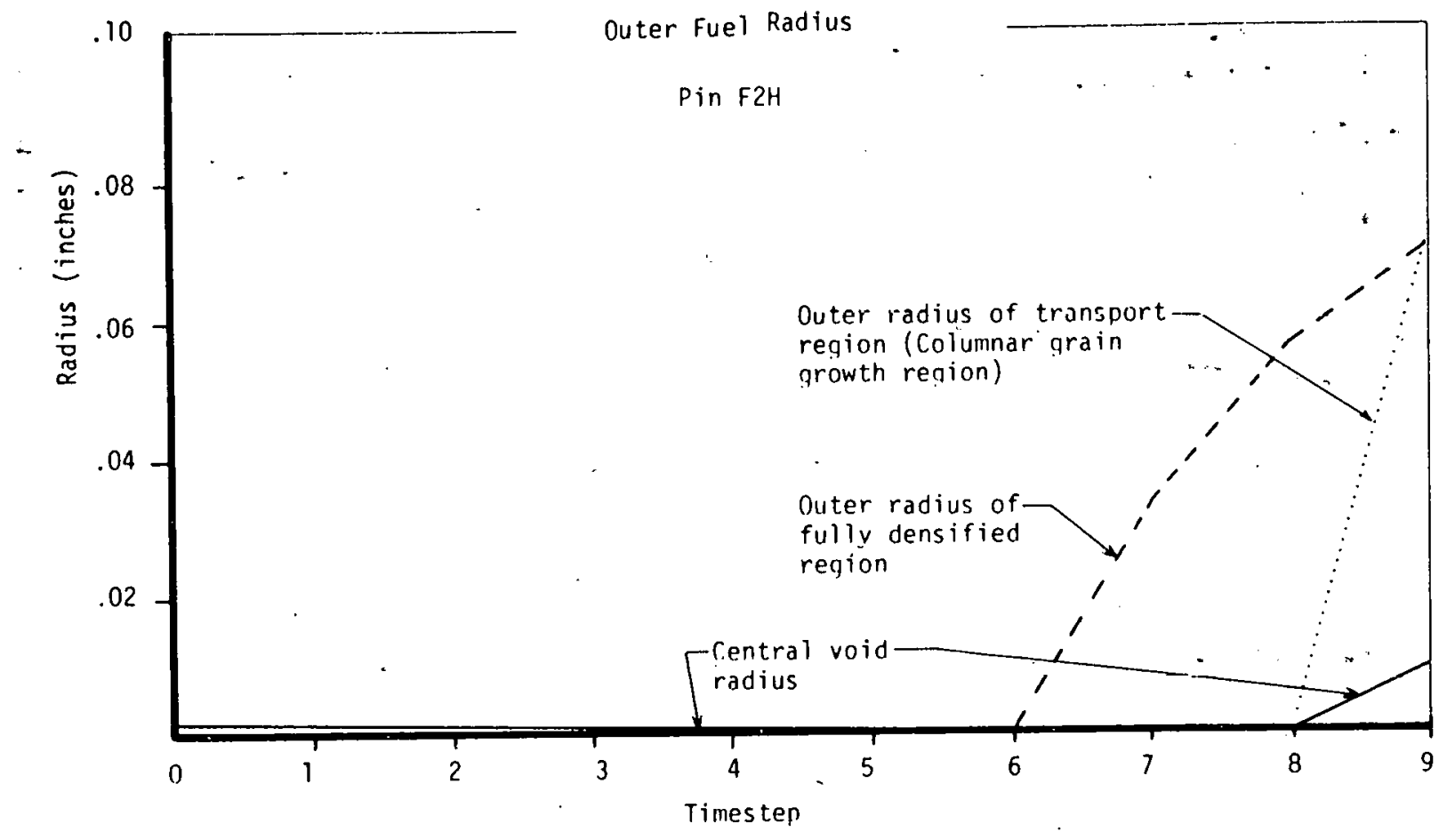

$5 \mathrm{hrs}$ +204 hrs

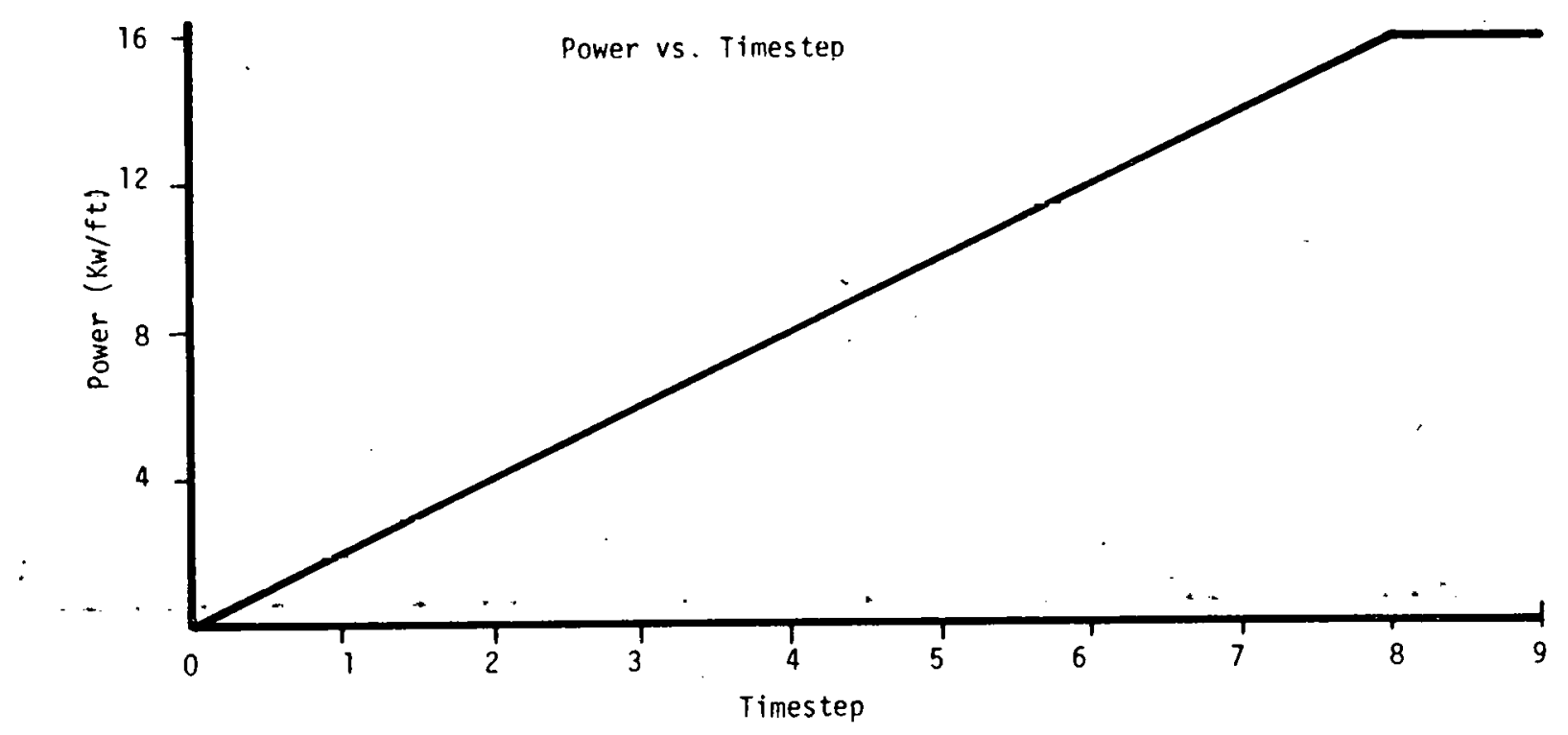

Figure 4-4. Radii of Microstructural Features and Pówer Plotted versus Timestep Number 
Figure 4.5 shows the several categories of strain plotted against length at the end of the irradiation. Discrete points indicate the positions of the five axial nodes used in the calculation. The percent diameter change curve is amenable to comparison with the same quantity derived from profilometry. The shape of the experimental curve contains much information which can be used to verify the correctness of mechanisms modeled in the program. Other curves show the axial distributions of steel swelling and effective plastic strain. The latter quantity is separated into three categories-short-term plastic strain, thermal creep, and irradiation creep. Effective short-term plastic strain is indicated to be greater than $\Delta D / D$ at the ends of the pin. The axial plastic strain incurred during startup caused a diameter decrease, but an effective strain increase; the latter quantity is always positive by definition.

Figure 4-6 shows the predicted radial distribution of porosity, radial and transverse cracks, and the predicted radius of the central void. The division of the fuel radially into from 10 to 30 rings provides for a great deal of detail in the representation of radially distributed variables such as the porosity and crack. volumes. The end-of-life crack pattern calculated for this pin is due solely to differential shrinkage of the fuel during the final shutdown. Comparison of model predictions of these quantities with experimental data would yield a great deal of information regarding mechanisms of fuel-cladding interaction and gaseous fission product swelling. Unfortunately, crack and porosity distributions are not now routinely measured in post-irradiation examinations.

Figure 4-7 shows the predicted retention of fission gas within the fuel. The predicted fission gas distribution is amenable to comparison with the results of microprobe examinations and other techniques for determining the distribution experimentally. Results of such a comparison would aid in the verification of models of fuel swelling and fission gas release contained in the code. 


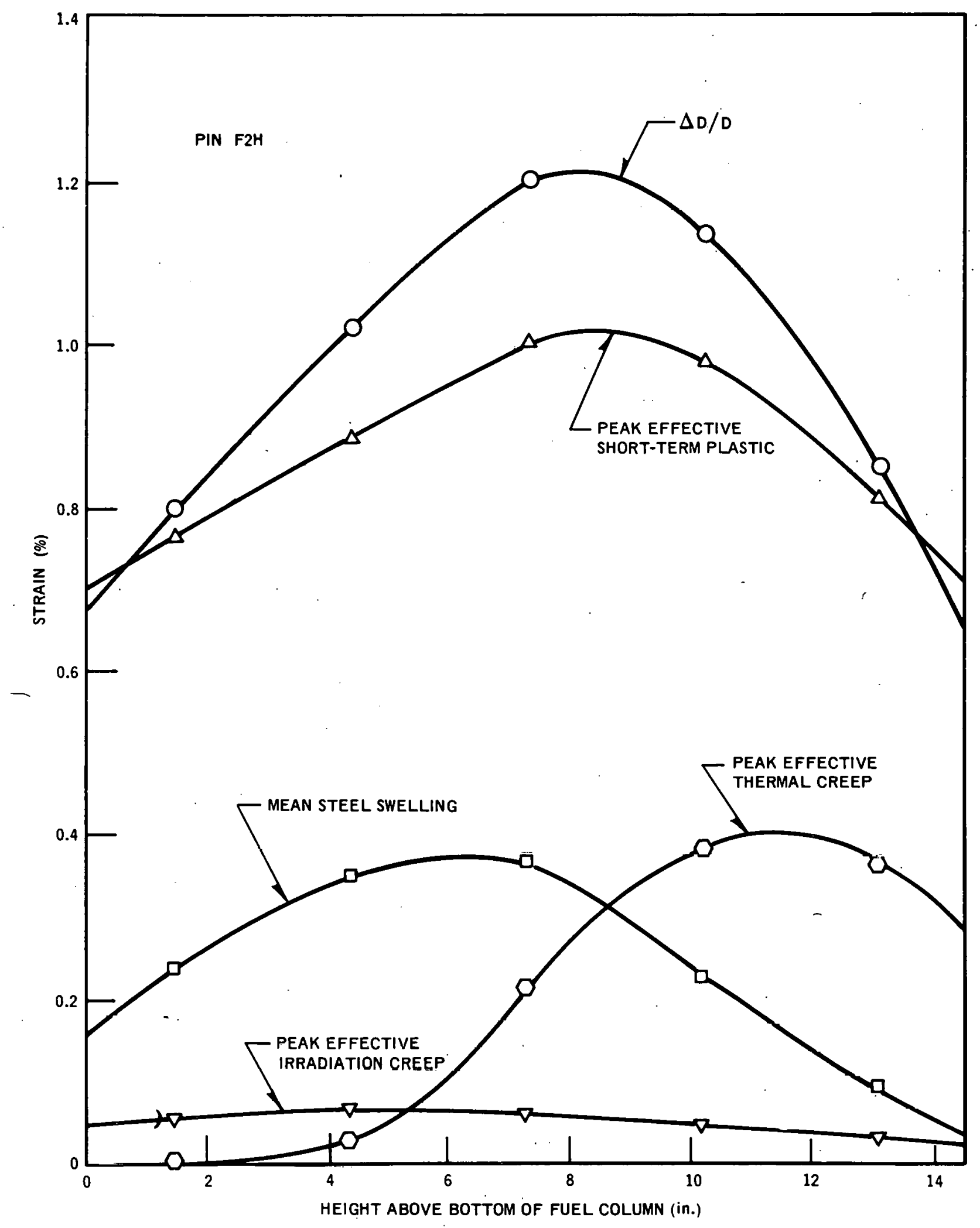

Figure 4-5. Predicted Strain Distributions at the End-of-Life Room Temperature Condition 


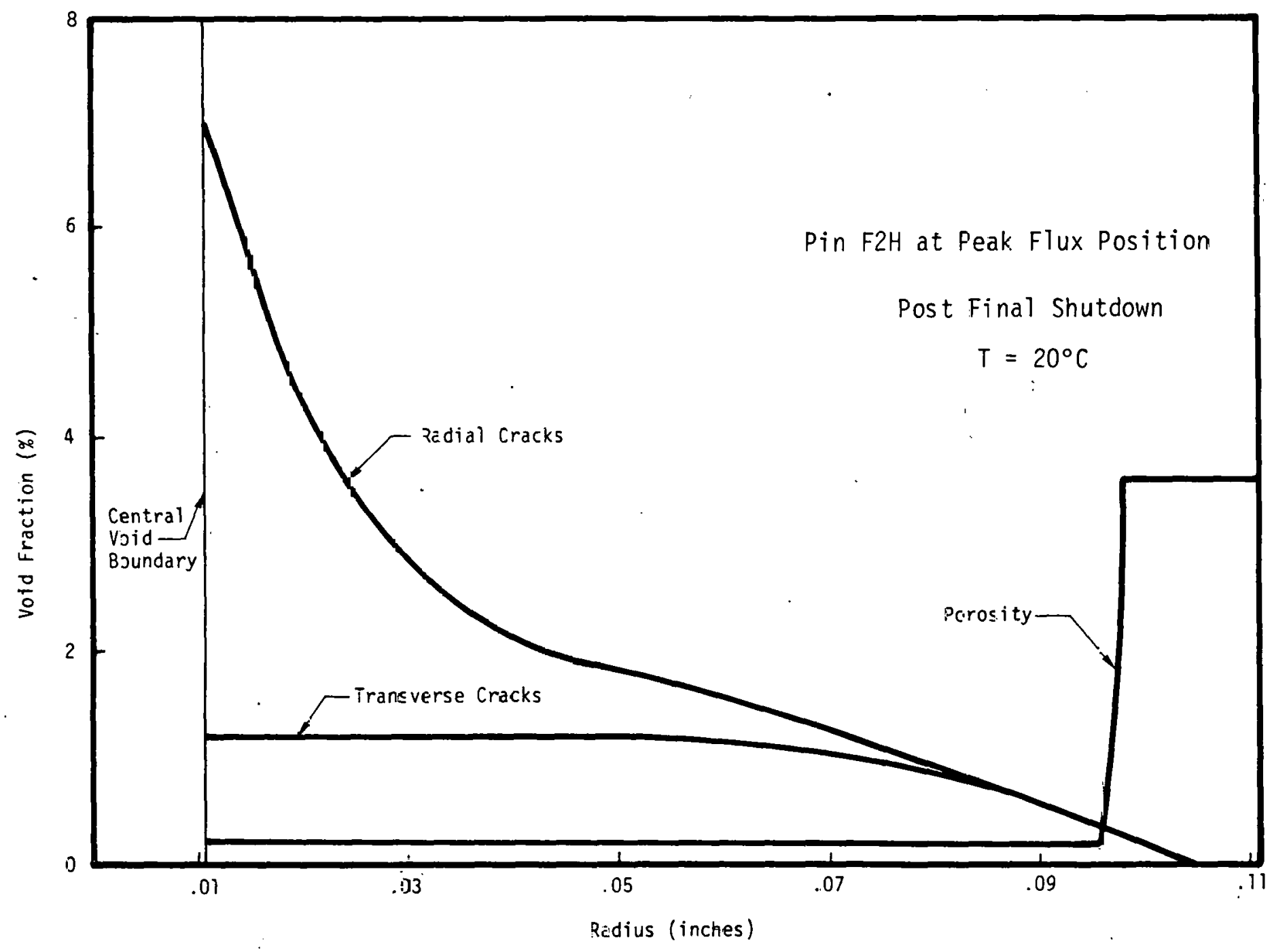

Figuie 4-6. Predicted Void Fraction Listributions After Final Shutdon'n 


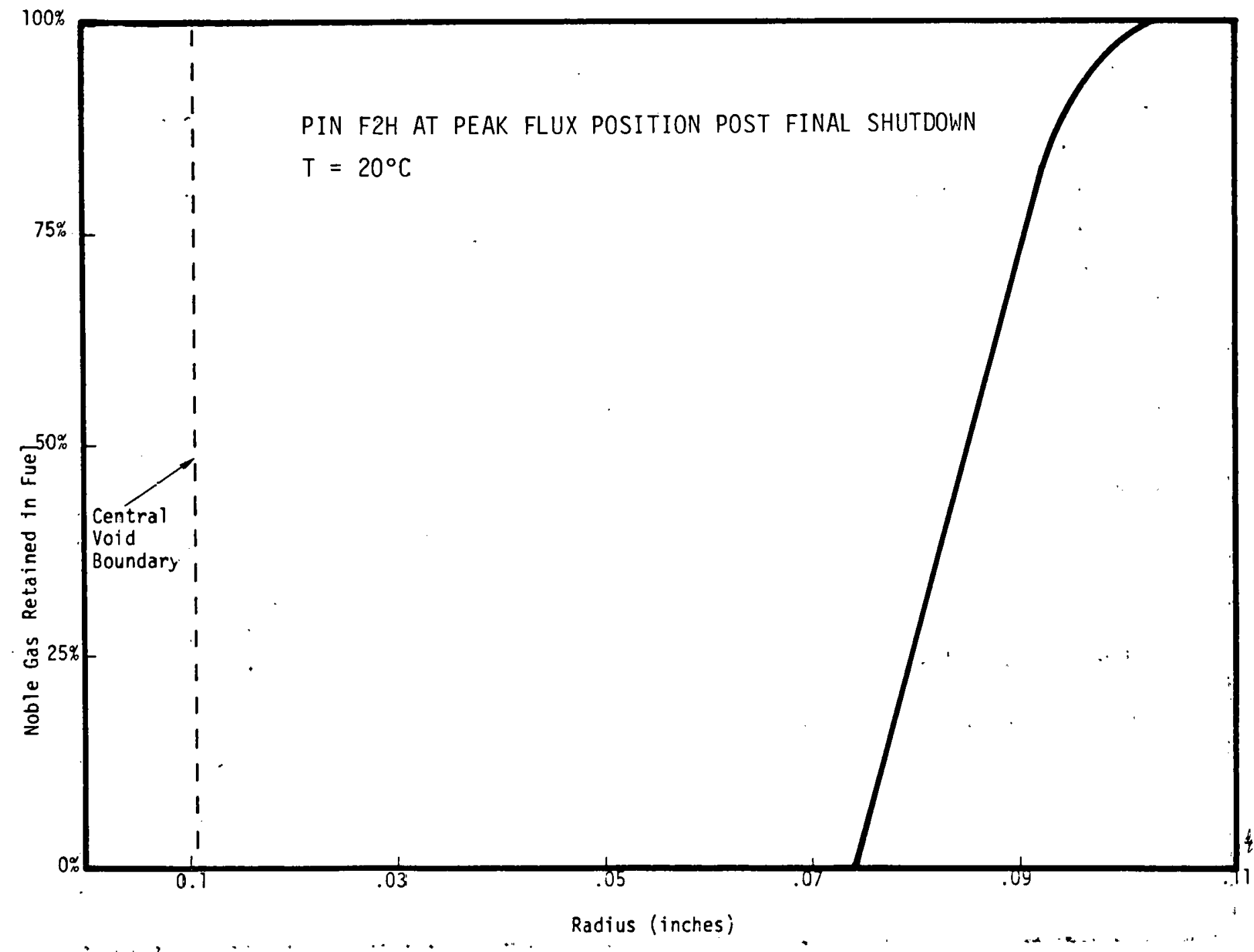

Figure 4-7. Prediction of Noble Gas Concentration versus Radius 


\section{USER'S INFORMATION}

\subsection{INPUT DECK FORMAT}

The input deck format is given in Figures 5-1a and 5-1b. A detailed description of each input variable follows.

INPUT VARIABLE

No. Axial Sections

No. Clad Rings

No. Structural Fuel Rings

No. Nontransport Fuel Rings

No. Transport Fuel Rings

Problem Identification

Fuel Pin Identification

Maximum Power Change

Clad o.d.

Clad i.d.

Clad Equation

Plenum Volume

Plenum Pressure

Initial Reactor Temperature

Axial Expansion Length

Dish Volume

Fisel Volume

\section{DETAILED DESCRIPTION}

Number of sections into which the fuel column is axially divided. Minimum number $=2$; maximum number $=5$.

Number of rings into which the cladding is divided radially. Minimum number $=1$; Maximum number $=10$. (Number to use depends on relative importance of internal cladding generated strains.)

Number of rings into which the structural fuel zone is divided radially. Minimum number $=2$; maximum number $=10$ (use of maximum number is suggested).

Number of rings into which the nontransport region is divided radially.

Minimum number $=2$; maximum number $=10$ (use of maximum number is suggested).

Number of rings into which the transport region is divided radially.

Minimum number $=2$; maximum number $=10$ (use of maximum number is suggested).

Word identifying problem.

Word identifying fuel pin.

Automatic time grid generator will subdivide input power history so that no power change per timestep exceeds value given here. Flux and inlet temperature are interpolated to provide values for these quantities at the generated time nodes. Fuel-cladding gap conductance and coolant pressure are not interpolated (see Figure 5-2). Recommended value for most problems is $2 \mathrm{~kW} / \mathrm{ft}$.

Outside diameter of cladding at $20^{\circ} \mathrm{C}$ before irradiation.

Inside diameter of cladding at $20^{\circ} \mathrm{C}$ before irradiation.

Identifier for steel swelling equation used in CLDSWL subroutine

Volume available for fission gas at $20^{\circ} \mathrm{C}$ before irradiation. Does not include void volume within fueled region.

Fill gas pressure in unirradiated pin at $20^{\circ} \mathrm{C}$. All voidage within the fueled region as well as within the plenum is assumed to be filled with gas at the plenum pressiure. The effects of adsorbẹ gases are not considered.

Reactor temperature immediately before the first application of power to the fuel pin

Clearance between top of the fuel column and the rigid axial restraint at $20^{\circ} \mathrm{C}$ before irradiation (see Figure 5-3). Where no axial restraint exists, a large number (e.g., 2 inches) should be input.

A set of numbers describing the radial distribution of transverse crack volume in the unirradiated pin. May be used to simulate dished pellet fuel or the interpellet crack volume existing before irradiation due to lack of squareness ot the pellet ends.

Dividing the fuel meat into a number of equal thickness rings equal to the previously input quantity "No. fuel rings structural zone," the magnitude of the quantity is 


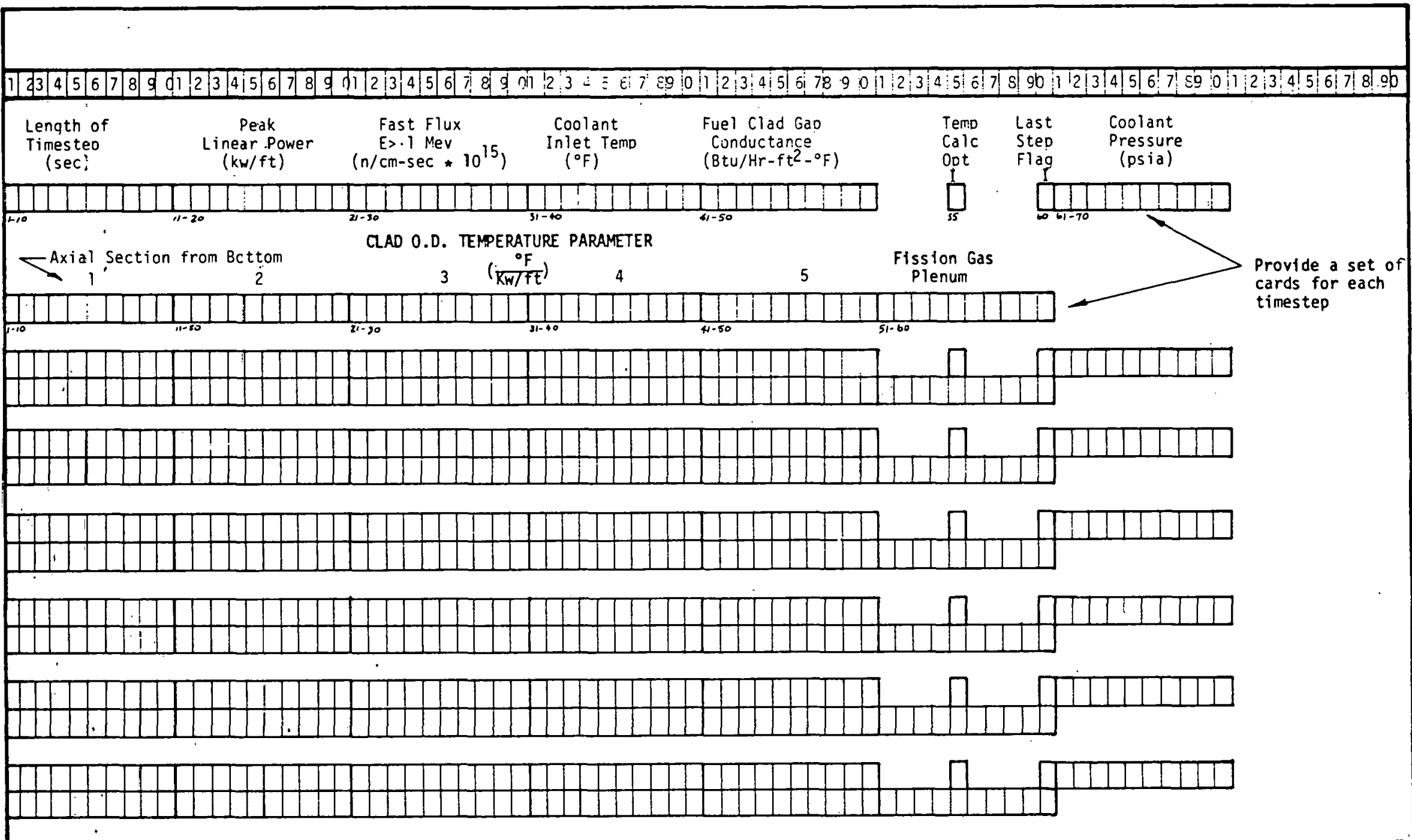

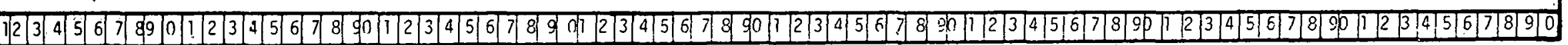

Figure 5-1b. Format of Time Varying Information Supplied in Order Shown, One Set for Each Timestep 

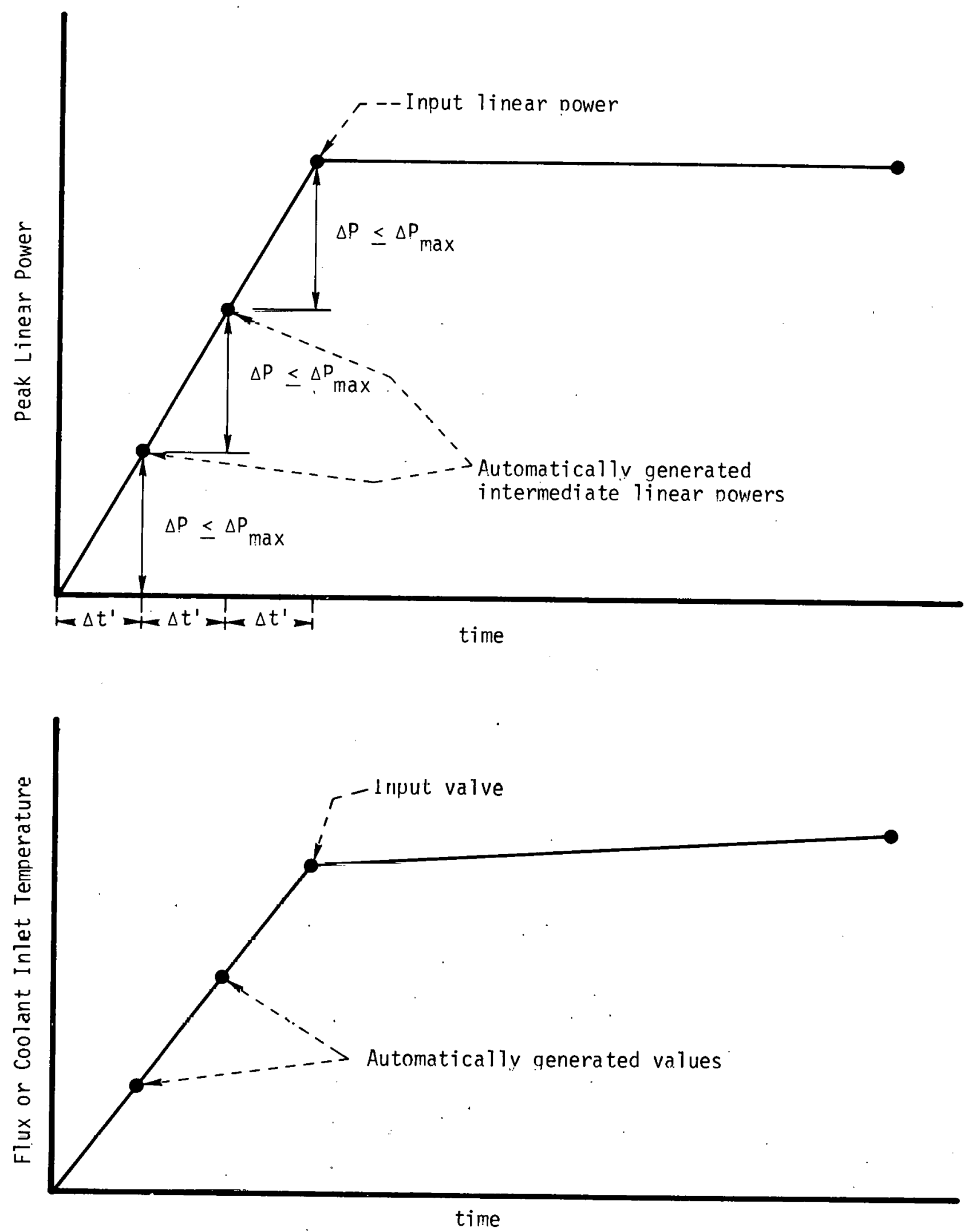

Figure 5-2. Automatic Time Grid Gerieration to Hold Maximum Power Change Less Than Input Maximum Power Change 


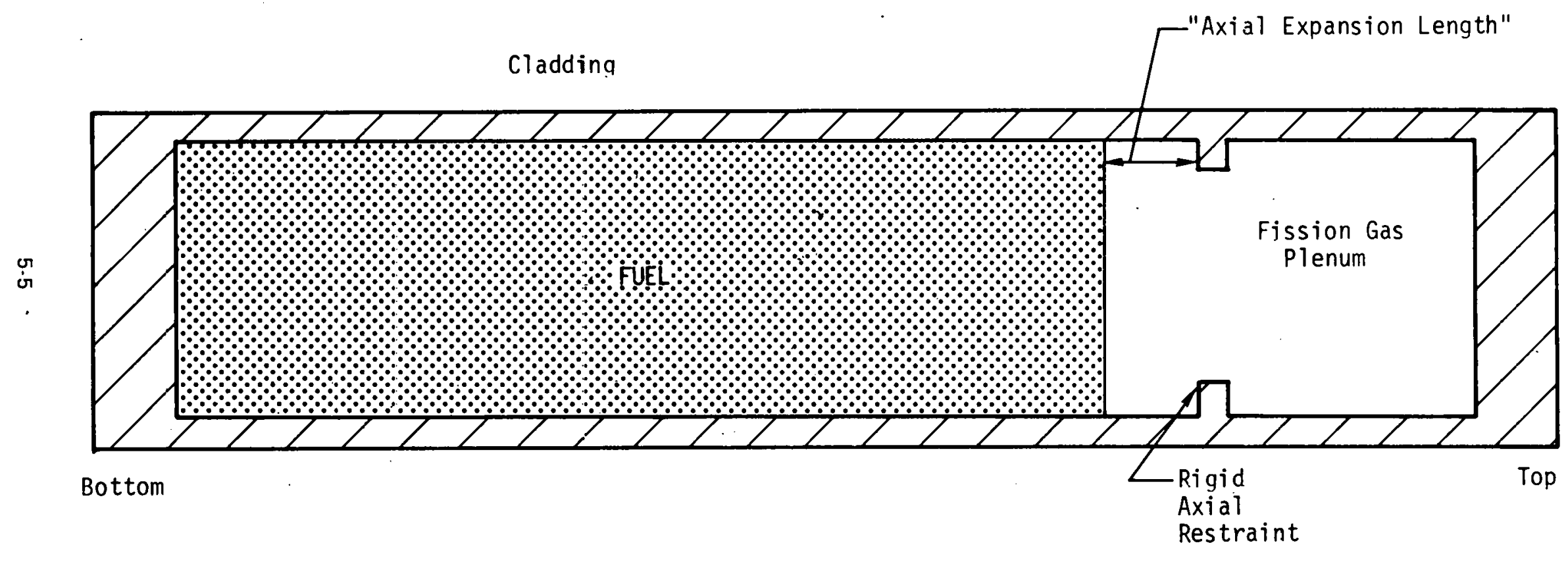

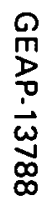

Figure 5-3. Definition of the Input Quantity "Axial Expansion Length" in the Unirradiated Fuel Pin at $20^{\circ} \mathrm{C}$ 
Fuel Swelling Rate

Energy per Fission

\author{
Atoms of Fission \\ Gas per Fission \\ Fuel Pellet Porosity \\ $\cdot$.
}

Fuel o.d.

Fuel I.d.

Length this Axial Section

Local Fission Rate

Peak Fission Rate

$\frac{\text { Local Fast Flux }}{\text { Peak Fast Flux }}$

Length of Timestep

Peak Linear Power

Peak Fast Flux (E >0.1 MeV)

Coolant Inlet Temperature

Fuel-Clad Gap Conductance

Temperature Calculation Option

Last Timestep Flag

Coolant Pressure

Clad o.d. Temperature Parameter defined as the fraction of a ring's volume in the form of transversely oriented crack volume. Values should be provided for each ring counting from the outermost ring and working inward (see Figure 5-4).

The constant isotropic rate at which each element of fuel matrix material (as opposed to fuel porosity) is assumed to dilate as a result of the accumulation of solid and gaseous fission products.

MeV's of thermal energy deposited in fuel per fission event.

Noble gas atoms created per fission event (assumed to be constant):

Fraction of the fuel pellet volume in this axial section assumed to be in the form of spherically shaped voidage.

Outside diameter of the fuel in this axial section.

Inside diameter of the fuel in this axial section (diameter of fabricated center hole).

Axial distance over which this axial section extends.

Fission rate (fissions/unit weight of heavy metal-sec) at the fuel outer surface in this axial section divided by fission rate at the fuel outer surface in that axial section having the maximum fission rate. Ratio is assumed constant throughout the irradiation history.

Flux of neutrons with energies $>0.1 \mathrm{MeV}$ in this axial section divided by same quantity in that axial section having the maximum flux. Ratio is assumed constant throughout the irradiation histur'y.

Length of this timestep. Where automatic time grid generation is used this quantity will be subdivided into smaller timesteps (see "Maximum Power Change"). It is pecomimendien that timestep length be restricted to values less than luUU hours.

Peak linear power at the end of this timestep. *

Peak fast neutron flux at the end of this timestep."

Inlet temperature of the reactor coolant at the end of this timestep. *

Thermal conductance between the fuel outer surface and cladding inner surface (assumed to pertain over the whole length of the fuel pin).

Always $=3$ for quasi-steady-state heat transfer option described in this report. Suveral other optlone Including translent heat transfer are under develópimént.

Set $=1$ if last timestep. Otherwise leave blank.

Pressure assumed to act at the outside of the fuel pin during this timestep.

Quantity defining the cladding outer surface temperature at each axial section and in the plenum region at the end of the timestep. Defined as (local cladding outer surface temperature-coolant inlet temperature) divided by (peak linear power). The parameter is almost power independent for constant coolant flow rate for a single-phase coolant, a convenience in preparing data input.

\footnotetext{
*Where automatic time grid generation is used, this quantity will be changed from previously input value in smaller increments. (See "Maximum Power Change".)
} 


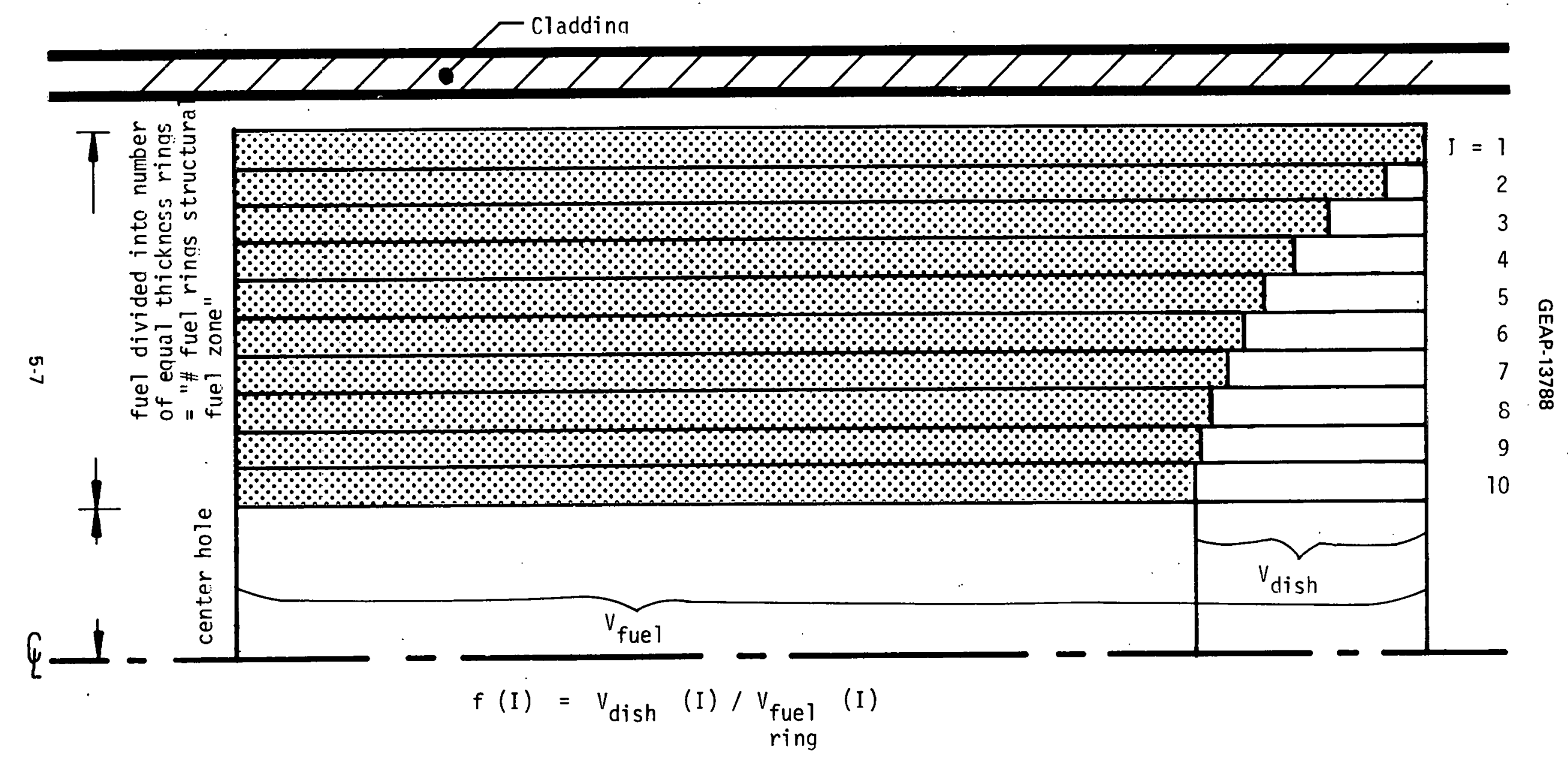

Figure 5-4. Definition of the Input Array "Radial Fuel Dish Volume Distribution" 


\subsection{USER SUPPLIED SUBROUTINES}

\subsubsection{Irradiation-Induced Swelling of Cladding}

The subroutine CLDSWL describes

DVV (ICTYPE, TEMP, FLUX, FLUENC, STRAIN)

where

DVV $=\frac{\text { volume increase }}{\text { original volume }}$
ICTYPE $=$ swelling equation identifier,
TEMP $=$ temperature $\left({ }^{\circ} \mathrm{C}\right)$,
FLUX $=$ neutron flux $\left(\mathrm{n} / \mathrm{cm}^{2}-\sec [E>0.1 \mathrm{MeV}]\right)$,
FLUENC $=$ neutron fluence $\left(\mathrm{n} / \mathrm{cm}^{2}[E<0.1 \mathrm{MeV}]\right)$, and
STRAIN $=$ effective short-term plastic strain.

The version given below, supplied with the program, contains only three equations for swelling. The user is encouraged to use his own, up to date, version of the subroutine.

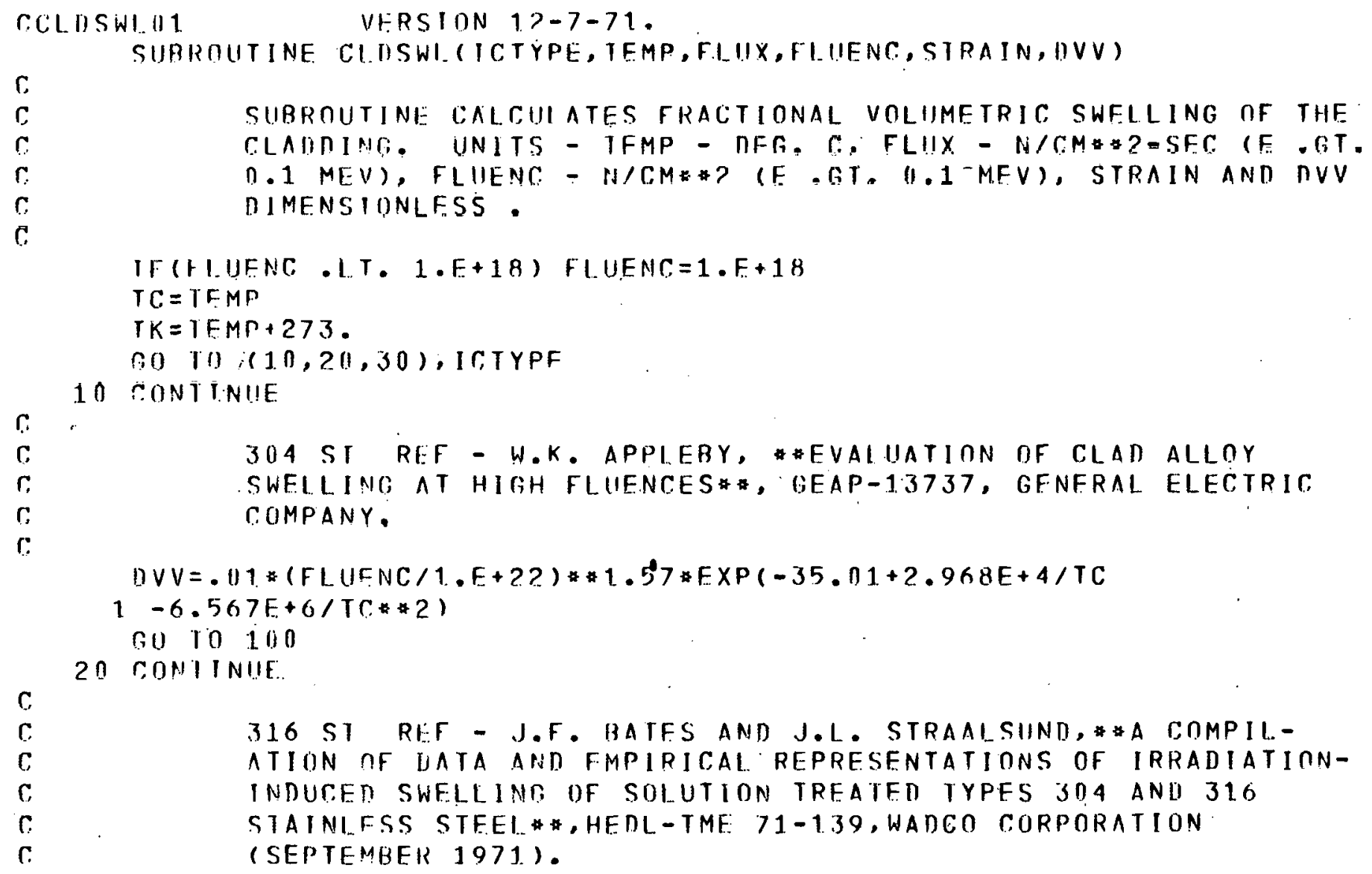


C.

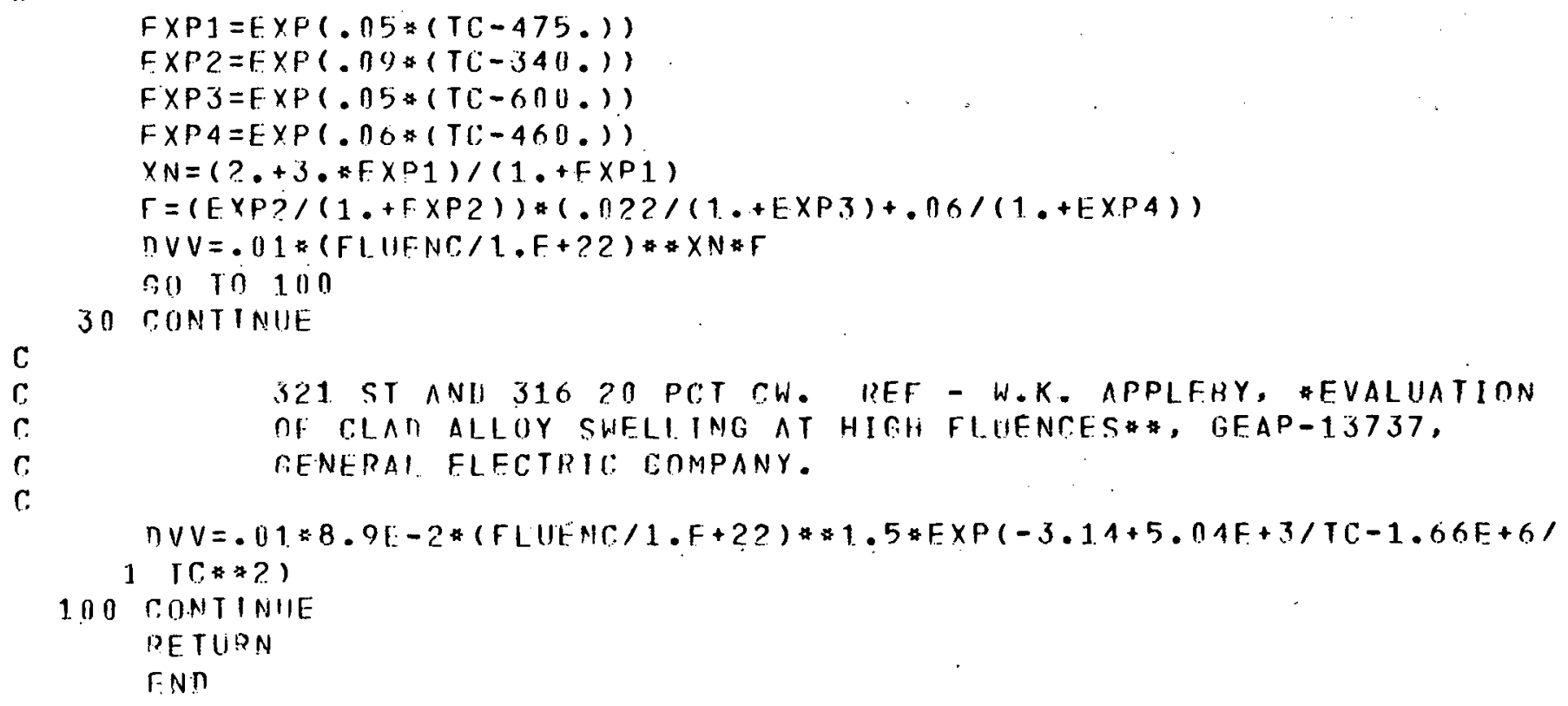

C,

C.

321 ST ANU 31620 PCT CW. REF - W.K. APPLFBY, EVALUATION OF CLAN ALLUY SWELIIMG AT HIGH FLUENCES , GEAP-13737, RENERAI. FLECTRII: EOMPANY.

nVV $=.01 * 8.9 E-2 *(F L U E N C / 1 . F+22) * 1.5 * E \times P(-3.14+5.04 F+3 / T C-1.66 E+6 /$

$1 \quad T C * 2$. I

100 COONTINIIE

DETURN

FNN

The code determines swelling during a timestep by calling the subroutine twice, giving initial and final values of fluence, mean values for temperature and flux, and the initial value for short-term plastic strain. The difference in the two calculated values of DVV is the volumetric swelling during the timestep. This method of determining the instantaneous rate of swelling, given time variable irradiation conditions, constitutes a theory of material behavior. The theory is reasonable but unverified by experiment.

\subsubsection{Self Shielding}

Subroutine SELFSH describes.FACTOR (RNORM) where

$$
\begin{aligned}
& \text { FACTOR }=\frac{\text { local fission rate }}{\text { fission rate at outside of fuel }} \\
& \text { RNORM }=\frac{\text { local radius }}{\text { radius of outside of fuel }}
\end{aligned}
$$

The same radial fission rate distribution is assumed to persist througl out the irradiation. The version given below supplies a flat radial fission rate distribution. It is appropriate for fast flux irradiations. For thermal flux irradiation conditions the ueer should supply his own subroutine.

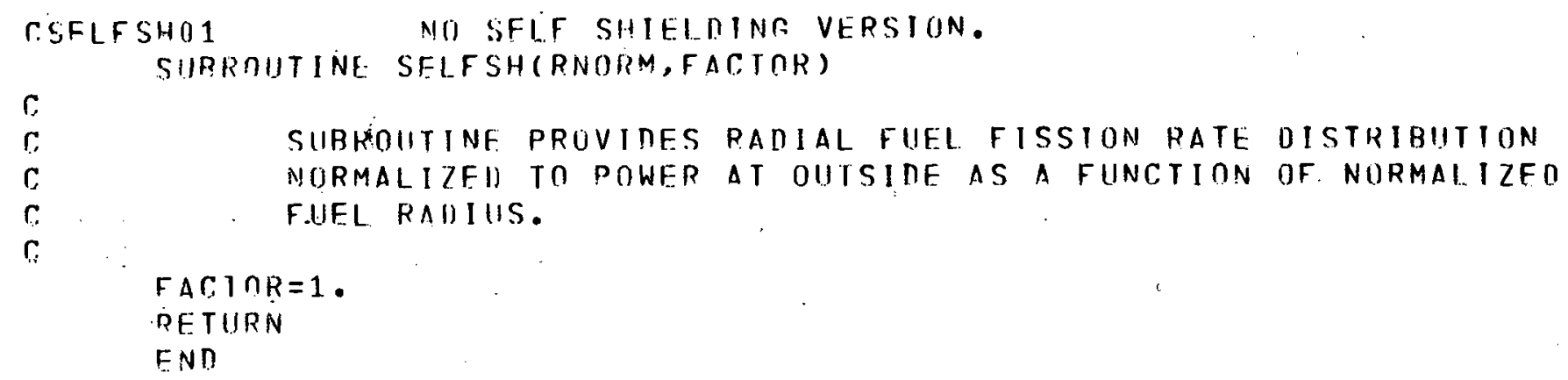




\subsection{RUN DECK FORMAT}

A run deck for running off of an $R^{*}$ file (program object file) using the GE-635 computer is presented below. If the two user-supplied subroutines described in subsection 5.2 are used, they must be placed, in object deck form, in the order shown. If these decks are not supplied, the versions described in subsection 5.2 are used.

\begin{tabular}{|c|c|c|}
\hline \$ & $I \cap F \cap T$ & $A \cap \| \cap, X Y 7 . ; S \vee 92 \pi, N \cap N P R O$ \\
\hline क & USER I I & FSח $\cap 60$ APASSWORU \\
\hline T & $F \| L \cap I T$ & $, \ldots, N$ ETER \\
\hline S & PRMFL & \&R, R/W, S,FSOU60/SIONEY \\
\hline 4 & $M \Delta S S$ & $\mathrm{R} * x+\mathrm{SS}, 10 \mathrm{~L}$ \\
\hline \$. & ПА Т & $* C,, \operatorname{cop} Y$ \\
\hline
\end{tabular}
by user's verston of SELFSH in object form. by user's version of CLDSWL in object form.

OPTION FORTRAN

EXECUTE

LIMITS $10,41000,20000$

MASS R*, XASS,10L

MASS H*.XSS.25R

SYSOIUI P*

SYSOUT 03

SYSOUT 02 ?

INCOOF IRMF

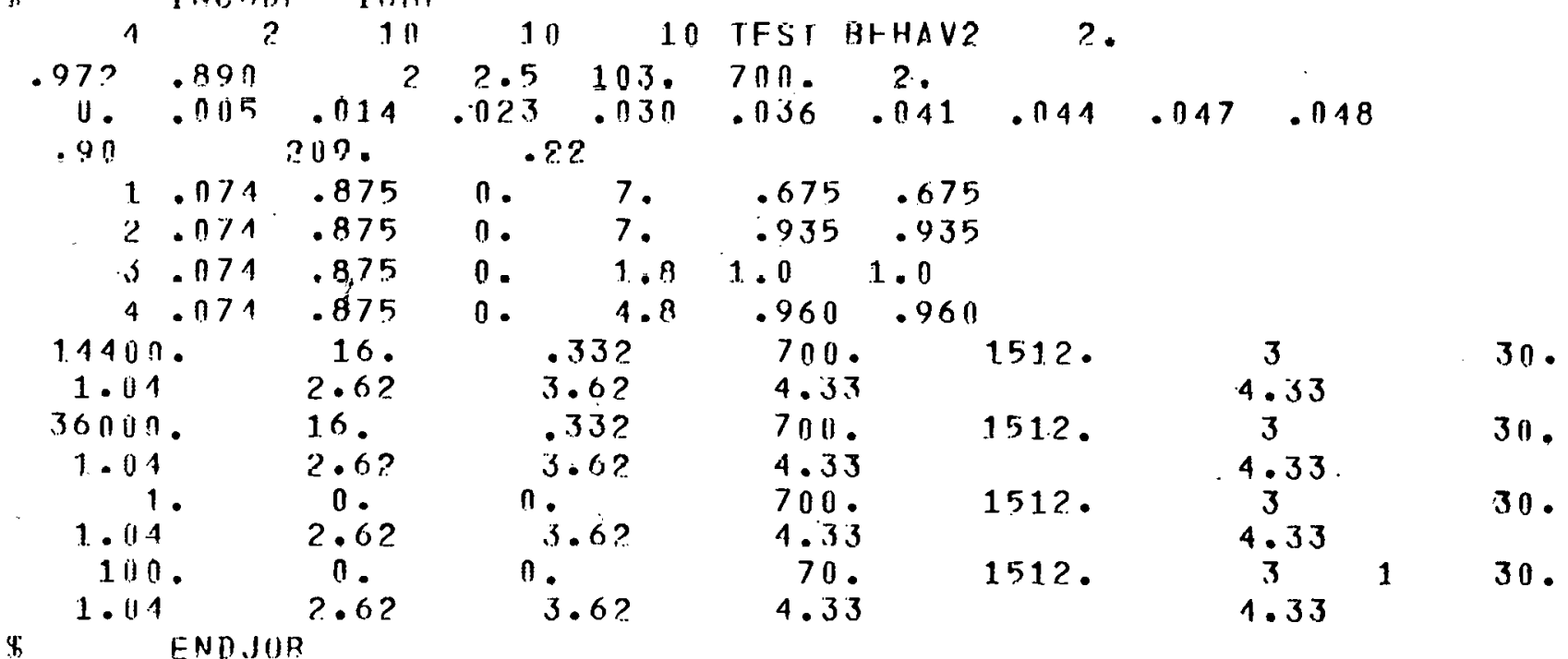




\subsection{RUNNING A PROBLEM}

Difficulties that have been encountered in initial runs of the program may be avoided by reference to the following points:

1. It is best to avoid large changes in the quantities "Fuel-Clad Gap Conductance" and "Clad o.d. Temperature Parameter" between timesteps. Discontinuous changes in these quantities sometimes result in anomalous thermal stresses generated by the sudden change in temperatures.

2. Where temperatures are of primary importance, one should remember that the geometry at the beginning of a timestep is used to calculate temperatures at the end of the timestep. Subdivision of the power history into more timesteps lessens the problem of inaccuracy due to geometry-temperature coupling.

3. An "event," meaning a period of a constant rate of power change or a period of steady-state operation, should be divided into timesteps of roughly equal lengths. In one case, representation of a 1,000-hour period by a 1-second timestep followed by a 1,000-hour timestep led to anomalous plastic strain of the cladding. A small variation in fuel temperature during the 1 -second timestep caused such a high strain rate in the fuel that it was not deformable and instead strained the cladding.

4. As a general rule, the entire output for a simulation should be scanned for reasonableness. Where unphysical situations arise, the problem can usually be rectified by modifying the input power history in an intelligent manner.

\subsection{OUTPUT}

\subsubsection{Non-Time Varying Information Printed on File Code $\mathbf{0 3}$}

Figure 5-5 shows the format of the non-time varying information which is printed out once at the beginning of a problem on file code 03 .

\subsubsection{Time-Varying Information Printed on File Code $\mathbf{0 3}$}

Figure 5-6 shows the format of time-varying information printed out at the end of each timestep on file code 03 . Data printed out in this file consist of axially varying and geometry-independent quantities. A list of definitions of output variables for which the meaning is not obvious follows.

Output Variable

SHEAR STRESS AT FUEL-CLAD INTERFACE

FUEL ZERO VOLUME, ETC.

DELTA L/L FUEL (HOT,

DELTA L/L CLAD (HOT)

DELTA L/L CLAD (COLD)

\section{Description}

Shear stress is positive if the force on the fuel is downward.

The volume inside the cladding is considered to be comprised of the six categories of zero volume, porosity, radial cracks, transverse cracks, thermal expansion relative to $0^{\circ} \mathrm{C}$, and fuel swelling volume. Zero volume represents the volume the matrix material would occupy at $0^{\circ} \mathrm{C}$ less swelling volume.

The change in length of the fuel column trom its unirradiated length at $20^{\circ} \mathrm{C}$ divided by the original length.

The change in length of the section of cladding coincident with the fuel column in the unirradiated condition at $20^{\circ} \mathrm{C}$ divided by the original length.

This parameter is equal to DELTA L/L CLAD (HOT) less the mean thermal expansion of the cladding from $20^{\circ} \mathrm{C}$ to the oper. ating temperature. It is a measure of elastic and plastic plus steel swelling strain. 
MOLES GAS RETAINED IN LATTICE

MOLES GAS RELEASED WITHIN FUEL

MODE

IGASB

IAXRE

FRACTIONAL POROSITY

FRACTION RADIAL CRACKS

FRACTION TRANSVERSE CRACKS

K.RAK

FRACTION THERMAL EXPANSION VOLUME

FRACTION FUEL SWELLING VOLUME

MELT FRACTION

LINEAR EXPANSION RATE

CREEP MODULUS
Total moles of gas in solution or tightly restrained at high pressure in the form of small bubbles.

Total moles of gas within the fuel in the form of pores large enough that surface tension restraint is negligible.

If $M O D E=1$, the inviscid zone contains compressible porosity: the zone acts on the structural fuel zone as a known pressure boundary condition.

If $M O D E=2$, the inviscid zone has densified to its maximum extent; under further expansion it acts on the structural fuel zone. as a known displacement rate boundary condition.

If $I G A S B=0$, no gas bottle effect is considered to be occurring. This is the only option currently in operation.

If IAXRE = 1, the fuel column has encountered the rigid restraint and the top of the fuel column is no longer tree to move upward, relative to the cladding.

The volume fraction of the fuel, not including crack volume, in llie furm of porès of large enough size that surface tension is negligible.

The volume fraction of a ring of fuel in the form of radially oriented cracks.

The volume fraction of an axially oriented fiber of fuel in the form of transversely oriented cracks.

KRAK $=1$ : ring is uncracked.

KRAK $=2$ : ring is cracked radially.

KRAK $=3$ : ring is cracked transversely.

KRAK = 4: ring is cracked radially and trá isver sely.

Fraction of a ring's volume made up of thermal expansion relative to $0^{\circ} \mathrm{C}$.

Fraction of a ring's volume made up of fission product swelling as defined in subsection 3.2.3.

Fraction of the way between solidus (assumed to be at $2776^{\circ} \mathrm{C}$ ) and liquidus (assumed to be at $2842^{\circ} \mathrm{C}$ ).

Rate at which the ring material would be expanding due to thermal expansion and swelling if it were stress-free (dilatation rate).

The analug in a stress-strain rate domain of Young's modulus in a stress-strain domain. It is a measure of the deformability of the material under elastic, plastic, and creep deformation (see subsection 2.3.2.11. 


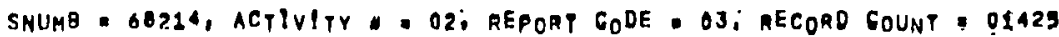

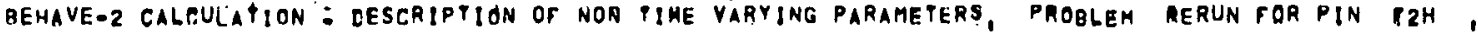

NODAL STAUCTURE -

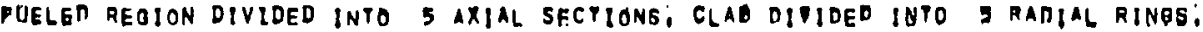

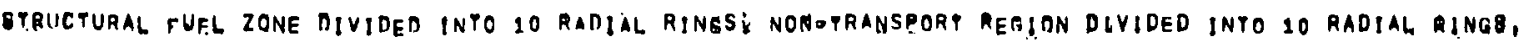

TRANGPORT REGION DIVIDED INTO 10 RADIKL RIAGS:

PHYSICAL DESGRIPPION OF UNIRRADIATED PIN AT 10 DRG: $C$.

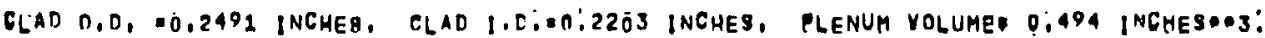

mlenum pressure i5:0 psi: clad omelling equatiore 2

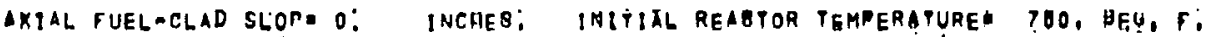

AXIAL SECPION: COUNTING FROM AOTYON OF PIN

FOEL $0, D$, (INCHES )

0.2181

2

s

4

,

0.

$0.2 \$ 83$

0.2170

0.2174

0,2171

FUEL 1.0, INCHES

0

$0:$

0.

0,

PRACPIONAL FUEL POROSITY

$0.046 \quad 0.041$

0.036

0,043

$0: 035$

- LEMGPH OF THIS AXIAL SECTION (INCHES)

2,87

$2 i 67$

$2 ; 89$

$2: 87$

2,89

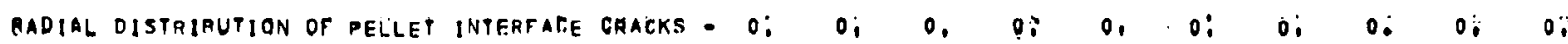
THERMAL AND PHYSICS DATA:

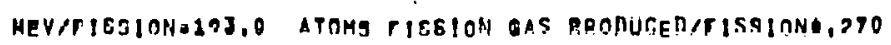

FUEL SHELLING RATE 0.90 (TRACTICN SKFLLINGIATOM FRACTION BUBNUP)

AXIAL SECTION COUNTING RROM BOTYOM OF PIN

1

2

了

4

3

LDGAL FISSION RATE/PEAK FISSION RATE

0,860

0,980

$0: 990$

0,890

0,760

LOCAL FAST FLUX (E :GT, I MEVI,PEAK TASY FLUX

$0.850 \quad 0,470$

$0: 990$

0.10

0.660

BADIAL DISTAIGUTION OF rISSION RAT.E.

$1,0001,0001,000 \$ 20001,0001,0001,0001,0001,0801,000$

Figure 5-5. Format of Nori-Time Varying Information Printed Out at the Start of Each Problem 


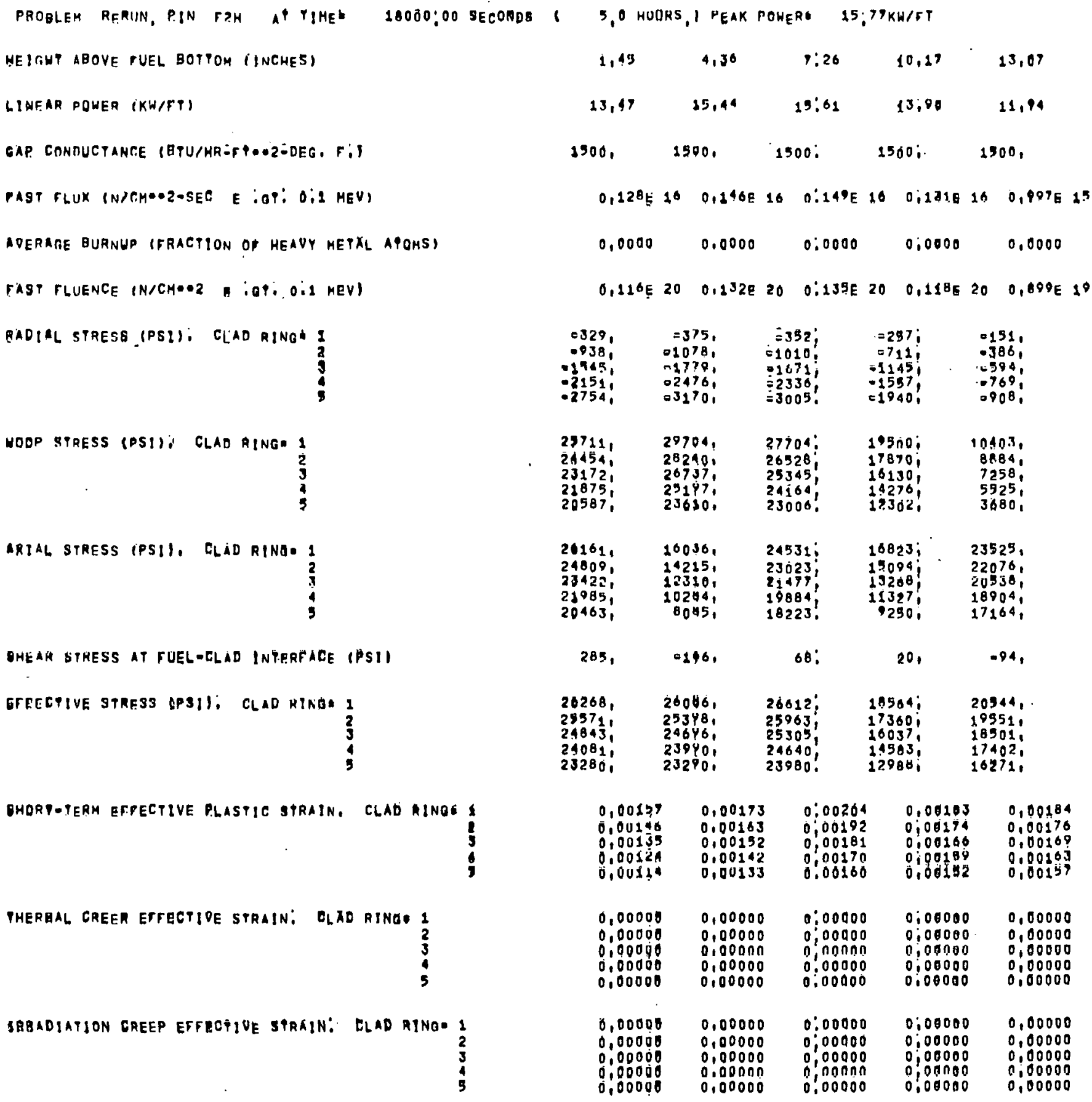

Figure 5-6. Format of Time-Varying Information Printed Out on File Code 03 
DELTS D/D $=$ GLAD Q,D, (HOT)

OELTA DOD OLAD D,D, (COLD)

CLAD SHELLING SPRAIN, ELAD RINGE 1

$$
\begin{aligned}
& 1 \\
& 2 \\
& 3 \\
& 4 \\
& 5
\end{aligned}
$$

meak clad tegperature (Deg: C) (DEG: I)

hLEL CENTER temperature (DEE, C) (DEO, F)

TaAngport temrerature (nER: C)

FUEL TERO VOLUME/GLAD I:D: VOLUME

FUEL POROSITY VOLUMF/FLLA I:D: VOLUHE

FUEL RADIAL GRACK VOLIMHF/CLAD I:D, voliume

FUel transvense crack VolUma/CLAd I:D. volume FUEL TENTRAL VOID VOLOME/CLAD I:O, VOLUME

puel phermal expansion volumeiclad tin: volume

TUEL SMELLING YOLUME/OLID I:D: VOLUME

PUEL MELT FRACTION,

$\begin{array}{llllll}0,00938 & 0,02027 & 0,01054 & 0,00987 & 0,00048 \\ 0,00058 & 0,00103 & 0,00084 & 0,0,00002 & 0,00049 \\ & & & & \\ 0,00000 & 0,00000 & 0,00000 & 0,00000 & 0,00000 \\ 0,00000 & 0,00000 & 0,00000 & 0,00000 & 0,00000 \\ 0,00000 & 0,00000 & 0,00000 & 0,00000 & 0,00000 \\ 0,00000 & 0,00000 & 0,00000 & 0,00000 & 0,00000 \\ 0,00000 & 0,00000 & 0,00000 & 0,00000 & 0,00000\end{array}$

\begin{tabular}{|c|c|c|c|c|}
\hline $\begin{array}{l}527, \\
980,\end{array}$ & $\begin{array}{r}5221 \\
1026,\end{array}$ & $\begin{array}{r}378: \\
1872:\end{array}$ & $\begin{array}{r}586 \\
1087\end{array}$ & $\begin{array}{r}587, \\
2089,\end{array}$ \\
\hline $\begin{array}{l}2259, \\
9099_{1}\end{array}$ & $\begin{array}{l}2529, \\
4638,\end{array}$ & $\begin{array}{l}2611: \\
731:\end{array}$ & $\begin{array}{l}2403 \\
9388_{0}^{\prime}\end{array}$ & $\begin{array}{l}2500, \\
3812,\end{array}$ \\
\hline
\end{tabular}

2002, 2971, 2890: 3097, 2822,

$\begin{array}{lllll}0,00408 & 0,90807 & 0,90963 & 0,90239 & 0,90767\end{array}$

$0,04160 \quad 0.03234 \quad 0,03094 \quad 0,035 \$ 1 \quad 0,03319$

$\begin{array}{lllll}0,00404 & 0,00234 & 0,00337 & 0,00283 & 0,02037\end{array}$

$0,00079 \quad 0.00044 \quad=0,00002 \quad 00,00003 \quad 0,00036$

o. 0,$0 ; 0,00000 \quad 0,00000$

$\begin{array}{lllll}0,04881 & 0,05806 & 0,06080 & 0,03428 & 0,04622\end{array}$

$0,00002 \quad 0,00002 \quad 0,00002 \quad 0,00002 \quad 0,00002$

o. 01 o: $0_{1}$ o.

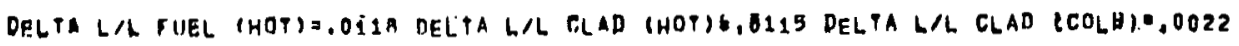

PRESGIIRE IN INYISGID ZONE: 46.11. PST; PRHSEUAE IN PLENUM, 38: PS?, COULANT PRESSURE: 30. PS!,

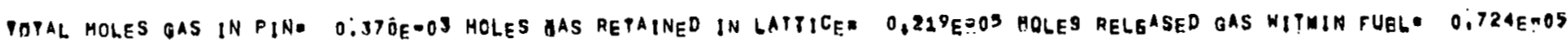

MOLFE GAS IN CENTRAL DOIDE 0:133E:13 MOLES GAS IN PLENUMa 0.360E=03

MODE 2 IOASB. O LAXRE= 1

Figure 5-6 (Continued) 


\subsubsection{Time-Varying Information Printed on File Code 02}

Figure 5-7 shows the format of time-varying information printed out at the end of each timestep on file code 02 . Data printed on this file consist primarily of quantities which vary both radially and axially. The following points should be understood by the user in reading this output:

1. Columns of numbers, from left to right, refer to axial sections in the fuel pin from the bottom to the top.

2. Rows of numbers from top to bottom refer to radial positions from the outside of the cladding inward.

3. The radial position in space of temperatures and displacement rates are defined by the corresponding numbers in the array "inter-ring radius."

4. Radial positions of other variables are defined by the midpoint of the correspunding ring as defined in "inter-ring radius."

5. Axial positions of all variables are defined by the axial midpoint of the corresponding axial section ds defined in the array "new-coordinates-top of fuel sections." The bottom of the fuel column is the zero datum.

6. Equal radii indicate that a region or regions (transport or nontransport) does not exist under the timetemperature conditions of the timestep.

7. When fuel is extruded into a new axial section it is always added to the innermost fuel ring. Thus, even when no transport region otherwise exists, a finite width ring will be found at the center of the fuel if fuel material has been transferred from another axial section.

8. Negative crack fractions may be encountered in some rings. This is perfectly normal; it occurs because the logic is unaware of the fact that the crack has closed up until the crack fraction has gone past zero and become negative. During the next timestep, the negative crack volume will be eliminated by an artificial "thermal expansion" equal in volume to the negative crack volume.

\subsection{RUNNING COSTS AND MEMORY REQUIREMENTS}

The simulation of fuel pin $\mathrm{F} 2 \mathrm{H}$, which was described in Section 4, used five axial sections, five radial rings in the cladding, ten rings each in the structural zone, nontransport region, and transport region. The power histury was approximated by 37 timesteps. The cost of this run was $\$ 96$ on the GE-635. Running costs are proportional to the number of space nodes times the number of timesteps. In the linked version, 41,000 words of memory are required to load the job. 
DEYAILED VARIABLE OUTPUT AFTFR SUBRCIITINE DPLACE; PROBLEM RERUN FOK PIN F ${ }^{H}$

TIME: 28000:00 SECONDS , 5.0 HOURS II PEAK POWER 15,7 TKW/FT.

VALUES OF RADIALLY AIIR AXIALLY DISTRIRUTED VARIARLES-

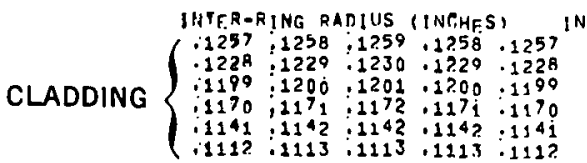

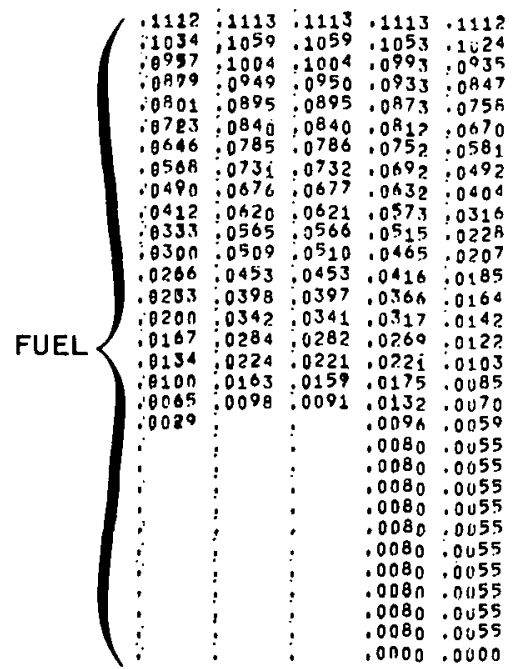

NTEFINING TEMPERATURE (DEG, C) 483. $503 ; 529 ; 543 ; 550$. $500.512: 538: 551: 565$. 509 , 532, 558: 568 : 572 . $527,552: 578,586 ; 587$ :

820. 887 : 917: 888: 84?, 973. 1017,1050 ; 1017 . 1001. $1130: 1151,1187 ; 1149,1158$ : $128 \mathrm{a}, 1286: 1326$ : 1282: 1312 . 1442. 1421: $1454: 1413$ : 1459, 1588,$1554 ; 1599 ; 1541 ; 1596:$ 1846,$1802 ; 1852,1778 ; 1826$. 1952, 19i6: 1967 : $1884: 1915$. 2043 , 2020, 2072: 1981; 1986 . 2117: 2115: 2167: 2067: 2039 : 2168. 2201: 2334: 2190: 2000 . 2190 . 2349 : 2402 : 2241 : 2069 . 2208 . 2408: 2460: 2284 ; 2077 . 2224. 2455: 2507: 2321: 2083 , 2236. 2443: 2545: 2331:2089, 26.4. 2522: 2574 : 2394 : 2094 . 2254: 2543: $2594: 2390: 2097$ : $2559.2559: 2011: 2403: 2100$. 2द. 25.: 2559: 2011: $2403: 2100$. 2259: 2559 2011: $2403: 2100$ : 2759. 2559: 2611, 2403: 2100 . 2259 . 2559: $2011: 2403 ; 2100$. 250. $2559: 2611$ : 2403: $200 \%$ $2559,2559,2611,2403,2100$.

2690 . 2559: 2611: 2403 : 2100 .
INTFK=HING UISPLACEMENT RATE (INCHES/SEC)

$0,794 E=07 \quad 0,902 E \equiv 07 \quad 0,988 E 007 \quad 0,683 E=07 \quad 0,434 E=07$ $0.198 E=07 \quad 0.004 E=07 \quad 0.993 E=07 \quad 0.079 E=07 \quad 0.424 E=07$ $0.802 E=07 \quad 0,907 E=07 \quad 0,998 F-07 \quad 0.6 / 5 E=07 \quad 0.425 E-07$ $0.007 E=07 \quad 0.909 E \equiv 07 \quad 0.100 E=06 \quad 0.671 E=07 \quad 0.420 E=07$ $\begin{array}{lllll}0.011 E=07 & 0.911 E=07 & 0,101 E=00 & 0,607 E=07 & 0,415 E=07 \\ 0.810 E=07 & 0.014 E=07 & 0.101 E=06 & 0.602 E=07 & 0.410 E=07\end{array}$

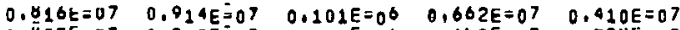
$0.003 E=07 \quad 0,902 E=07 \quad 0,100 E=06 \quad 0,632 E=07 \quad 0,385 E=07$ $\begin{array}{lllll}0.767 E=07 & 0.877 E \equiv 07 & 0,974 E=07 & 0,017 E=07 & 0.341 E=07 \\ 0.706 E=07 & 0,836 E=07 & 0,923 E=07 & 0,375 E=07 & 0.276 E=07\end{array}$ $0,831 F=07 \quad 0,526 E=07 \quad 0,138 E=07$ $0.305 E=07 \quad 0.743 E \equiv 07 \quad 0.759 E=07 \quad 0.418 E=07=0.131 E=08$ $0.436 E=07 \quad 0.687 E=07 \quad 0,716 E=07 \quad 0,345 E=07=0.159 E=07$ $0.592 E=07 \quad 0.711 E=07 \quad 0.820 E=07 \quad 0,275 E=07=0.307 E=07$ $0,308 E=07 \quad 0,448 E=07 \quad 0,610 E=07 \quad 0.245 E=07=0.418 E-07$

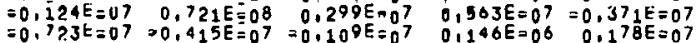

NEY COORDINATES - TOP OF FUEL SFCTIOAS (INCHES)

2.905

$5.815 \quad 8: 714 \quad 11.616 \quad 14: 519$

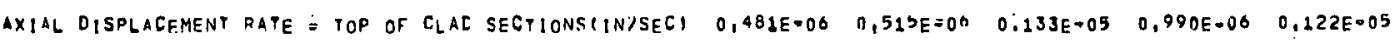

AXIAL DISPLAGFMENT RATE = TOP OF FLEL SECTIONSIIN7SEC) $0,501 E=06$ 0,494E=06 0,135E 005 0,969E-06 0,122F005

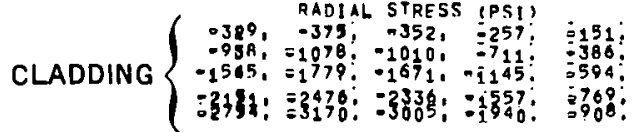

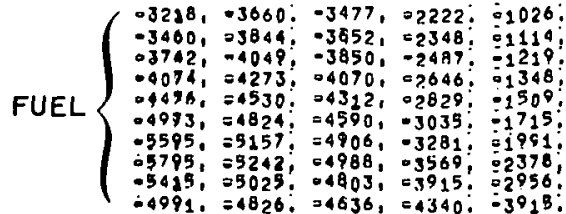

HOOP STRESS (PSI)

$25711,29704: 27704,19500,10405$, $2445,28240,26528,17870,2884$,

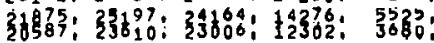

\begin{tabular}{|c|c|c|c|}
\hline $\begin{array}{l}538, \\
=38, \\
=38, \\
=38, \\
=38, \\
=38, \\
=38, \\
561,\end{array}$ & $\begin{array}{r}-38, \\
-38, \\
-38, \\
-38, \\
-38, \\
-38, \\
-38, \\
=8124 \\
=7490 \\
=8879\end{array}$ & $\begin{array}{r}-38, \\
-38, \\
-38, \\
=38, \\
-38, \\
-38, \\
-38, \\
-7438 ; \\
-6917 ; \\
-6318,\end{array}$ & $\begin{array}{l}=38, \\
=38, \\
=38, \\
=38, \\
=38, \\
=38, \\
=38, \\
=38, \\
=38, \\
=38,\end{array}$ \\
\hline
\end{tabular}

AXIAL STRESS (PSI) $26161 ; 16036,24531,16823,23525$ $24809,14215,23023,15094,22076$, $21985 ; 18284 ; 19889 ; 12327 ; 18984 ;$

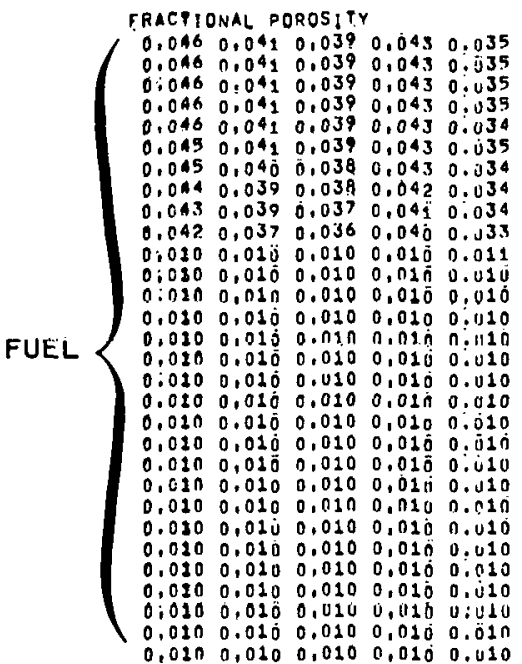

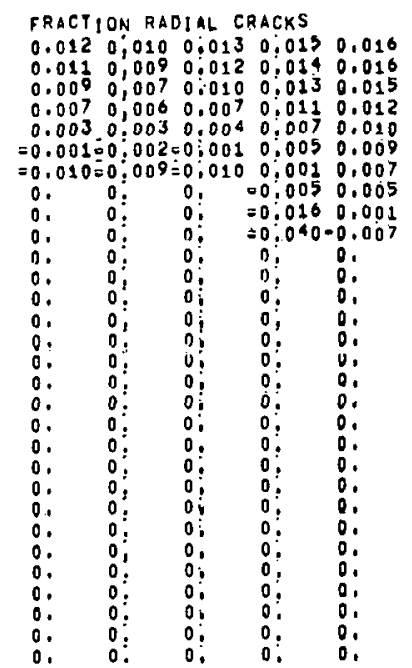

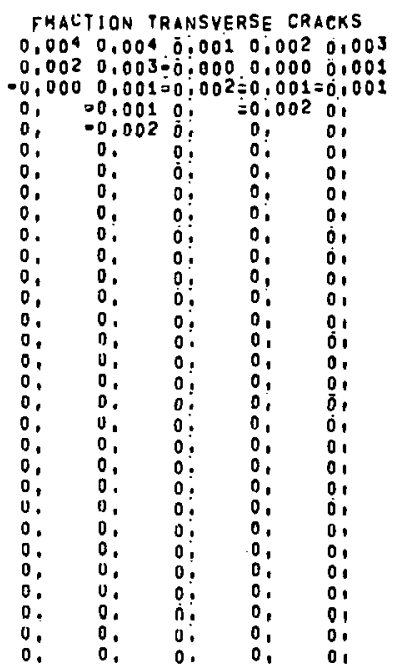

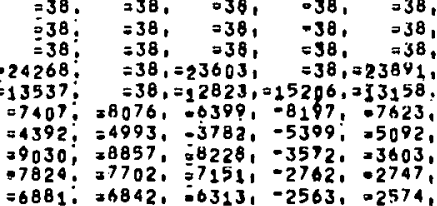

$0,0200,0100,0100,0100.410$

$\begin{array}{ccccc}\text { KRAK } & & \\ 4 & 4 & 4 & 4 & 4 \\ 4 & 4 & 4 & 4 & 4 \\ 4 & 4 & 4 & 4 & 4 \\ 2 & 4 & 2 & 4 & 2 \\ 2 & 4 & 2 & 2 & 2 \\ 2 & 2 & 2 & 2 & 2 \\ 2 & 2 & 2 & 2 & 2 \\ 1 & 1 & 1 & 2 & 2 \\ 1 & 1 & 1 & 2 & 2 \\ 1 & 1 & 1 & 2 & 2 \\ 1 & 1 & 1 & 1 & 1 \\ 1 & 1 & 1 & 1 & 1 \\ 1 & 1 & 1 & 1 & 1 \\ 1 & 1 & 1 & 1 & 1 \\ 1 & 1 & 1 & 1 & 1 \\ 1 & 1 & 1 & 1 & 1 \\ 1 & 1 & 1 & 1 & 1 \\ 1 & 1 & 1 & 1 & 1 \\ 1 & 1 & 1 & 1 & 1 \\ 1 & 1 & 1 & 1 & 1 \\ 1 & 1 & 1 & 1 & 1 \\ 1 & 1 & 1 & 1 & 1 \\ 1 & 1 & 1 & 1 & 1 \\ 1 & 1 & 1 & 1 & 1 \\ 1 & 1 & 1 & 1 & 1 \\ 1 & 1 & 1 & 1 & 1 \\ 1 & 1 & 1 & 1 & 1 \\ 1 & 1 & 1 & 1 & 1 \\ 1 & 1 & 1 & 1 & 1 \\ 1 & 1 & 1 & 1 & 1 \\ & & & \end{array}$

111121

Figure 5-7. Format of Time-Varying Information Printed Out on File Code 02 

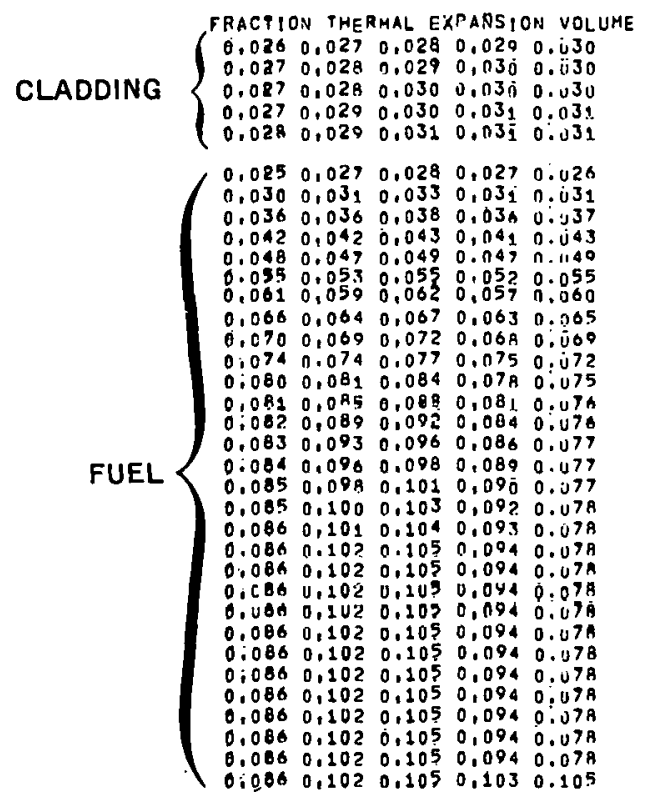

FRAETION SHELLING VOLUME $0.0000 .000 \quad 0.000 \quad 0,000 \quad 0,000$ $0.000 \quad 0.000 \quad 0.000 \quad 0.000 \quad 0.000$ $0.000 \quad 0.0000,000 \quad 0,000 \quad 0,040$ $0.000 \quad 0,000 \quad 0,000 \quad 0,000 \quad 0,000$

$0,0000,0000,0000,0000,000$ $0,000 \quad 0,000 \quad 0,000 \quad 0,0000,000$ $0.000 \quad 0,000 \quad 0,000 \quad 0,0000,000$ $0.0000 .000 \quad 0.000 \quad 0.0000 .000$ $0,0000,8000,0000,0000,808$ $0,0000,0000,0000,0000,000$ $0,000,0,000,0000,0000,000$ $0.0000,000 \quad 0,000 \quad 0,000 \quad 0,000$ 0.000 0.000 a.000 0.000 0,000 $0.000 \quad 0.000 \quad 0.0000 .0000,000$ 0.0000 .0000 .0000 .0000 .000 - 000 0.000 0,000 0,000 0,000 $0.000,000$, $0000,0000,000$ $0,0000,0000,0000,0000,000$ $0.0000 .0000 .0000 .0000,000$ ..000 0.000 0.000 0.0000.0.000 $0+000$ n, hno $9,000,0,0000,000$ D.0n $0.0000,0000,0000,000$ 0.0000 .000 0,000 0,000 0,000 $0.090 \quad 0.000 \quad 0,000 \quad 0,0000,000$ $0.000 \quad 0.000 \quad 0.000 \quad 0,000 \quad 0.000$ $0,0000.600 \quad 0,000 \quad 0,0000,000$ $0,000 \quad 0,000 \quad 0,000 \quad 0,000 \quad 0,000$ $0,000 \quad 0,000 \quad 0,000 \quad 0,0000,000$ $0,0000,0000,000000000,000$ $0,0000,8000,0000,0000,000$
MELT FRACTION

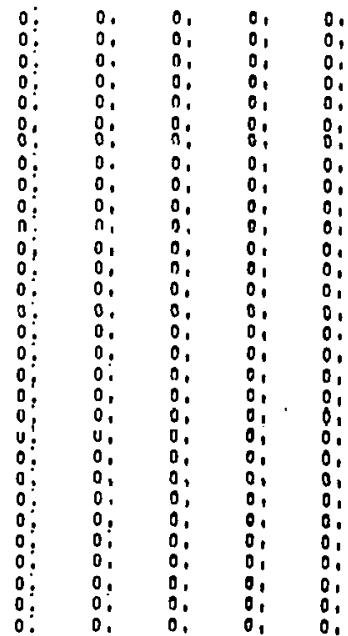
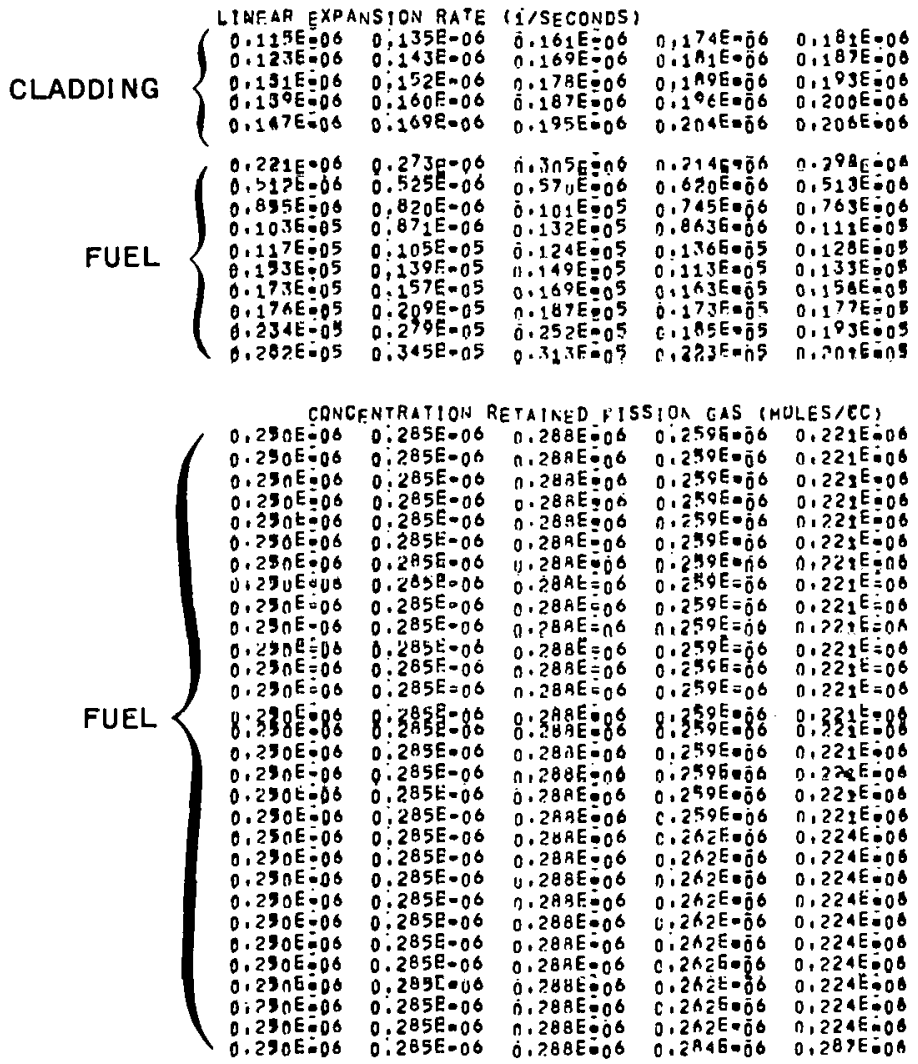

CREEH MODULUS (PSI-SECONDS)

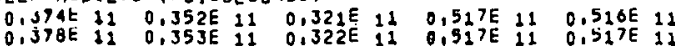
$0.3 \mathrm{ABE} 11$ 0.355E 11 $0.325 \mathrm{SE} 11$ 0.527E 11 0.317E 12 $0.905 E$ i2 $0.364 E_{11} 0.336 E_{11} 0.517 E$ 11 $0.517 E_{11}$ $0.080 E+110,300 E 11$ 0.585E 11 0.384E $11 \quad 0,343$ E 1 0,300 II $0.586 E$ 11 $0.585 E$ 11 $0,580 E$ II $0.593 \mathrm{EE}$ 11

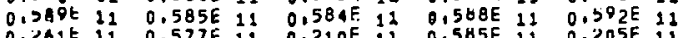

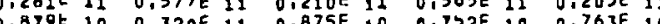

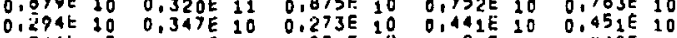

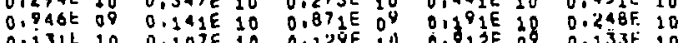

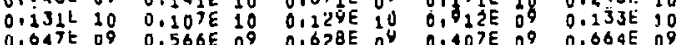

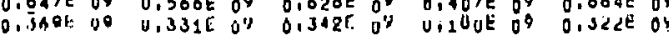

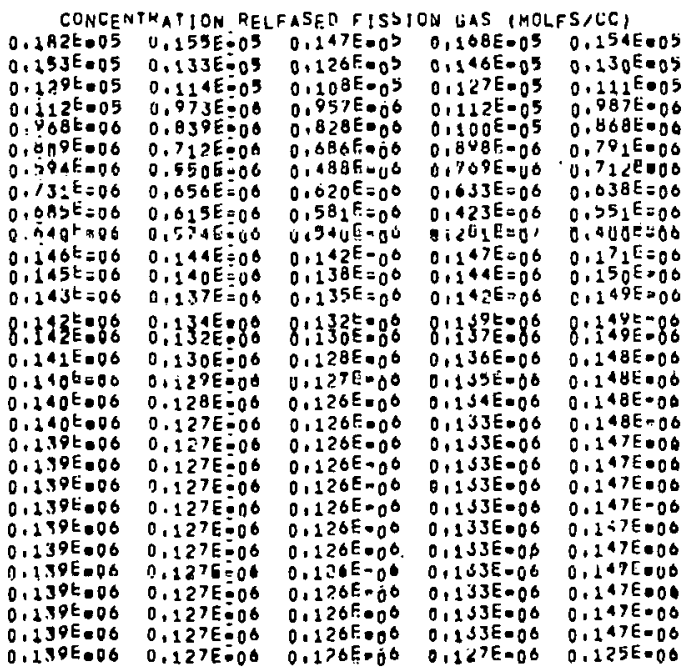

Figure 5-7 (Continued) 


\section{ACKNOWLEDGMENTS}

D. P. Hines has contributed ${ }^{7,8,9}$ substantially to the elucidation of a number of mechanisms, important in fuel pin behavior, which the BEHAVE-2 code models. M. O. Marlowe and D. C. Bullington significantly. enhanced the author's understanding concerning the assets and limitations of models of fuel swelling and fission gas release. D. L. Brown, N. R. McBurney, and D. K. English graciously shared their programming expertise during the initial period of debugging, and C. F. Barrett patiently acted as guinea pig user during initial runs of the code. The administrative support given by J. D. Stephen, F. E. Gelhaus, and E. L. Zebroski is gratefully acknowledged.

\section{REFERENCES}

1. Friedrich, C. M., CYGRO-Stress Analysis of the Growth of Concentric Cylinders, Westinghouse Electric Corporation, September 1965 (WAPD-TM-514).

2. Friedrich, C. M., and Guilinger, W. H., CYGRO-2-A Fortran IV Computer Program for Stress Analysis of the Growth of Cylindrical Fuel Elements with Fission Gas Bubbles, Westinghouse Electric Corporation, November 1966 (WAPD-TM-547).

3. Duncombe, E., et al., CYGRO-3-A Computer Program to Determine Temperatures, Stresses and Deformations in Oxide Fuel Rods, Westinghouse Electric Corporation, March 1970 (WAPD-TM-961).

4. Boltax, A., et al., "Fast Reactor Fuel Pin Performance Model Development," Nucl. Appl. Technol., 9, 326 (1970).

5. Jankus, V.Z., and Weeks, R. W., LIFE-I, A Fortran IV Computer Code for the Prediction of Fast Reactor Fuel-Element Behavior, Argonne National Laboratory, November 1970 (ANL-7736).

6. Cox, C. M., and Homan, F.H., "Performance Analysis of a Mixed-Oxide LMFBR Fuel Pin," Nucl. Appl. Technol., 9, 317 (1970).

7. Hines, D. P., Oldberg, S., Jr., and Zebroski, E. L., "Non-Steady-State Factors in Models for Swelling of Oxide Fuels," Nucl. Appl. Technol., 9, 338 (1970).

8. Oldberg, S., Jr., and Hines, D. P., "Mechanical Model of Thermal Differential Expansion at First Startup of a Mixed-Oxide Fuel Pin;" Trans. Am. Nucl. Soc., 13, 573.(1970).

9. Oldberg, S., Jr., and Hines, D. P., “Important Mechanisms in the Explanation of Clad Diametral Increases in Mixed-Oxide Fuel Pins,"' Trans. Am. Nucl. Soc., 14, Spl. 1, 6 (1971).

10. Rabin, S. A., et al., Short Term Fast Flux EBR-l/ Irradiation of $\mathrm{PuO}_{2}-\mathrm{UO}_{2}$ Fuel Pins, General Electric Company, October 1967 (GEAP-5570).

11. Nelson, R. C., Performance of Plutonium-Uranium Mixed Oxide Fuel Pins in a Fast Reactor (EBR-11) to 50,000 $M W d / T e$, General Electric Company, August 1969 (GEAP-13549).

12. Neimark, L. A., et al., "Performance of Mixed Oxide Fuel Elements-ANL Experience," Trans. Am. Nucl. Soc., 14, Spl 1, 22.

13. Small, N. C., An Inelastic Continuum Theory for Dilatating Aggregate Materials, Westinghouse Electric Corporation, February 1965 (WAPD-TM-421). 
14. Bohaboy, P. E., et al., Compressive Creep Characteristics of Stoichiometric Uranium Dioxide, General Electric Company, May 1969 (GEAP-10054).

15. Duncombe, E., et al., Comparisons with Experiment of Calculated Dimensional Changes and Failure Analysis of Irradiated Bulk Oxide Fuel Test Rods Using the CYGRO-1 Computer Program. Westinghouse Electric Corporation, September 1966 (WAPD-TM-583).

16. Lustman, B., "Irradiation Effects in Uranium Dioxide," Uranium Dioxide: Properties and Nuclear Applications, J. Belle, Ed., USAEC, Washington, D. C. p. 431 (1961).

17. Böhm, H., et al., Irradiation Behavior of Fast Reactor Fuel Pins and Their Components, International Conference on the Peaceful Uses of Atomic Energy, Geneva, Switzerland, 6-16 September 1971 (CONF-710901-137).

10. Mal luvwe. M. O., "High Tẹmperature leotharmal Elastic Moduli ul $\mathrm{UO}_{2}, "$ Journal of Nuclear Materials, 33, 242 (1969).

19. Fast Flux Test Facility, Quarterly Technical Report, September, October, November, 1969, Battelle Memoria! Institute, January 1970 (BNWL-1275) p. 7.12.

20. Fast Flux Test Facility, Monthly Informal Technical Progress Report, January 1970, Battelle Memorial Institute, January 1970 (BNWL-1300-1) p. 6.1.

21. Lauritzen, T., et al., Mechanical Properties Evaluation of Austenitic Stainless Stee/s Irradiated in EBR-2, General Electric Company, July 1969 (GEAP-10066).

22. Mechanical and Physical Properties of the Austenitic Chromium-Nickel Stainless Steels at Elevated Temperatures, International Nickel Company (1963).

23. Rubin, B. F., Summary of $(U, P u) \mathrm{O}_{2}$ Properties and Fabrication Methads, General Electrio Company, November $19 \% 0$ (GEAP-13582).

24. Christensen, J. A., "Thermal Expansion and Change in Volume of Uranium Dloxide on Melting," J. Am. Ceram. Soc., 46, 607-8 (December 21, 1963).

25. Oxide Fuel Element Development Quarterly Progress Report for Period Ending September 30, 1969. (WARD-4135-1).

26. Kampf, H., and Karsten, G., "Effects of Different Types of Void Volumes on the Radial Temperature Distribution of Fuel Pins," Nucl. Appl. Technol., 9, 288 (1970).

27. Martin, W. R., Mechanical Cladding-Fuel Interactions During Thermal Cycling of Metal-Clad Fuel Elements, Oak Ridge National Laboratory, March 1965 (ORNL-3514) p. 162.

28. Nichols, F. A., Behavior of Gaseous Fission Products in Oxide Fuel Elements, Westinghouse Electric Corporation, October 1966 (WAPD-TM-570).

29. Barnes, R. S., and Nelson, R. S., AIME Nucl. Met. Symp. on Radiation Effects in Solids, Asheville, N. C. (1965).

30. Marlowe, M. O., and Kaznoff, A. 1., J. Nucl. Mat., 25, 328 (1968).

31. Reynolds, G. L., J. Nucl. Mat., 24, 69 (1967).

32. Potter, T. J., and Elyard, C. A., Columnar Grain Growth in Uranium Dioxide, Proceedings of the British Ceramic Society, No. 7, Nuclear Engineering and Ceramics, Stoke-on-Trent (1967). 
33. MacEwan, J. R., and Lawson, V. B., "Grain Growth in Sintered Uranium Dioxide: 11, Columnar Grain Growth," J. Am. Ceram. Soc., 45, 42 (1962).

34. Hausner, $\mathrm{H}_{\text {., }}$ and Neison, R. C., Correlation of $\mathrm{UO}_{2}$ Microstructures from In-Pile and Out-of-Pile Experiments, General Electric Company, 1964 (GEAP-4535).

35. Baily, W. E., et al., "Thermal Conductivity of Uranium-Plutonium Oxide Fuels," Nuclear Metallurgy, 13, International Symposium on Plutonium Fuels Technology, Metallurgical Society of A:ME. (1968).

36. Christensen, J. A., Thermal Performance Limits for Fast Reactor Oxide Fuels, WADCO Corporation, April 1971 (HEDL-SA-89).

37. Marlowe, M. O., Limitations of Fission Gas Bubble Growth by the Re-Solution Process, General Electric Company, November 1970 (GEAP-12148).

38. Wolfe, R. A., and Kaufman, S. A., Mechanical Properties of Oxide Fuels, Westinghouse Electric Corporation, October 1967 (WAPD-TM-587).

39. Perry, K. J., Performance of Mixed Oxide Fuel Pins Irradiated to 11 Atom \% Burnup in EBR-2. General Electric Company (to be published) (GEAP-13538).

40. Nelson, R. C., et al., Irradiation Induced Swelling Rates of $\mathrm{PuO}_{2}-\mathrm{UO}_{2}$ Fuel With Strong Radial Restraint, General Electric Company, March 1971 (GEAP-13686).

41. Notley, M. J. F., et al., Measurements of the Fission Product Gas Pressures Developed in $\mathrm{UO}_{2}$ Fuel Elements During Operation, Atomic Energy of Canada Ltd., November 1966 (AECL-2662).

42. Burley, T.B., and Freshley, M. D., "Internal Gas Pressure Behavior in Mixed-Oxide Fuel Rods During Irradiation," Nucl. Appl. Technol., 9, 233 (1970).

43. Bain, A. S., Cracking and Bulk Movement in Irradiated Uranium Oxide Fuel Elements, Atomic Energy of Canada Ltd., September 1963 (AECL-1827).

44. Bain, A. S., Crack Healing and Void Movement During Irradiation of $\mathrm{ThO}_{2}-2$ wt $\% \mathrm{UO}_{2}$. Atomic Energy of Canada Limited, May 1967 (AECL-3008).

45. Hilbert, R. F., et al., "Swelling of $\mathrm{UO}_{2}-\mathrm{PuO}_{2}$ in the Equiaxed Grain Growth Region," Trans. Am. Nucl. Soc., 14, $582(1971)$.

46. Grando, C., et al., "Unrestrained Swelling and Fission-Gas-Release Experiments of Fast Reactor Fuels," Trans. Am. Nucl. Soc., 14, Spl 1, 36 (1971).

47. Michels, L. C., et al., "Behavior of Fission Gas Bubbles in Mixed-Oxide Fuel," Trans. Am. Nucl. Soc., 14, 581 (1971).

48. Mustelier, J. P., "French Irradiation Experience with Mixed Oxide Fuels for Fast-Reactor Application," Nuclear Metallurgy, 13, International Symposium on Plutonium Fuels Technology, Metallurgical Society of AIME (1968).

49. Reactor Development Progress Report, February 1969, Argonne National Laboratory, March 1969 (ANL-7553) p. 88. 


\section{DISTRIBUTION}

Director, Contracts Division

U. S. Atomic Energy Commission

San Francisco Operations Office

2111 Bancroft Way

Berkeley, California 94704

RDT Site Office

U. S. Atomic Energy Corrmission

General Electric Company

310 DeGuigne Drive

Sunnyvale, California 94086

Chief, California Patent Group

U. S. Atomic Energy Commisșion

San Francisco Operations Office

P. O. Box 808

Livermore, California 94550

Manager

Westinghouse Electric Corporation Advanced Reactors Division

P. O. Box 158

Madison, Pennsylvania 15663

Division of Reactor Development and Technology, Headquarters

U. S. Atomic Energy Commission Washington, D. C. 20545

Attn: Assistant Director,

Engineering Standards

Division of Reactor Development and Technology, Headquarters

U. S. Atomic Energy Coumuissiun Washington, D. C. 20545

Attn: Assistant Director, Nuclear Safety

Division of Reactor Development and Technology, Headquarters

U.S. Atomic Energy Commission Washington, D. C. 20545

Attn: Assistant Director.

Plant Engincering

Division of Reactor Development and Technology, Headquarters

J. S. Atomic Energy Corninission Nashington, D. C. 20545

Attn: Assistant Director,

Program Analysis

1 Division of Reactor Development and Technology, Headquarters U. S. Atomic Energy Commission Washington, D. C. 20545

Attn: Assistant Director.

Project Management

1

Division of Reactor Development and Technology, Headquarters U. S. Atomic Energy Commission Washington, D. C. 20545

Attn: Assistant Director,

Reactor Engineering

1

Division of Reactor Development and Technology, Headquarters U. S. Atomic Energy Commission Washington, D. C. 20545

Attn: Assistant Director, Reactor Technology

- Division of Reactor Development and Technology, Headquarters. U. S. Atomic Energy Commission Washington, D. C. 20545

1

Attn: Chief, Fuels and Materials Branch

Division of Reactor Development and Technology, Headquarters U. S. Atomic Energy Commission Washington, D. C. 20545

Attn: Chief, Fuel Engineering Branch

Division of Reactor Development and Technology, Headquarters

U. S. Atomic Energy Commission Washington, D. C. 20545

Attn: Chief, Reactor Vessels Branch

Assistant Director for

Pacific Northwest Programs, RDT

U. S. Atomic Energy Commission

P. O. Box 550

Richland, Washington 99352

1

RDT Site Office

1

U. S. Atomic Energy Commission Argonne National Laboratory Building 2,

Argonne, Illinois 60439 
RDT Senior Site Representative

U. S. Atomic Energy Commission

P.O. Box 2325

San Diego, California 92112

Division of Naval Reactors

Chief, Nuclear Materials Branch

U. S. Atomic Energy Commission

Washington, D. C. 20545

Director

Division of Reactor Licensing

U. S. Atomic Energy Commissinn

Washington, D. C. 20545

Director

Mettalurgy Division

Argonne National Laboratory

9700 South Cass Avenue

Argonne, Illinois 60439

Manager, FFTF Project

Pacific Northwest Laboratory

P. O. Box 999

Richland, Washington 99352

Manager

Chemistry and Metallurgy Division

Pacific Northwest Laboratory.

P. O. Box 999

Richland, Washington 99352

RDT Site Office

U. S. Atomic Energy Commission

Oak Ridge National Laboratory

P. O. Box X

Oak Ridge, Tennessee 37830

Director

Division of Reactor Standards

U. S. Atomic Energy Commission

Washininlun, D. C. 20545

Division of Technical

Information Extension

U. S. Atomic Energy Commission

P. O. Box 62

Oak Ridge, Tenniesset 37831

Director

LMFBR Program Office

Argonne National Laboratory.

9700 South Cass Avenue

Argonne, Illinois 60439
1 Director

Chemical Engineering Division

Argonne National Laboratory

9700 South Cass Avenue

Argonne, Illinois 60439

1

FFTF Fuels Department

Pacific Northwest Laboratory

P. O. Box 999

Richland, Washington 99352

3

RDT Site Orfice

U.S. Atomic Energy Commission

Atomics International

2 P. O. Box 1446

Canoga Park, Californiạ 91304

RDT Site Office

U.S. Atomic Energy Commission

Argonne National Laboratory

6 P. O. Box 2108

Idaho Falls, Idaliu 03401

Division Leader (CMB)

1

1 Chemistry and Metallurgy Division

Los Alamos Scicntific Laboratory

P. O. Box 1663

Los Alamos, New Mexico 87544

Director

1 Metallurgy and Materials

Science Division

Brookhaven National Laboratory

Upton, New York 11973

Division Chief, M \& S Division

1

2 NASA - Lowis Research Center

21000 Brookpark Road

Cleveland, Ohin 441.35

General Manager

Westinghouse Electric Corporation

Bettis Atomic Power Laboratory

P. O. Box 79

West Mifflin, Penņsylvania 15122

Associate Manager

1

2

\}

Materials Engineering Department

Battelle Memorial Institute

Columbus Laboratories

505 King Avenue

Columbus, Ohio 43201 
Manager, Nuclear Laboratories

Combustion Engineering Inc.

Nuclear Division

Prospect Hill Road

Windsor, Connecticut 06095

Manager, Plutonium Chemistry and Ceramics Fuels Developmient

Nuclear Materials and Equipment

Corporation

Plutonium Laboratory

Leechburg, Pennsylvania 15656

Head, Fuels and Materials

Atomic Power Development Associates

1911 First Street

Detroit, Michigan 48226

Director

Metals and Ceramics Division

Oak Ridge National Laboratory

P. O. Box X

Oak Ridge, Tennessee 37830

Director, Liquid Metal

Engineering Center

Atomics International

P. O. Box 1449

Canoga Park, California 91304

Manager-Advanced Development Activity

General Electric Company

Knolis Atomic Power Laboratory

P. O. Box 1072

Schenectady, New York 12301

Director, LMFBR Technology Program

Atomics International

P. O. Box 309

Canoga Park, California 91304

Director

Nuclear Development Center

The Babcock and Wilcox Company

Atomic Energy Division

Lynchburg, Virginia 24501

Laboratory Assistant Director

Gulf General Atomic Incorporated

- P. O. Box 608

San Diego, California 92112
1 - Manager, Research

1

United Nuclear Corporation

Research and Engineering Center

Grasslands Road

Elmsford, New York 10523

1 Director

3

Nuclear Safety Program

Oak Ridge National Laboratory

P. O. Box Y

Oak Ridge, Tennessee 37830

K-2 Group Leader

1

1 Reactor Division

Los Alamos Scientific Laboratory

P. O. Box 1663

Los Alamos, New Mexico 87544

2 Westinghouse Electric Corporation

Technical Director

Advanced Reactors Division

P. O. Box 158

Madison, Pennsylvania 15663

1 Manager

Liquid Metal Information Center

Atomics International

P. O. Box 1449

Canoga Park, California 91304

1 Irradiation Coordinator

EBR-II Project

Argonne National Laboratory

P. O. Box 2528

Idaho Falls, Idaho 83401

Experiment Manager

1 EBR-II Project

Argonne National Laboratory

9700 South Cass Avenue

Argonne, lllinois 60439

1 Director

9

Reactor Safety \& Analysis Dlvision

Argonne National Laboratory

9700 South Cass Avenue

Argonne, lllinois, 60439

1 Technical Director, FFTF Project
P. O. Box 1970

Richland, Washington 99352 
U.S. Atomic Energy Commission

Region 11 - Division of Compliance Suite 818

230 Peach Tree Street, N. W.

Atlanta, Georgia 30303

Dr. Knox M. Broom, Jr.

Nuclear Specialist

Middle South Services, Inc.

P.O. Box 61000

New Orleans, La.
Assistant Director of Pacific Northwest Programs, RDT

U.S. Atomic Energy Commission

P.O. Box 550

Richland, Washington 99352

1

Technical Director, FFTF Project
P.O. Box 1970

Richland, Washington 99352 
BREEDER REACTOR DEPARTMENT

SUNNYVALE, CALIFORNIA 94086

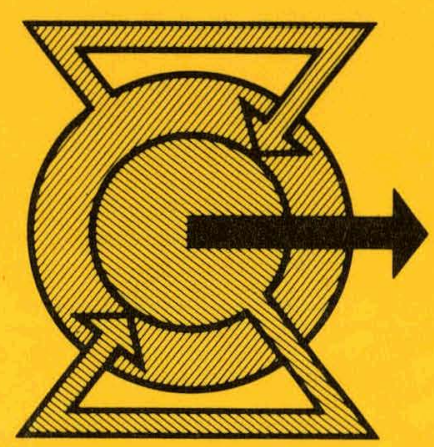

Expanding the World's Energy Reserves

GENERAL ELECTRIC 